\title{
New species and additional records of Lathrobium and Elytrobium from the Palaearctic region, with special reference to the fauna of East Yunnan (Coleoptera: Staphylinidae: Paederinae)
}

\author{
With 149 figures and 2 maps
}

VOLKER ASSING ${ }^{1}$

${ }^{1}$ Gabelsbergerstraße 2, 30163 Hannover, Germany. - vassing.hann@t-online.de Published on 2015-06-30

\section{Summary}

Seventeen species of Lathrobium Gravenhorst, 1802 and one of Elytrobium Assing, 2013 are (re-)described and illustrated: Lathrobium struyvei spec. nov. (Spain), a close relative of L. dimidiatipenne BERNHAUER, 1910; L. kiruense spec. nov. (Nepal: Annapurna) of the L. emodense group; L. undosum spec. nov. (Nepal: Solu Khumbu), tentatively assigned to the L. discissum group; L. crenatum spec. nov. (China: East Yunnan), L. rostratum spec. nov. (China: East Yunnan), L. tricarinatum spec. nov. (China: East Yunnan), and L. laciniatum spec. nov. (China: East Yunnan), all four of them of the L. tentaculatum group; L. daweianum spec. nov. (China: Southeast Yunnan) of the newly established L. daweianum group; L. coadultum spec. nov. (China: Southeast Yunnan) of the newly established L. coadultum group; L. grebennikovi spec. nov. (China: Shaanxi: Qinling Shan) and L. cavisulcatum spec. nov. (China: Shaanxi: Qinling Shan) of the L. varisternale group; L. abruptum spec. nov. (China: Sichuan: Gongga Shan), a close relative of L. hailuogouense Peng et al., 2012; L. erectum spec. nov. (China: Guizhou: Fanjing Shan) of the L. fissispinosum group; L. scaphiforme spec. nov. (Japan: Honshu); L. volutum spec. nov. (Japan: Honshu); L. trabale spec. nov. (Japan: Honshu); L. oharai Watanabe, 2014; Elytrobium edentulum spec. nov. (China: Shaanxi: Qinling Shan). The diversity, biogeography, natural history, and phylogenetic affiliations of the Lathrobium fauna of East Yunnan, from where the genus is reported for the first time, are discussed. The general distribution of Lathrobium and the individual distributions of the newly described species in Yunnan are mapped. Additional records of 30 described and one unnamed Lathrobium species are reported from Middle Asia (one species), Nepal (five species), from the Chinese provinces Yunnan (five species), Sichuan (five species), Shaanxi (one species), and Guizhou (one species), from Taiwan (one species), and from Japan (13 species). Three of these species are reported from Japan for the first time. Additional records of two Elytrobium species are reported from China and Japan. Lathrobium is now represented in the Palaearctic region by 563 species and ten subspecies, in China by 206 species ( 67 of which are confined to Yunnan), in Japan by 114, and in the Himalaya by 70 species. Elytrobium currently includes a total of seven species distributed in China, Taiwan, and Japan.

\section{Key words}

Coleoptera, Staphylinidae, Paederinae, Lathrobiina, Lathrobium, Elytrobium, Palaearctic region, China, Yunnan, taxonomy, new species, species groups, sexual size dimorphism, diversity, distribution maps, new records

\section{Zusammenfassung}

Siebzehn Arten der Gattung Lathrobium Gravenhorst, 1802 und eine der Gattung Elytrobium Assing, 2013 werden beschrieben bzw. redeskribiert und abgebildet: Lathrobium struyvei spec. nov. (Spanien), nah verwandt mit L. dimidiati- 
penne Bernhauer, 1910; L. kiruense spec. nov. (Nepal: Annapurna) aus der L. emodense-Gruppe; L. undosum spec. nov. (Nepal: Solu Khumbu), wahrscheinlich aus der L. discissum-Gruppe; L. crenatum spec. nov. (China: Ost-Yunnan), L. rostratum spec. nov. (China: Ost-Yunnan), L. tricarinatum spec. nov. (China: Ost-Yunnan) und L. laciniatum spec. nov. (China: Ost-Yunnan) aus der L. tentaculatum-Gruppe; L. daweianum spec. nov. (China: Südost-Yunnan) aus der neu begründeten L. daweianum-Gruppe; L. coadultum spec. nov. (China: Südost-Yunnan) aus der neu begründeten L. coadultum-Gruppe; L. grebennikovi spec. nov. (China: Shaanxi: Qinling Shan) und L. cavisulcatum spec. nov. (China: Shaanxi: Qinling Shan) aus der L. varisternale-Gruppe; L. abruptum spec. nov. (China: Sichuan: Gongga Shan), nah verwandt mit L. hailuogouense Peng et al., 2012; L. erectum spec. nov. (China: Guizhou: Fanjing Shan) aus der L. fissispinosum-Gruppe; L. scaphiforme spec. nov. (Japan: Honshu); L. volutum spec. nov. (Japan: Honshu); L. trabale spec. nov. (Japan: Honshu); L. oharai WATANABE, 2014; Elytrobium edentulum spec. nov. (China: Shaanxi: Qinling Shan). Die Diversität, Biogeographie, Ökologie und phylogenetischen Beziehungen der Lathrobium-Fauna von Ost-Yunnan, von wo die Gattung erstmals gemeldet wird, werden diskutiert. Die Gesamtverbreitung von Lathrobium sowie die Verbreitungsgebiete der neu beschriebenen Arten in Yunnan werden anhand von Karten illustriert. Weitere Nachweise von 30 beschriebenen und einer unbenannten Lathrobium-Arten werden aus Zentralasien (eine Art), Nepal (fünf Arten), aus den chinesischen Provinzen Yunnan (fünf Arten), Sichuan (fünf Arten), Shaanxi (eine Art) und Guizhou (eine Art), sowie von Taiwan (eine Art) und aus Japan (13 Arten) gemeldet. Drei dieser Arten werden erstmals aus Japan nachgewiesen. Weitere Nachweise von zwei Elytrobium-Arten werden aus China und Japan gemeldet. Lathrobium ist in der Paläarktis derzeit mit 563 Arten und zehn Unterarten, in China mit 206 Arten (davon allein 67 in Yunnan), in Japan mit 114 und im Himalaya mit 70 Arten vertreten. Elytrobium enthält nunmehr sieben Arten aus China, Taiwan, and Japan.

\section{Introduction}

According to a previous contribution (Assing 2014a), the Holarctic genus Lathrobium Gravenhorst, 1802 was represented in the Palaearctic region sensu Smetana (2004) by 536 named species and ten subspecies, two nomina dubia not considered. In the meantime, the descriptions of eleven additional species from Italy, China, and Japan have been published (Bordoni \& Magrini 2014; Peng et al. 2015; Watanabe 2014). The country with, by far, the greatest diversity is China (mainland), from where as many as 196 described species have been recorded, the vast majority of them micropterous and locally endemic. The fauna of Japan previously comprised 108 named species, 104 of them micropterous, three macropterous, and one wing-dimorphic (AssING 2013f; Watanabe 2014).

According to a recent article specifically dealing with the Lathrobium fauna of Yunnan, 58 species were known from this province alone, making it by far the most diverse of all Chinese province faunas (Assing 2013c). Since then, four additional species have been described and one species has been moved to the new genus Sinlathrobium Assing, 2013 (Assing 2013d, 2013e, 2014a; Peng et al. 2014), so that Lathrobium was previously represented in Yunnan by 61 exclusively micropterous and locally endemic species. Remarkably, all these species had been recorded from western Yunnan and not a single species was known from the east of the province.

The genus Elytrobium Assing, 2013 previously included six species distributed in Japan (one species), Taiwan (one species), and China (four species). Material of Elytrobium species is extremely rare: three of the six species are represented only by their respective holotypes and, with one exception, all known records are based on single specimens (Assing 2013e).

The present study is based on material collected during a recent field trip conducted by Michael Schülke and the author to eastern Yunnan in late summer 2014. This material included six undescribed micropterous Lathrobium species, the first records of the genus from this region. A study of Lathrobium from other regions made available to me by Aleš Smetana (Ottawa) and several other colleagues yielded eleven additional new species of Lathrobium and Elytrobium from Spain, Nepal, China, and Japan, as well as numerous records of zoogeographic interest, among them three newly recorded species from Japan.

\section{Material and methods}

The material treated in this study is deposited in the following public and private collections:

BMNH The Natural History Museum, London (R.G. Booth)

CAS Chinese Academy of Sciences, Beijing

CNC Canadian National Collection of Insects, Arachnids and Nematodes (A. Smetana)

MNHUB Museum für Naturkunde der HumboldtUniversität Berlin (J. Frisch)

NME Naturkundemuseum Erfurt (M. Hartmann)

cAss author's private collection

cSch private collection Michael Schülke, Berlin

cSme private collection Aleš Smetana, Ottawa

cStr private collection Tim Struyve, Mechelen

The morphological studies were conducted using a Stemi SV 11 microscope (Zeiss Germany) and a Jenalab compound microscope (Carl Zeiss Jena). The images of some forebodies, the aedeagi in dry preparation, and of the female tergites IX and X were created using a photographing device constructed by Arved Lompe (Nienburg) and CombineZ software. A digital camera 
(Nikon Coolpix 995) was used for the remaining photographs. The maps were created using MapCreator 2.0 (primap) software.

Body length was measured from the anterior margin of the mandibles (in resting position) to the abdominal apex, the length of the forebody from the anterior margin of the mandibles to the posterior margin of the elytra, head length from the anterior margin of the frons to the posterior constriction of the head, elytral length at the suture from the apex of the scutellum to the posterior margin of the elytra (at the suture), and the length of the aedeagus from the apex of the ventral process to the base of the aedeagal capsule. The "parameral" side (i.e., the side where the sperm duct enters) is referred to as the ventral, the opposite side as the dorsal aspect.

\section{New species and additional records of Lathrobium}

\subsection{West Palaearctic region}

\section{Lathrobium struyvei spec. nov.}

(Figs 1-11)

Type material: Holotype $\sigma^{*}$ : "E - Ciudad Real, Herencia, $39.30^{\circ} \mathrm{N}, 3.36^{\circ} \mathrm{W}, 29 . I V .2012$, leg. Struyve / Holotypus o Lathrobium struyvei spec. nov., det. V. Assing 2014" (cAss).

Paratypes: $1 \sigma^{\star}, 1$ : : same data as holotype (cStr, cAss).

Etymology: This species is dedicated to Tim Struyve, who collected the type specimens.

Description: Body length 9.5-10.5 mm; length of forebody 4.7-4.9 mm. Habitus as in Fig. 1. Coloration: head, pronotum, and abdomen blackish; elytra dark-reddish, anteriorly more or less distinctly, narrowly and diffusely darker; legs reddish; antennae brown to dark-brown.

Head (Fig. 2) oblong, 1.05-1.10 times as long as broad; posterior angles broadly convex in dorsal view, nearly obsolete; punctation moderately coarse, dense in lateral and posterior portions, distinctly sparser in median dorsal portion; interstices narrower than diameter of punctures in lateral and posterior dorsal portions, with shallow microsculpture. Eyes weakly projecting from lateral contours of head, $0.25-0.30$ times as long as distance from posterior margin of eye to neck. Antenna (Fig. 3) approximately $2.5 \mathrm{~mm}$ long.

Pronotum (Fig. 2) approximately 1.2 times as long as broad and 1.02-1.06 times as broad as head; punctures of somewhat variable size, partly as coarse as that of head, partly finer, less dense than punctation in lateral and posterior portions of head; impunctate midline moderately broad; interstices without microsculpture.

Elytra (Fig. 2) approximately 0.9 times as long as pronotum; punctation dense, less defined than that of pronotum. Hind wings present, shallow and moderately dense; inter- stices without microsculpture. Protarsomeres I-IV with weakly pronounced sexual dimorphism.

Abdomen narrower than elytra; punctation fine and dense; posterior margin of tergite VII with palisade fringe; tergite VIII with sexual dimorphism.

$\sigma^{*}$ : protarsomeres I-IV strongly dilated (Fig. 1); tergite VIII with convex posterior margin; sternite VII (Fig. 4) strongly transverse, with impression of subtriangular shape in postero-median portion, this impression with very weakly modified (slightly shorter) setae, posterior margin weakly concave; sternite VIII (Fig. 5) transverse, with extensive, but shallow postero-median impression, posteriorly without pubescence in the middle, posterior margin broadly concave; aedeagus (Figs 6-9) approximately $2.2 \mathrm{~mm}$ long; ventral process long and slender, basally with three pronounced carinae and moderately bulging in lateral view, apically acute, and subapically with distinct tooth; dorsal plate with large and distinctly sclerotized apical portion with a median dorsal carina, without evident basal portion; internal sac with a pair of dark membranous structures apically extending into sclerotized spear-shaped processes and with a median dark membranous structure.

ㅇ: protarsomeres I-IV strongly dilated, only slightly less so than in male; posterior margin of tergite VIII truncate; sternite VIII (Fig. 10) longer than tergite VIII, weakly oblong, posterior margin distinctly truncate in the middle; tergite IX (Fig. 11) with long and undivided antero-median portion and moderately short posterolateral processes; tergite $\mathrm{X}$ (Fig. 11) short, 0.75 times as long as antero-median portion of tergite IX.

Comparative notes: Based on the similar modifications of the aedeagus (ventral process long and slender, basally with carinae and strongly bulging in lateral view, apically acute, and subapically with distinct tooth; dorsal plate of similar shape and with median dorsal carina), the similar male secondary sexual characters (particularly the shapes of sternites VII and VIII), as well as the highly similar female secondary sexual characters, L. struyvei is undoubtedly closely allied to L. dimidiatipenne Bernhauer, 1910 (distributed from Middle Asia to the Russian Far East, doubtfully reported also from the Caucasus and Ukraine) and L. bernhaueri $\mathrm{KocH}$, 1937 (and its presumed junior synonym L. tichomirovae CoIffait, 1981; distributed in the Caucasus region). It differs from both by the shape (posterior margin only weakly concave) and chaetotaxy of the male sternite VIII and by the shape of the aedeagus (ventral process less bulging in lateral view). It is additionally distinguished from $L$. dimidiatipenne by the longer and more slender apical portion of the ventral process of the aedeagus in lateral view.

Distribution and natural history: The type locality is situated in Ciudad Real, Castilla-La Mancha, Spain. The type material was sifted from moist litter near a stream (STruyve pers. comm.). 


\subsection{Middle Asia}

\section{Lathrobium marani KocH, 1939}

Material examined: Kyrgyzstan: 4 exs., Jalal Abad, NE Kara-kul, SEE Kekbel: Karasu river, $41^{\circ} 41^{\prime} \mathrm{N}, 72^{\circ} 59^{\prime} \mathrm{E}$, 1230 m, 2.VII.2012, leg. Frisch (MNHUB, cAss); 1 ex., Jalal Abad, NE Tash-Kumyr, Shing-Say, $41^{\circ} 20^{\prime} \mathrm{N}, 72^{\circ} 15^{\prime} \mathrm{E}$, 720 m, 16.VI.2012, leg. Frisch (MNHUB); 2 exs., Talas, NW Toktogul, Chychkan river, $42^{\circ} 07^{\prime} \mathrm{N}, 72^{\circ} 48^{\prime} \mathrm{E}, 1680 \mathrm{~m}$, 3.VII.2012, leg. Frisch (MNHB); 1 ex., Batken, SE Sovetsky, Katrang-Too range, $40^{\circ} 05^{\prime} \mathrm{N}, 71^{\circ} 23^{\prime} \mathrm{E}, 1790 \mathrm{~m}$, 20.VI.2012, leg. Frisch (cAss); 2 exs., Batken, Isfana-
Isfara, WSW Ozgorush, tributary of Lyailek river, $39^{\circ} 44^{\prime} \mathrm{N}$, $70^{\circ} 00^{\prime} \mathrm{E}, 1560 \mathrm{~m}, 23 . \mathrm{VI} .2012$, leg. Frisch (MNHUB, cAss); 1 ex., Batken, Isfana-Isfara, WSW Ozgorush, Lyailek river, $39^{\circ} 44^{\prime} \mathrm{N}, 70^{\circ} 00^{\prime} \mathrm{E}, 1520 \mathrm{~m}, 22 . \mathrm{VI} .2012$, leg. Frisch (MNHUB).

Comment: The distribution of L. marani is confined to Middle Asia, where it is one of the more common species of the genus.

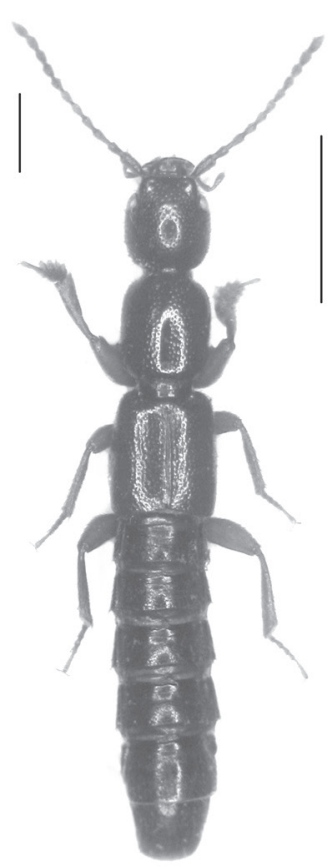

1

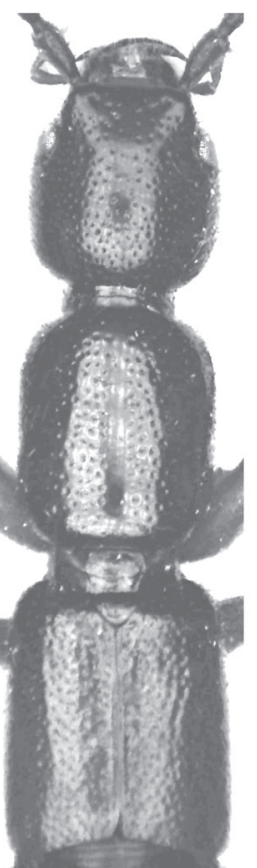

2

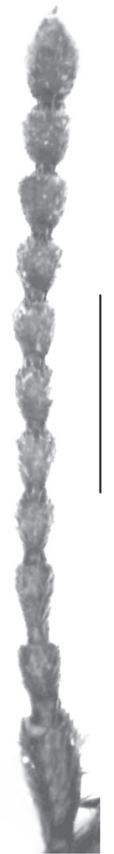

3

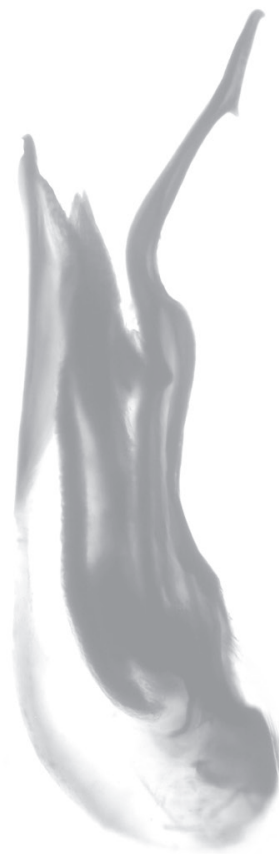

6

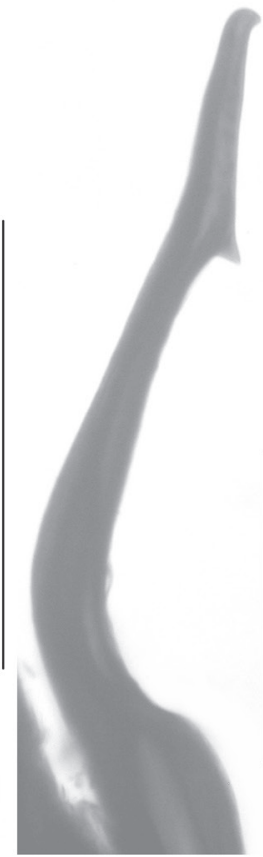

7

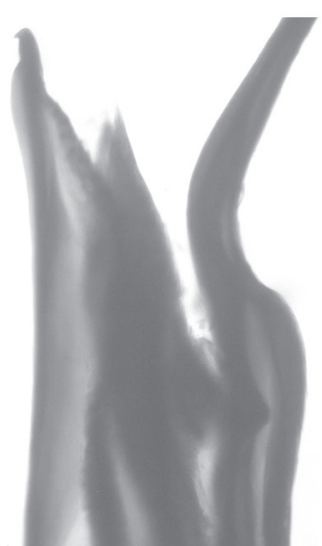

8

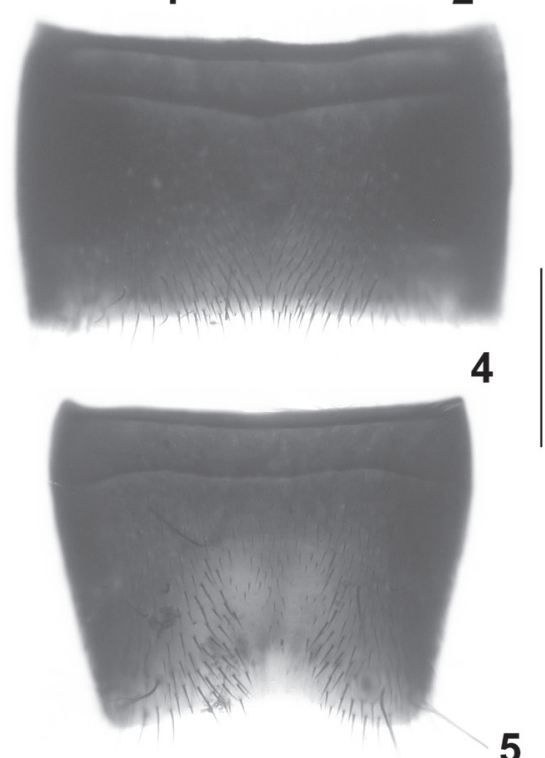

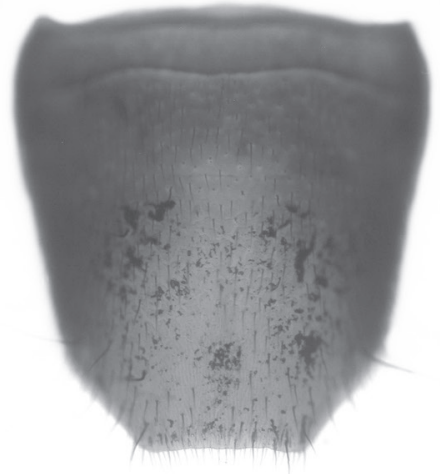

10

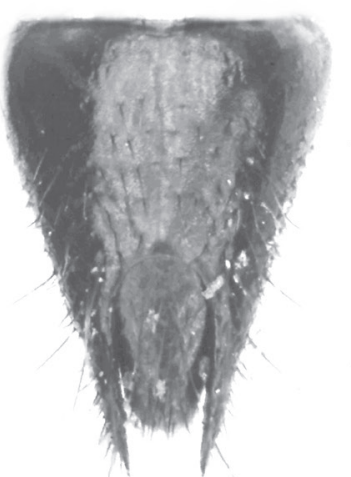

11

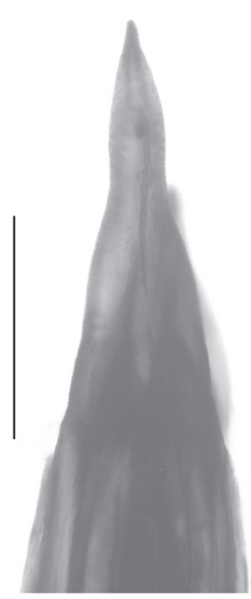

9

\section{5}

Figs 1-11: Lathrobium struyvei spec. nov.: male habitus (1); forebody (2); antenna (3); male sternite VII (4); male sternite VIII (5); aedeagus in lateral view (6); ventral process of aedeagus in lateral view (7); median portion of aedeagus in lateral view (8); ventral process of aedeagus in ventral view (9); female sternite VIII (10); female tergites IX-X (11). Scale bars: 1-2: 1.0 mm; 3-11: $0.5 \mathrm{~mm}$. 


\subsection{Nepal}

\section{Lathrobium rectaculeatum Assing, 2014}

Material examined: Nepal: $2 \sigma^{*} \sigma^{*}, 3$ 우, SW-Dhaulagiri, NW Dhorpatan, $28^{\circ} 31^{\prime} \mathrm{N}, 83^{\circ} 02^{\prime} \mathrm{E}, 3100-3200 \mathrm{~m}$, 15.\&18.V.2012, leg. Schmidt (NME, cAss).

Comment: The above material was collected at the type locality.

\section{Lathrobium hebes Assing, 2014}

Material examined: Nepal: $1 \sigma^{\star}, 1 \%$, SW-Dhaulagiri, Jaljala La env., $28^{\circ} 30^{\prime} \mathrm{N}, 83^{\circ} 15^{\prime} \mathrm{E}, 3300-3500 \mathrm{~m}, 12 ., 13 . \&$ 21.V.2012, leg. Schmidt (NME, cAss).

Comment: The above specimens were collected near the type locality.

\section{Lathrobium spinosissimum AssING, 2012}

Material examined: Nepal: $10^{\star}$, Kaski, Lamjung Himal, Kori, $28^{\circ} 25^{\prime} \mathrm{N}, 84^{\circ} 10^{\prime} \mathrm{E}, 3850 \mathrm{~m}$, 16.IX.2013, leg. Hagge \& Schmidt (NME)

Comment: The original description is based on three specimens collected in a nearby locality at an altitude of 3700 m (Assing 2012).

\section{Lathrobium kiruense spec. nov.}

(Figs 12-15)

Type material: Holotype o [slightly teneral]: "NEPAL, D: Kaski, env. Kiru Pass, 3800-4200 m, 11.-12.IX.2013, $28^{\circ} 24^{\prime} \mathrm{N}, 84^{\circ} 03^{\prime} \mathrm{E}$, leg. J. Schmidt / Holotypus o Lathrobium kiruense spec. nov., det. V. Assing 2014" (NME).

Etymology: The specific epithet (adjective) is derived from the name of the pass where the type locality is situated.

Description: Small species; body length $5.6 \mathrm{~mm}$; length of forebody $2.8 \mathrm{~mm}$. External characters (Fig. 12) as in the closely related L. spinosissimum Assing, 2012.

$\sigma^{*}$ : protarsomeres I-IV strongly dilated; tergite VIII with truncate posterior margin; sternite VII (Fig. 13) 1.6 times as broad as long, with shallow and extensive posteromedian impression, this impression with a cluster of numerous moderately modified stout black setae, posterior margin weakly concave; sternite VIII (Fig. 14) weakly transverse, 1.07 times as broad as long, with long median impression, this impression with numerous moderately modified stout black setae, posterior excision small and of nearly semi-circular shape; aedeagus (Fig. 15) $1.0 \mathrm{~mm}$ long; ventral process tapering apicad and apically acute; dorsal plate with long and apically somewhat hooked apical portion (lateral view) and with short lamellate basal portion; internal sac with several large and more or less distinctly curved spines.

q: unknown.

Comparative notes: Based on the male sexual characters, particularly on the similar modifications of the aedeagus (shapes of ventral process and of dorsal plate; internal sac with several long and curved sclerotized spines), L. kiruense is most closely related to L. spinosissimum of the L.emodense group, from which it is distinguished only by the slightly more extensive clusters of slightly longer setae on the male sternites VII and VIII, by the slightly differently shaped posterior excision of the male sternite VIII, by some differences in the shape of the aedeagus (ventral process apically slightly less strongly tapering and basally slightly more distinctly curved), and especially in the shapes of the internal structures of the aedeagus (L. spinosissimum: apical internal structures apically abruptly curved). Except for the shapes of the internal structures of the aedeagus, the observed differences are slight, but nevertheless interpreted as interspecific variation. For illustrations of L. spinosissimum see Assing (2012).

Distribution and natural history: The type locality is situated in the southeastern Annapurna range, some $20 \mathrm{~km}$ to the north-northeast of Pokhara in Central Nepal. The slightly teneral holotype was collected at an altitude between 3800 and $4200 \mathrm{~m}$.

\section{Lathrobium lamjunense Assing, 2012}

Material examined: Nepal: $3 \sigma^{\star} \sigma^{\star}, 4$ 우 우 [1 $\sigma^{\star}, 1$ i teneral], Lamjung Himal, Dudh Pokhar, $28^{\circ} 27^{\prime} \mathrm{N}, 84^{\prime \circ} 16^{\prime} \mathrm{E}, 4600 \mathrm{~m}$, 19.IX.2013, leg. Schmidt (NME, cAss); 1 ㅇ, Lamjung Himal, Furja, $28^{\circ} 26^{\prime} \mathrm{N}, 84^{\prime \circ} 17^{\prime} \mathrm{E}, 4150 \mathrm{~m}$, 19.IX.2013, leg. Hagge \& Schmidt (NME).

Comment: This species is endemic to the Lamjung Himal, where it was previously recorded at altitudes of 4300-4600 m (Assing 2012).

\section{Lathrobium undosum spec. nov.}

(Figs 16-20)

Type material: Holotype $0^{\star}$ : "NEPAL: Solu Khumbu, Lamiura Danda, $3500-3800 \mathrm{~m}, 2^{\circ} 34^{\prime} \mathrm{N}, \quad 86^{\circ} 30^{\prime} \mathrm{E}$, 28.V.-29.V.2013, leg. Hagge \& Schmidt / Holotypus o* Lathrobium undosum spec. nov., det. V. Assing 2014" (NME). 
Etymology: The specific epithet (Latin, adjective: wavy) alludes to the shape of the dorsal plate of the aedeagus in lateral view.

Description: Small species; body length $5.3 \mathrm{~mm}$; length of forebody $2.6 \mathrm{~mm}$. Coloration: forebody brown; abdomen dark-brown with slightly paler apex; legs yellowishbrown; antennae dark-reddish.

Head (Fig. 16) weakly transverse, approximately 1.03 times as broad as long, distinctly widened behind eyes; punctation rather coarse and dense, sparser in median dorsal portion; interstices without microsculpture. Eyes small and weakly convex, not projecting from lateral contours of head, approximately one-fifth as long as postocular region in dorsal view and composed of approximately 20 ommatidia. Antenna $1.45 \mathrm{~mm}$ long. Pronotum (Fig. 16) 1.25 times as long as broad and 0.95 times as broad as head; punctation slightly finer than that of head; impunctate midline rather broad; interstices without microsculpture.

Elytra (Fig. 16) 0.55 times as long as pronotum, weakly dilated posteriad; humeral angles moderately marked;

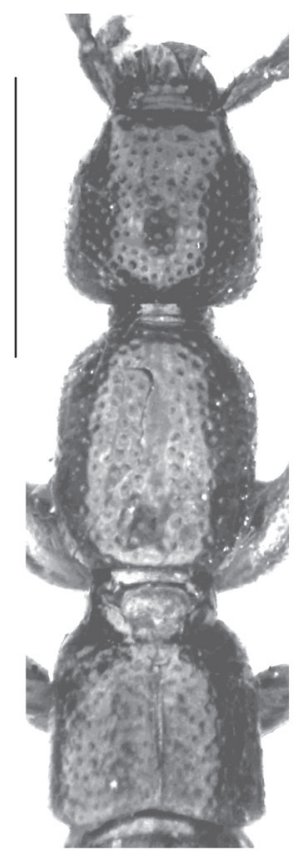

12

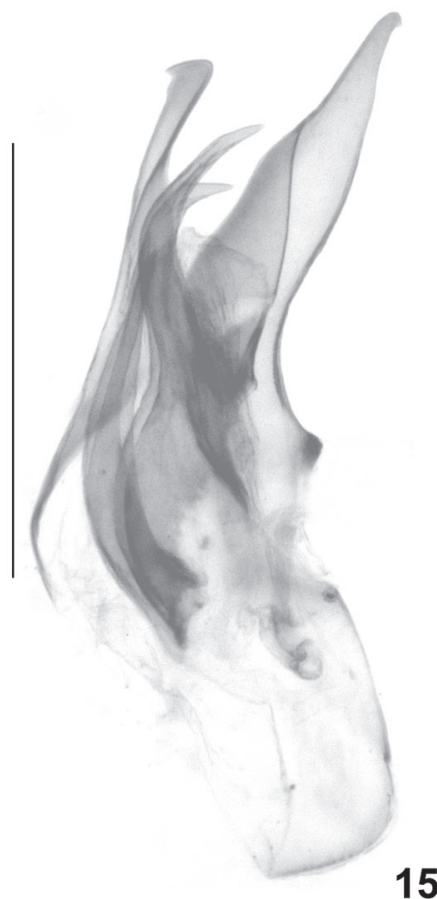

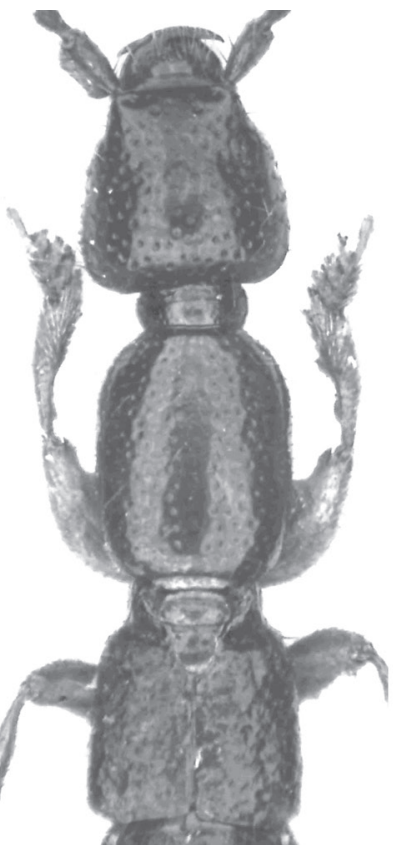

16

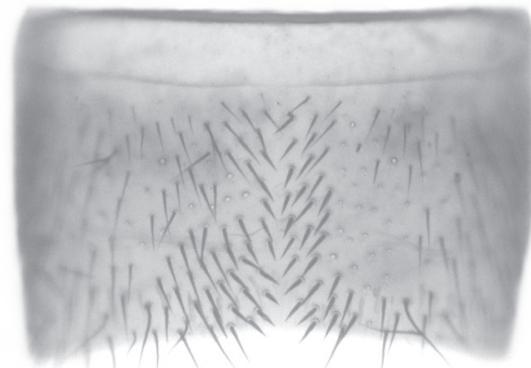

13

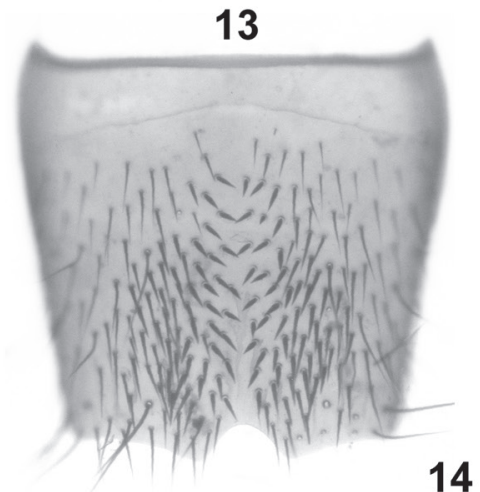

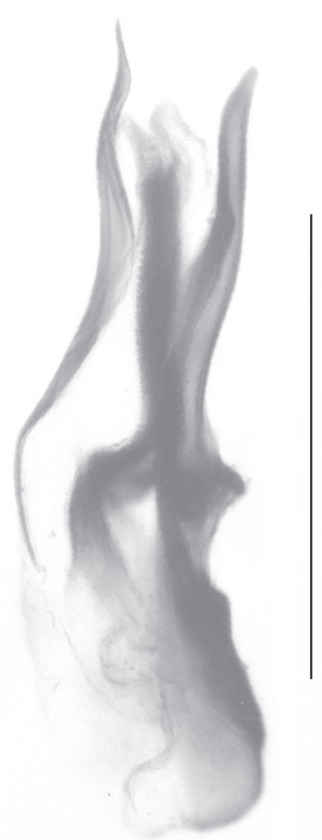

19

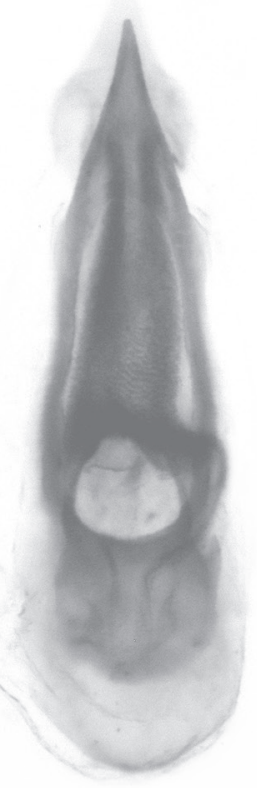

20

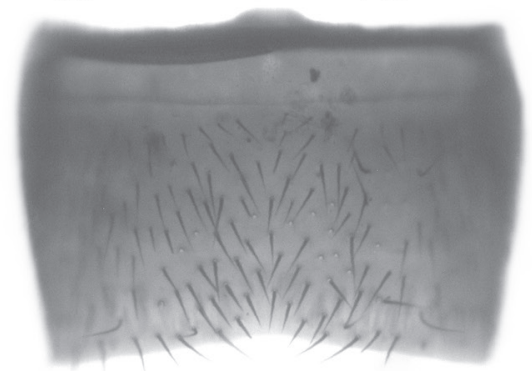

17

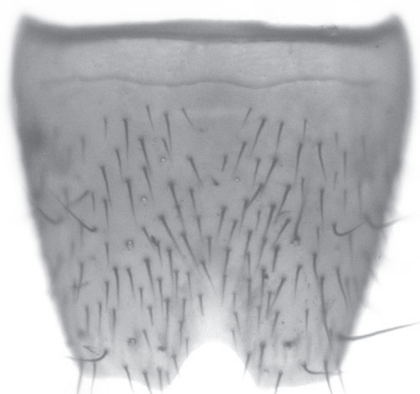

18

Figs 12-20: Lathrobium kiruense spec. nov. (12-15) and L. undosum spec. nov. (16-20): forebody (12-16); male sternite VII (13, 17); male sternite VIII $(14,18)$; aedeagus in lateralview $(15,19)$; aedeagus in ventral view $(20)$. Scale bars: 12, 16: 1.0 mm; 13-15, 17-20: $0,5 \mathrm{~mm}$. 
punctation moderately dense and shallow, weakly defined. Hind wings completely reduced.

Abdomen approximately 1.1 times as broad as elytra; punctation fine and shallow, moderately dense on tergites III-VI, sparser on tergites VII-VIII; interstices with shallow transverse microsculpture composed of isodiametric and short transverse meshes; posterior margin of tergite VII without palisade fringe.

$\mathrm{o}^{\text {t }}$ : protarsomeres I-IV strongly dilated; tergite VIII with weakly convex posterior margin; sternite VII (Fig. 17) moderately strongly transverse, approximately 1.5 times as broad as long, with rather indistinct postero-median impression, pubescence not distinctly modified, posterior margin weakly concave; sternite VIII (Fig. 18) transverse, approximately 1.1 times as broad as long, posterior excision of nearly semi-circular shape, pubescence not distinctly modified; aedeagus (Figs 19-20) $0.83 \mathrm{~mm}$ long and symmetric, dorso-ventrally somewhat flattened; ventral process flat, gradually tapering apicad and apically acute in ventral view; dorsal plate with apical portion lamellate, moderately sclerotized, and multisinuate in lateral view, basal portion short and lamellate; internal sac with long dark membranous structure. o: unknown.

Comparative notes: Primarily based on the nearly unmodified pubescence of the male sternites VII and VIII, as well as on the dorso-ventrally flattened aedeagus with a long membranous structure in the internal sac, L. undosum is tentatively assigned to the L. discissum group, which previously included three described species from eastern Nepal and West Bengal. However, unlike the previously described representatives of this group, the aedeagus of L. undosum has a long dorsal plate. This species is readily distinguished from the species of all other Himalayan species groups by the absence of microsculpture on the head and by the distinctive morphology of the aedeagus.

Distribution and natural history: The type locality is situated in Solu Khumbu, eastern Nepal, some $120 \mathrm{~km}$ to the east of Kathmandu. The holotype was collected at an altitude between 3500-3800 m.

\section{Lathrobium spec}

Material examined: Nepal: 5 ㅇ , Solu Khumbu, Lamiura Danda, $27^{\circ} 34^{\prime} \mathrm{N}, 86^{\circ} 30^{\prime} \mathrm{E}, 3500-3800 \mathrm{~m}, 28 .-29 . V .2013$, leg. Hagge \& Schmidt (NME, cAss).

Comment: The above females most likely represent an undescribed species of the L. nepalense group.

\subsection{China}

\subsubsection{The Lathrobium fauna of Yunnan}

\subsubsection{Diversity, biogeography, and natural history}

Including the new taxa described in this article, 206 described Lathrobium species are now known from China, approximately one-third of which (67 species) have been recorded from Yunnan. As was to be expected, the recent field trip to East Yunnan revealed that Lathrobium is present in this region, too, though apparently less diverse than in the west of the province (Map 1). Explanations for this may be the generally lower altitudes of the mountain ranges, as well as the limited accessibility and fragmentation of high-altitude forest and shrub habitats. In western Yunnan, Lathrobium species have been recorded at elevations between 2100 and $4100 \mathrm{~m}$, with the vast majority of records between 2300 and $3900 \mathrm{~m}$ (Assing 2013c). Accordingly, in the localities studied in eastern Yunnan, Lathrobium was generally found at altitudes of at least approximately 2300 m (range: 2290$2670 \mathrm{~m}$ ). The exception is the Dawei Shan near Pingbian in the very southeast of Yunnan, where two syntopic species were collected at $2100 \mathrm{~m}$. This locality, however, is distinguished from other habitats examined by extensive and largely unmanaged primary forests. In the environs of Kunming and Wuding at altitudes between 2290$2400 \mathrm{~m}$, Lathrobium was recorded only in semi-natural broad-leaved and mixed forests, whereas in the two localities near Dongchuan at elevations of more than $2600 \mathrm{~m}$, two species were recorded even in strongly degraded secondary pine forest.

Incidentally, the speciose Palaearctic paederine genus Nazeris FAUVEL, 1873, which exclusively includes micropterous species living in similar habitats as Lathrobium, but at generally somewhat lower altitudes (West Yunnan: 1900-3150 m; East Yunnan: 1500-2620 m), was found to be more diverse than Lathrobium in East Yunnan (twelve species of Nazeris versus six of Lathrobium). In West Yunnan, Nazeris is represented by significantly fewer described species than Lathrobium (33 species of Nazeris versus 62 of Lathrobium) (Assing 2013g, 2014b; present paper).

Interestingly, the discovery of two Lathrobium species in the Dawei Shan near Pingbian (Maps 1-2) represents the southernmost record of the genus in China, and the second record south of 23 degrees northern latitude in the Palaearctic region. The southernmost record is the Peitawushan in southern Taiwan, from where three species (L. extraculum Assing, 2010; L. follitum Assing, 2010; L. furcillatum Assing, 2010) have been reported (Assing 2010). 


\subsubsection{Species groups}

Primarily based on the male and female sexual characters, the six species recorded from East Yunnan are attributed to three species groups:

Four species (L.crenatum, L. rostratum, L. tricarinatum, L. laciniatum), all of them distributed in the region to the north of Kunming, belong to the L. tentaculatum group, which previously included only L. tentaculatum Assing, 2013 from the Ailao Shan. The distributions of the species of this group are illustrated in Map 2. They share an aedeagus of derived morphology (more or less distinctly asymmetric; dorso-ventrally flattened; ventral process more or less deeply excised apically; basal portion very small; dorsal plate short and broad; internal structures absent, except for the ring-shaped structure), similar external characters (robust black body with strongly transverse elytra and a rather broad and weakly oblong pronotum; large eyes; similar punctation), a similar morphology of the female tergites IX and $\mathrm{X}$ (antero-median portion very short and with suture; tergite $\mathrm{X}$ very long and flat), and a mostly sexually dimorphic, posteriorly more or less distinctly angled tergite VIII.

The L. daweianum group includes only a single species, L. daweianum, from the Dawei Shan in southeastern Yunnan (Map 2). It shares the long, slender, and strongly curved ventral process of the aedeagus and the morphol- ogy of the female tergite IX (anteriorly broadly undivided) with species of the L. curvatissimum group, which are distributed in northwestern Yunnan and Sichuan, but it is distinguished from them by much smaller body size, a more slender body (oblong head; much more oblong pronotum), the presence of massive internal spines in the internal sac of the aedeagus, a flat female tergite $\mathrm{X}$, and the presence of a large black internal structure in the female segment IX.

The L. coadultum group, which too is represented by a single species, L. coadultum, from the Dawei Shan (Map 2), is constituted above all by conspicuous and unique modifications of the female segments IX and $\mathrm{X}$, which have not been observed in any other species or species group of the genus: tergite IX (including the postero-lateral processes) and tergite $\mathrm{X}$ are completely fused without so much as traces of sutures, thus forming a single oblong and posteriorly tapering plate with a pair of needle-shaped posterior processes and extending far beyond the apices of the hemisternites IX. In addition, this group is characterized by pronounced microsculpture on the head, the presence of strongly modified setae on the male sternites VII and VIII, and by a slender aedeagus with a long and conspicuously acute ventral process and with two long sclerotized spines in the internal sac.

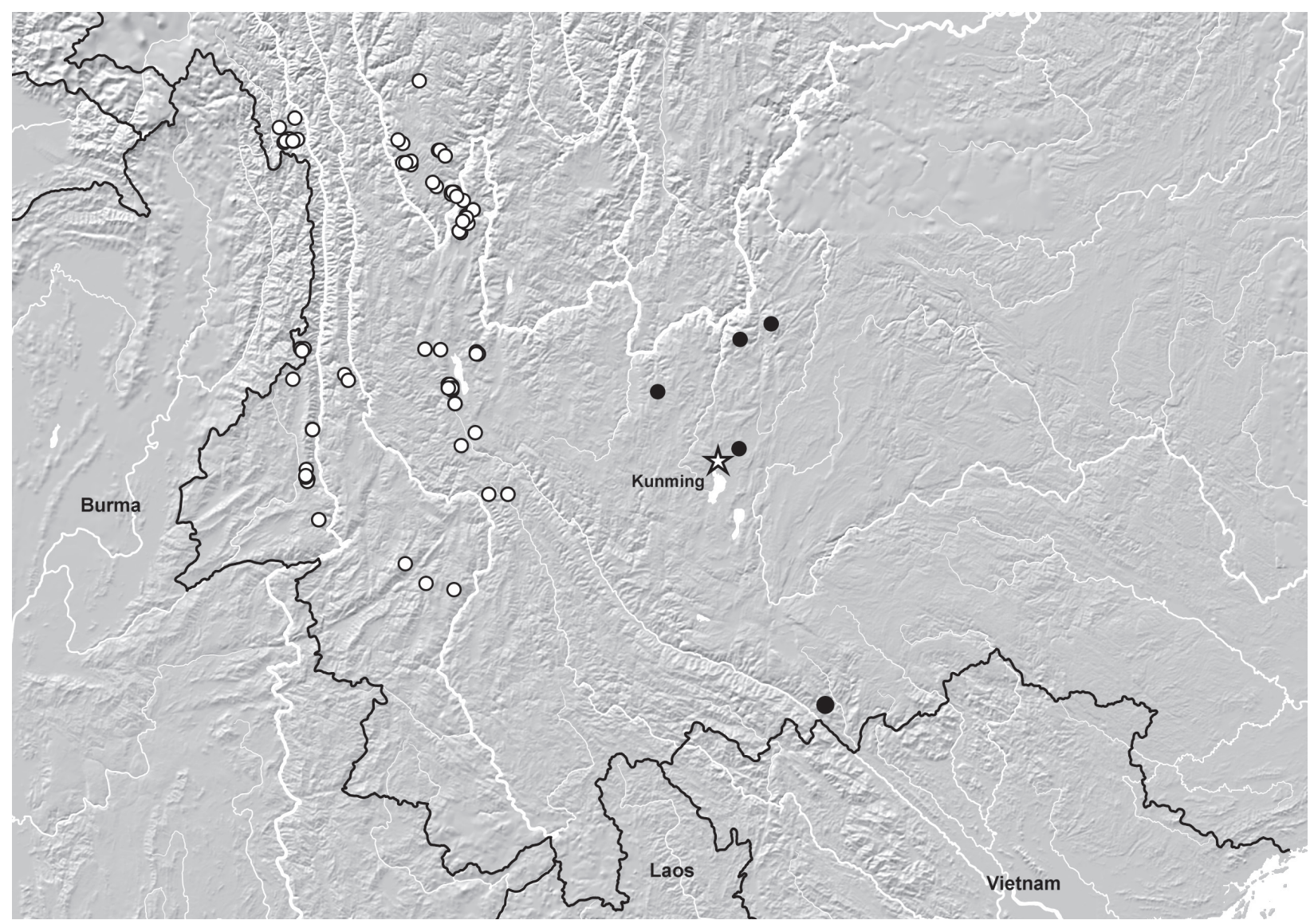

Map 1: Distribution of previously described (white circles) and newly described species (black circles) of Lathrobium in Yunnan (white star: Kunming). 


\subsubsection{Additional records}

\section{Lathrobium reticolle AssING, 2013}

Material examined: China: Yunnan: 3 exs., Haba Shan, $27^{\circ} 22^{\prime} \mathrm{N}, 100^{\circ} 07^{\prime} \mathrm{E}, 3830 \mathrm{~m}$, sifted, 19.VI.2012, leg. Grebennikov (CAS, cAss); 1 ex., Haba Shan, $27^{\circ} 21^{\prime} \mathrm{N}$, $100^{\circ} 07^{\prime} \mathrm{E}, 3450 \mathrm{~m}$, sifted, 24.VI.2012, leg. Grebennikov (cSme).

Comment: The above material was collected close to the type locality (Assing 2013c).

\section{Lathrobium stipiferum AssING, 2013}

Material examined: China: Yunnan: 1 ex., Haba Shan, $27^{\circ} 21^{\prime} \mathrm{N}, 100^{\circ} 07^{\prime} \mathrm{E}, 3450 \mathrm{~m}$, sifted, 24.VI.2012, leg. Grebennikov (cSme); 2 exs., Haba Shan, $27^{\circ} 22^{\prime} \mathrm{N}$, $100^{\circ} 06^{\prime} \mathrm{E}, 3330 \mathrm{~m}$, sifted, 23.VI.2012, leg. Grebennikov (CAS, cAss); 1 ex., Haba Shan, $27^{\circ} 22^{\prime} \mathrm{N}, 100^{\circ} 06^{\prime} \mathrm{E}, 3350 \mathrm{~m}$, sifted, 23.VI.2012, leg. Grebennikov (cSme).

\section{Lathrobium aokii WATANABE \& XIAO, 2000}

Material examined: China: Yunnan: 3 exs., Diancang Shan near Dali, $25^{\circ} 41^{\prime} \mathrm{N}, 100^{\circ} 08^{\prime} \mathrm{E}, 2720$, 12.V.2010, leg. Grebennikov (CAS, cSme, cAss).

Comment: This species is rather common in the southern Diancang Shan, where it has been recorded at altitudes of 2600-4060 m (Assing 2013c).

\section{Lathrobium daliense WatANABE \& XIAO, 1994}

Material examined: China: Yunnan: 3 exs., Diancang Shan near Dali, $25^{\circ} 41^{\prime} \mathrm{N}, 100^{\circ} 08^{\prime} \mathrm{E}, 2720$, sifted, 12.V.2010, leg. Grebennikov (CAS, cSme, cAss); 1 ex., Diancang Shan near Dali, $25^{\circ} 41^{\prime} \mathrm{N}, 100^{\circ} 08^{\prime} \mathrm{E}, 2690$, sifted, 11.V.2010, leg. Grebennikov (CAS).

Comment: Like L.aokii, L. daliense is endemic to, and rather common in, the Diancang Shan, where it has been found at altitudes of 2100-3000 m (Assing 2013c).

Comment: This recently described species is endemic to the Haba Shan (Assing 2013c).

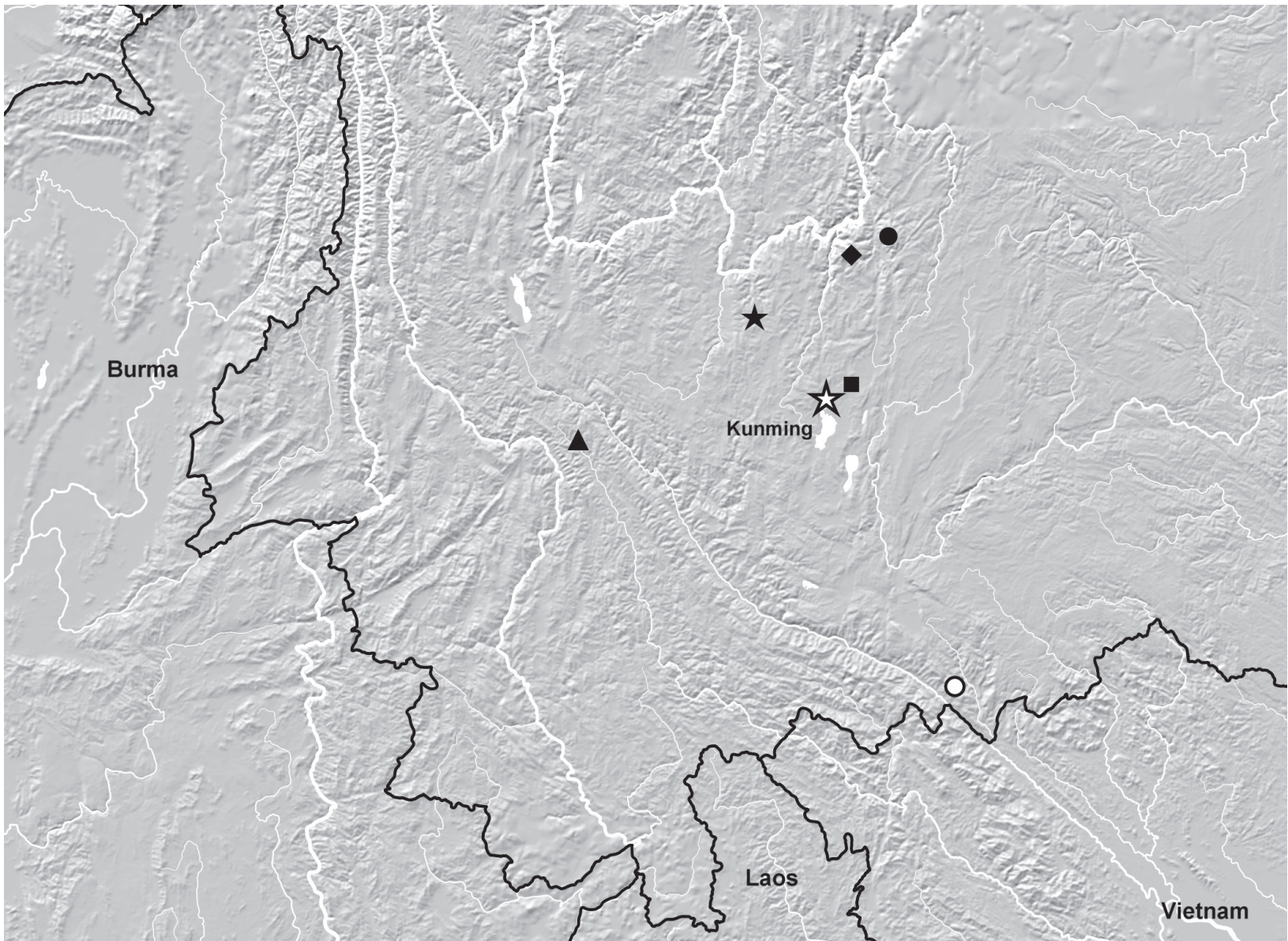

Map 2: Distributions of the L. tentaculatum (black symbols), L. daweianum, and L. coadultum groups (white circle) in Yunnan: L. crenatum spec. nov. (black circle); L. tricarinatum spec. nov. (black diamond); L. rostratum spec. nov. (black square); L. laciniatum spec. nov. (black star); L. tentaculatum Assing (black triangle); L. daweianum spec. nov. (white circle); L. coadultum spec. nov. (white circle). 


\subsubsection{Descriptions of new species}

\section{Lathrobium crenatum spec. nov.} (Figs 21-29)

Type material: Holotype $\sigma^{*}$ : "CHINA [2] - Yunnan, mts NE Dongchuan, $2670 \mathrm{~m}, 26^{\circ} 14^{\prime} 10^{\prime \prime} \mathrm{N}, 103^{\circ} 12^{\prime} 31$ "E, pine for., 9.VIII.2014, V. Assing / Holotypus o Lathrobium crenatum spec. nov., det. V. Assing 2014" (cAss).

Paratypes: $5 \sigma^{\top} o^{\top}, 5$ 우 우 : same data as holotype (cAss); $3 o^{\star} o^{\star}, 3$ 우 + same data as holotype, but leg. M. Schülke (cSch); $10^{*}, 1 \%$ : “CHINA [2a] - Yunnan, mts NE Dongchuan, $2670 \mathrm{~m}, 26^{\circ} 14^{\prime} 10^{\prime \prime} \mathrm{N}, 103^{\circ} 12^{\prime} 31^{\prime \prime E}$, bushes, 9.VIII.2014, V. Assing" (cAss).

Etymology: The specific epithet is an adjective derived from the Latin noun crena (notch) and alludes to the profoundly notched apex of the aedeagus.

Description: Species of moderate size, without evident sexual size dimorphism; body length 7.5-9.0 mm; length of forebody $3.7-4.0 \mathrm{~mm}$. Habitus as in Fig. 21 . Coloration: body black; legs dark-brown, with the proand mesotibiae paler brown and the tarsi yellowish to yellowish-brown; antennae yellowish-red to reddish.

Head (Fig. 22) weakly transverse, 1.01-1.06 times as broad as long, usually weakly dilated behind eyes; punctation moderately coarse and moderately sparse, in median dorsal portion sparse; interstices with distinct microreticulation, on average slightly broader than diameter of punctures in lateral and posterior dorsal portions, much broader in median dorsal portion. Eyes weakly convex, weakly projecting from lateral contours of head and rather large, approximately half as long as postocular region in dorsal view and composed of significantly more than 50 ommatidia. Antenna 2.0-2.2 mm long.

Pronotum (Fig. 22) rather broad, 1.15-1.20 times as long as broad and 1.07-1.10 times as broad as head; punctation similar to that of head; impunctate midline moderately broad; interstices without microsculpture.

Elytra (Fig. 22) short and broad, approximately 1.75 times as broad (combined width) as long and 0.51-0.54 times as long as pronotum, not distinctly dilated posteriad; humeral angles moderately marked; punctation moderately dense, shallower than that of head and pronotum; interstices without microsculpture. Hind wings completely reduced. Protarsomeres I-IV with moderate sexual dimorphism.

Abdomen approximately 1.1 times as broad as elytra; punctation fine, rather dense on tergites III-VI, sparser on tergite VII; interstices with shallow transverse microsculpture; posterior margin of tergite VII without palisade fringe; tergite VIII with weak, but noticeable sexual dimorphism.

$\mathrm{o}^{\star}$ : protarsomeres I-IV distinctly dilated; posterior margin of tergite VIII very obtusely angled in the middle; sternite VII (Fig. 23) distinctly transverse, approximately 1.6 times as broad as long, posteriorly with shallow median impression and with a pair of weakly defined and sparse clusters of slightly stouter and longer black setae, posterior margin weakly concave in the middle; sternite VIII (Fig. 24) weakly transverse, approximately 1.05 times as broad as long, posteriorly with dense moderately modified stout black setae, posterior margin with relatively small median excision of nearly semicircular shape; aedeagus (Figs 25-27) 1.25-1.30 mm long and of highly derived morphology, strongly asymmetric, dorso-ventrally depressed, weakly sclerotized apically, and with small basal portion; ventral process asymmetric, apically deeply and asymmetrically notched, and with conspicuous latero-dorsal extension somewhat enwrapping latero-dorsal portion of aedeagus; dorsal plate asymmetric, rather weakly sclerotized, short, broad, and basally truncate, without basal portion; internal sac without noticeable structures, except for the usual ringshaped structure.

\%: protarsomeres I-IV dilated, but slightly less so than in male; posterior margin of tergite VIII distinctly angled in the middle (more so than in male); sternite VIII (Fig. 28) approximately 1.1 times as long as broad and with strongly convex posterior margin; tergite IX (Fig. 29) with very short and divided antero-median portion and with slender postero-lateral processes; tergite X (Fig. 29) flattened and very long, approximately ten times as long as antero-median portion of tergite IX.

Comparative notes: Among the species previously recorded from Yunnan, L. crenatum is most similar - and based on the similarly derived morphology of the aedeagus most closely related - to L. tentaculatum Assing, 2013 from the Ailao Shan, previously the sole representative of the L. tentaculatum group. Both species are externally similar (moderately large and robust black body with strongly transverse elytra and a rather broad pronotum; large eyes; similar punctation), a similar morphology of the female tergites IX and X (anteromedian portion very short and with suture; tergite $\mathrm{X}$ very long), a posteriorly angled tergite VIII, and particularly an aedeagus of derived morphology (distinctly asymmetric; dorso-ventrally flattened; ventral process deeply excised apically; basal portion very small; dorsal plate short and broad; internal structures absent, except for the ring-shaped structure). Lathrobium crenatum is distinguished from L. tentaculatum by smaller size, by the shapes and chaetotaxy of the male sternites VII and VIII, as well as by the shape of the aedeagus (L. tentaculatum: ventral process apically extending into a pair of long and slender processes). For illustrations of L. tentaculatum see Assing (2013c).

Distribution and natural history: The species was discovered in a mountain to the northeast of Dongchuan in northeastern Yunnan. The specimens were sifted from pine needles between rocks in a secondary pine forest and from litter on a scree slope with bushes and herbs at an altitude of $2670 \mathrm{~m}$. 


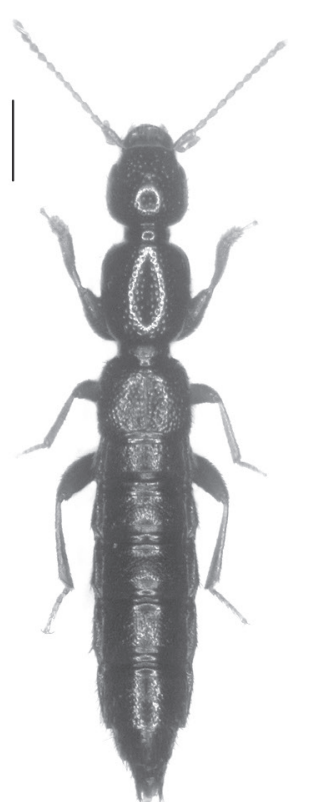

21

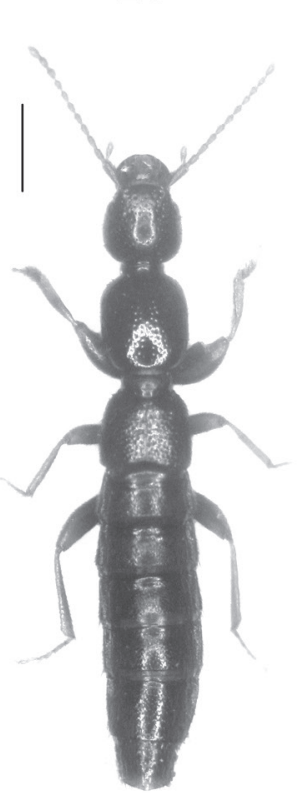

30

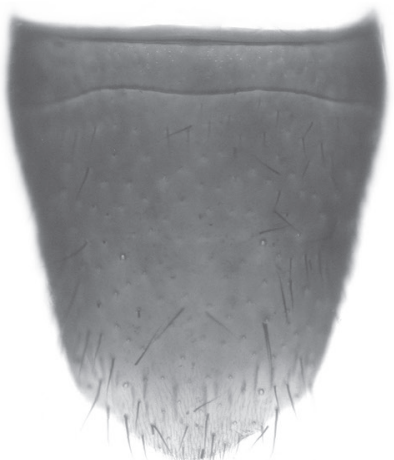

28

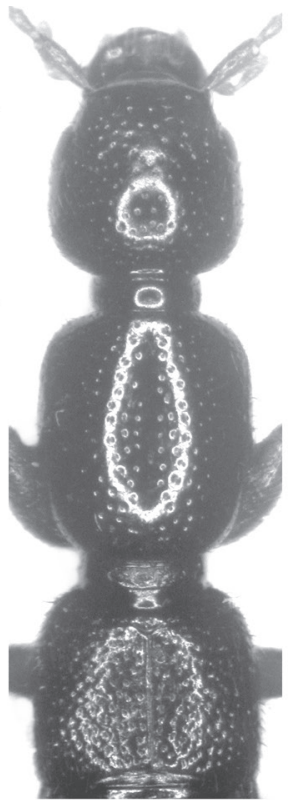

22

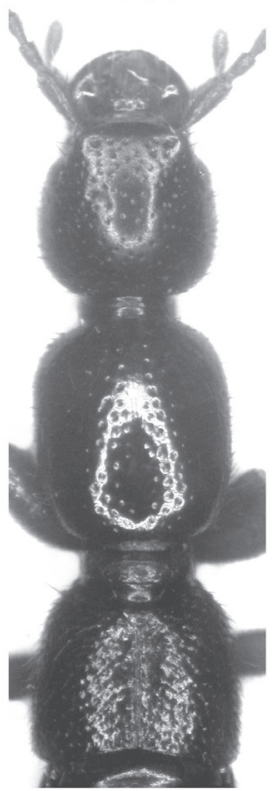

31

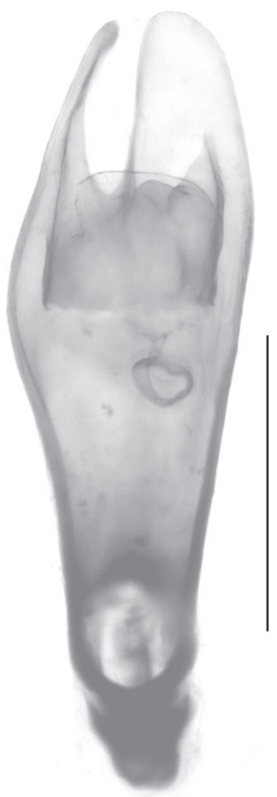

25

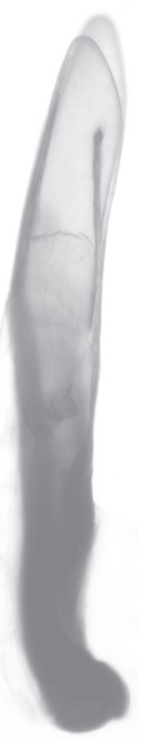

34

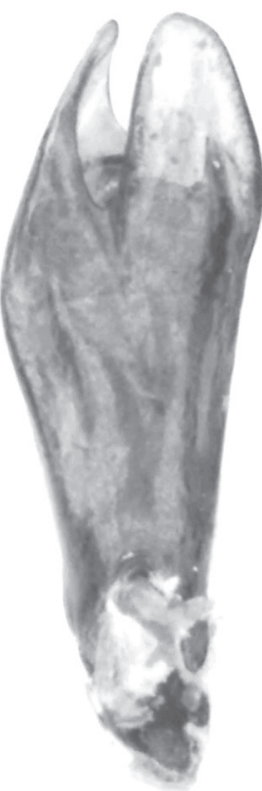

26

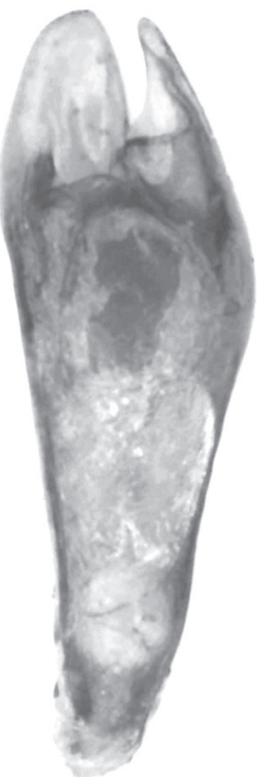

27

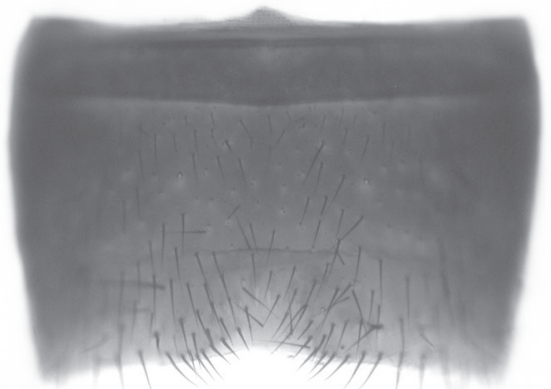

23

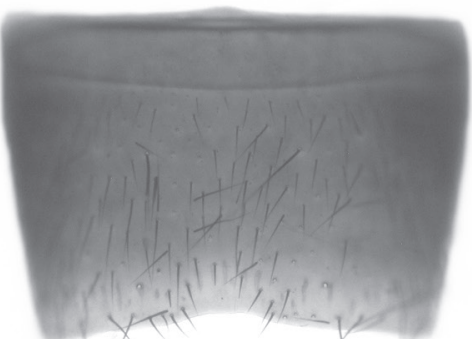

32

Figs 21-35: Lathrobium crenatum spec. nov. (21-29) and L. rostratum spec. nov. (30-35): habitus (21, 30); forebody (22, 31); male sternite VII $(23,32)$; male sternite VIII $(24,33)$; aedeagus in ventral view $(25,35)$; aedeagus in dry preparation in ventral and in dorsal view (26-27); female sternite VIII (28); female tergites IX-X (29); aedeagus in lateral view (34). Scale bars: 21-22, 30-31: $1.0 \mathrm{~mm} ; 23-29,32-35: 0.5 \mathrm{~mm}$. 


\section{Lathrobium rostratum spec. nov.}

(Figs 30-35, 77-78)

Type material: Holotype $\sigma^{*}$ : "CHINA [6] - Yunnan, NE Kunming, 250' $35^{\prime \prime} \mathrm{N}, 102^{\circ} 53^{\prime} 49^{\prime \prime E}, 2320$ m, mixed forest, sifted, 13.VIII.2014, V. Assing / Holotypus ơ Lathrobium rostratum spec. nov., det. V. Assing 2014" (cAss).

Paratypes: $9 \sigma^{\star} \sigma^{\star}, 7$ 우 우 [2 $\sigma^{\star} \sigma^{\star}, 2$ 우 우 teneral]: same data as holotype (cAss, MNHUB); $3 \sigma^{\star} \sigma^{\star}, 4$ 우 우 [1 9 teneral]: same data as holotype, but leg. M. Schülke (cSch); 3 o $^{\star} 0^{\star}$,

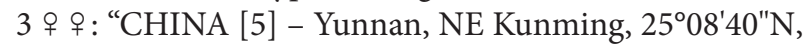
$102^{\circ} 53^{\prime} 48^{\prime \prime E}, 2290 \mathrm{~m}$, mixed forest, sifted, 11.VIII.2014, V. Assing" (cAss); 2 o o $^{*}$ [1 teneral], same data, but leg. M. Schülke (cSch).

Etymology: The specific epithet is an adjective derived from the Latin noun rostrum (beak) and alludes to the shape of the apex of the aedeagus.

Description: Species of moderate size, without evident sexual size dimorphism; body length 6.5-8.2 $\mathrm{mm}$; length of forebody $3.3-3.7 \mathrm{~mm}$. Habitus as in Fig. 30. Coloration: body black; legs brown, with the profemora and often also the meso- and metafemora dark-brown and with the tarsi yellowish-brown; antennae reddish.

Head (Fig. 31) weakly transverse, 1.01-1.04 times as broad as long, usually weakly dilated behind eyes; punctation rather sparse, in median dorsal portion even sparser, and moderately coarse to moderately fine; interstices with distinct microreticulation, on average distinctly broader than diameter of punctures in lateral and posterior dorsal portions. Eyes weakly convex, weakly projecting from lateral contours of head and of moderate size, approximately one-third as long as postocular region in dorsal view and composed of slightly more than 50 ommatidia. Antenna 1.8-2.0 mm long.

Pronotum (Fig. 31) rather broad and relatively weakly oblong, approximately 1.15 times as long as broad and approximately 1.1 times as broad as head; punctation usually slightly coarser than that of head; impunctate midline moderately broad; interstices without microsculpture.

Elytra (Fig. 31) short and broad, approximately 1.75 times as broad (combined width) as long and 0.52-0.54 times as long as pronotum, not distinctly dilated posteriad; humeral angles moderately marked; punctation moderately dense, shallower and usually finer than that of pronotum; interstices without microsculpture. Hind wings completely reduced. Protarsomeres I-IV with moderately pronounced sexual dimorphism.

Abdomen approximately 1.1 times as broad as elytra; punctation fine, rather dense on tergites III-VI, sparser on tergite VII; interstices with shallow transverse microsculpture; posterior margin of tergite VII without palisade fringe; tergite VIII with weak sexual dimorphism.

$\mathrm{o}^{\top}$ : protarsomeres I-IV distinctly dilated; posterior margin of tergite VIII very obtusely angled in the middle; sternite VII (Fig. 32) distinctly transverse, approximately
1.55 times as broad as long, posteriorly with shallow and rather small median impression and with broadly and weakly concave posterior margin, pubescence not distinctly modified; sternite VIII (Fig. 33) approximately as broad as long, posteriorly with excision of trapezoid shape, on either side of this excision with an ill-defined cluster of moderately modified black setae; aedeagus (Figs 34-35) approximately $1.2 \mathrm{~mm}$ long, slightly asymmetric, dorso-ventrally depressed, weakly sclerotized apically, and with small basal portion; ventral process slightly asymmetric, apically deeply bifid, the apices shaped like lamellae; dorsal plate weakly sclerotized, truncate basally and apically, and without separate basal portion; internal sac with an irregular membranous ringshaped structure, without additional structures.

$\%$ : protarsomeres I-IV dilated, but somewhat less so than in male; posterior margin of tergite VIII distinctly angled in the middle (more so than in male); sternite VIII (Fig. 77) approximately 1.1 times as long as broad and with strongly convex posterior margin; tergite IX (Fig. 78) with short antero-median portion with median suture and with slender postero-lateral processes; tergite X (Fig. 78) flattened and very long, approximately five times as long as antero-median portion of tergite IX.

Comparative notes: As can be inferred from the external and sexual characters, particularly from the similarly modified aedeagus, L. rostratum, too, belongs to the L. tentaculatum group. It is distinguished from L. crenatum by slightly smaller body size, distinctly smaller eyes, the shapes and chaetotaxy of the male sternites VII and VIII, the shape of the aedeagus, and by the long antero-median portion of the female tergite IX.

Distribution and natural history: The species was found in two geographically close localities to the northeast of Kunming. The specimens were sifted from litter in a mixed broad-leaved forest with scattered pine trees and in a mixed forest with alder, oak, and pine at altitudes of 2290 and $2320 \mathrm{~m}$, respectively. Some of the paratypes are teneral.

\section{Lathrobium tricarinatum spec. nov. \\ (Figs 36-44)}

Type material: Holotype ơ: "CHINA [7] - Yunnan, mts W Dongchuan, $2620 \mathrm{~m}, 26^{\circ} 06^{\prime} 08^{\prime \prime} \mathrm{N}, 102^{\circ} 54^{\prime} 46^{\prime \prime E}$, pine for., 14.VIII.2014, V. Assing / Holotypus o Lathrobium tricarinatum spec. nov., det. V. Assing 2014" (cAss).

Paratypes: $20^{\star} o^{\star}, 1$ ㅇ [1 $10^{\star}$ teneral]: same data as holotype (cAss).

Etymology: The specific epithet (Latin, adjective) alludes to the presence of three carinae on the ventral process of the aedeagus. 


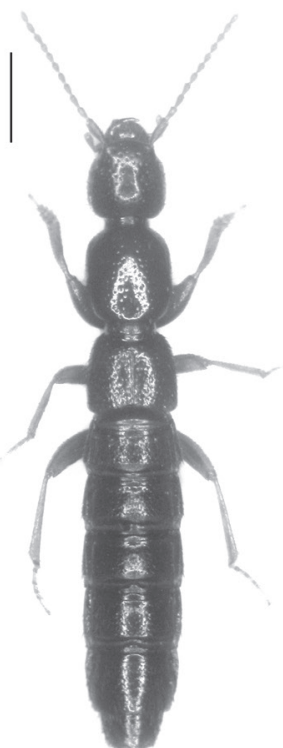

36

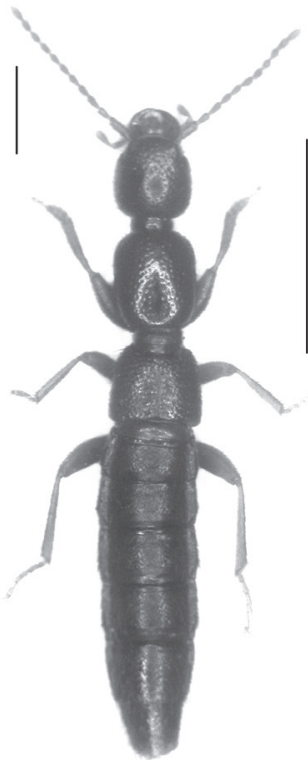

45

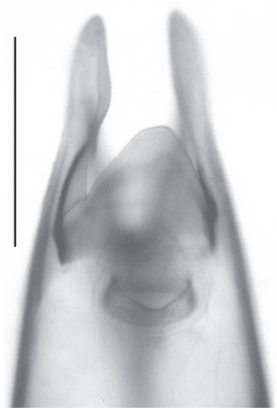

51

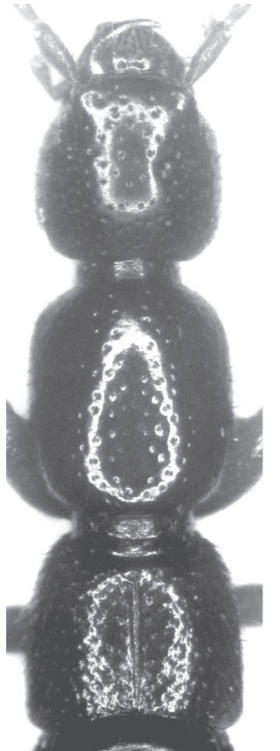

37

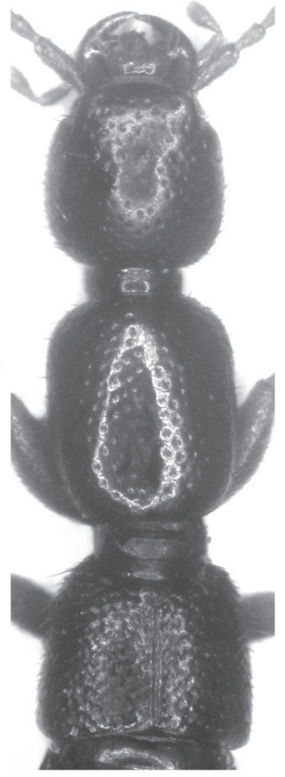

46

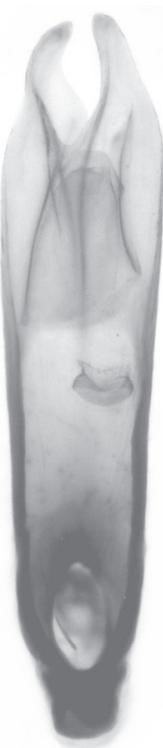

40

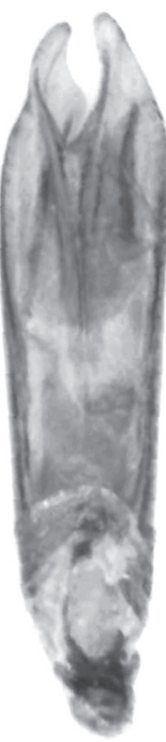

41

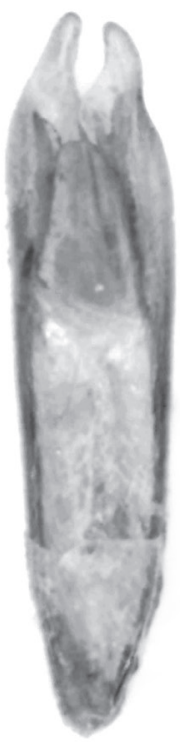

42

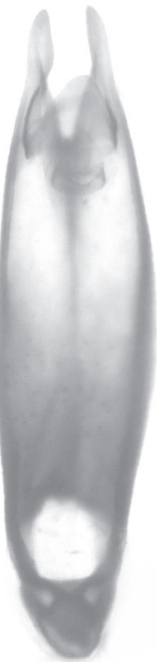

49

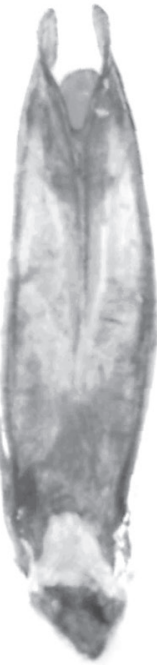

50

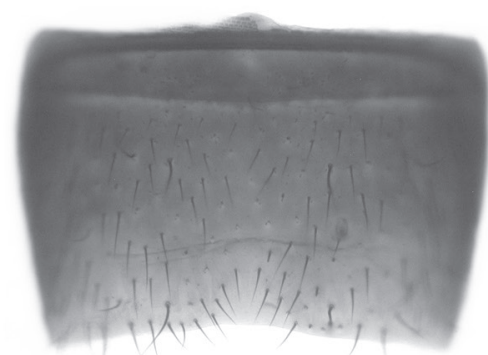

38

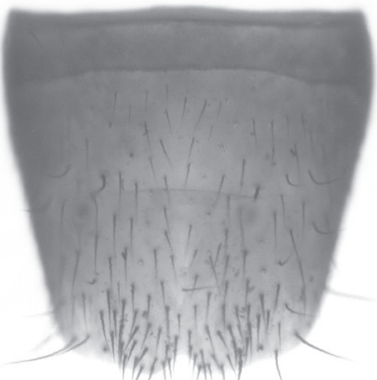

39

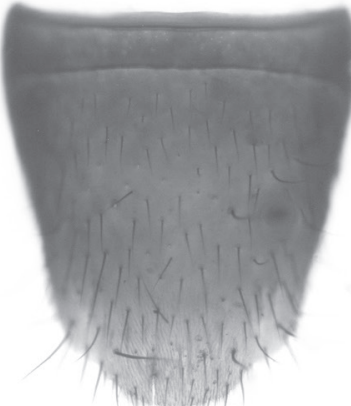

43

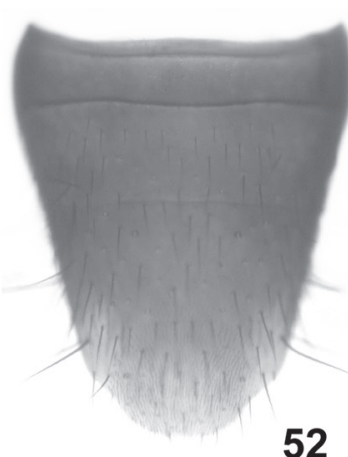

52

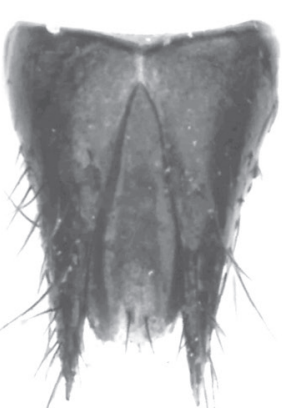

44

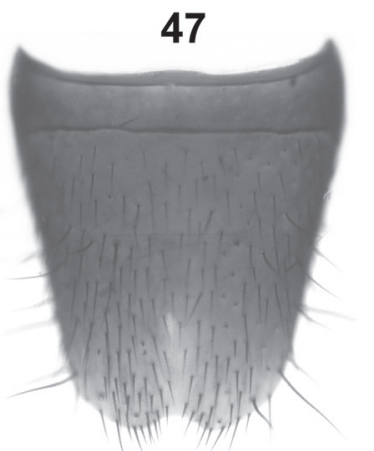

48

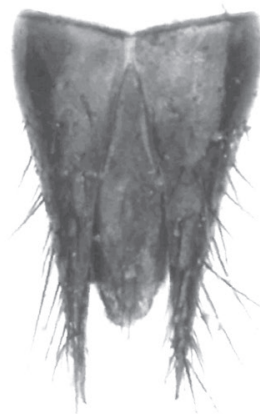

53

Figs 36-53: Lathrobium tricarinatum spec. nov. (36-44) and L. laciniatum spec. nov. (45-53): habitus $(36,45)$; forebody $(37,46)$; male sternite VII $(38,47)$; male sternite VIII $(39,48)$; aedeagus in ventral view $(40,49)$; aedeagus in dry preparation in ventral view $(41,50)$; aedeagus in dry preparation in dorsal view $(42)$; female sternite VIII $(43,52)$; female tergites IX-X $(44,53)$; apical portion of aedeagus in dorsal view (51). Scale bars: 36-37, 45-46: $1.0 \mathrm{~mm}$; 38-44, 47-50, 52-53: $0.5 \mathrm{~mm}$; 51: $0.2 \mathrm{~mm}$. 
Description: Species of moderate size, without evident sexual size dimorphism; body length 7.3-7.7 mm; length of forebody 3.3-3.5 mm. Habitus as in Fig. 36. Coloration: body black; legs pale-brown, with the profemora darkbrown and with the tarsi yellowish-brown; antennae reddish.

Head (Fig. 37) weakly transverse, approximately 1.03 times as broad as long, usually weakly dilated behind eyes; punctation moderately coarse and moderately sparse, in median dorsal portion sparser; interstices with distinct microreticulation, on average somewhat broader than diameter of punctures in lateral and posterior dorsal portions. Eyes weakly convex, weakly projecting from lateral contours of head and of moderate size, slightly less than half, but distinctly more than one-third as long as postocular region in dorsal view and composed of significantly more than 50 ommatidia. Antenna approximately $1.8 \mathrm{~mm}$ long.

Pronotum (Fig. 37) rather broad and relatively weakly oblong, 1.15-1.20 times as long as broad and approximately 1.1 times as broad as head; punctation similar to that of head; impunctate midline moderately broad; interstices without microsculpture.

Elytra (Fig. 37) short and broad, approximately 1.7 times as broad (combined width) as long and approximately 0.53 times as long as pronotum, not distinctly dilated posteriad; humeral angles moderately marked; punctation moderately dense, shallower than that of pronotum; interstices without microsculpture. Hind wings completely reduced. Protarsomeres I-IV with weak, but noticeable sexual dimorphism.

Abdomen approximately 1.1 times as broad as elytra; punctation fine, rather dense on tergites III-VI, sparser on tergite VII; interstices with shallow transverse microsculpture; posterior margin of tergite VII without palisade fringe; tergite VIII with weak sexual dimorphism.

$\sigma^{*}$ : protarsomeres I-IV distinctly dilated; posterior margin of tergite VIII very obtusely angled in the middle; sternite VII (Fig. 38) distinctly transverse, approximately 1.55 times as broad as long, posteriorly without distinct median impression and with broadly and weakly concave posterior margin, pubescence not distinctly modified; sternite VIII (Fig. 39) nearly as long as broad, posteriorly with very small excision and with an ill-defined cluster of moderately modified black setae; aedeagus (Figs 40-42) approximately $1.2 \mathrm{~mm}$ long, slightly asymmetric, dorsoventrally depressed, weakly sclerotized apically, and with small basal portion; ventral process slightly asymmetric, apically deeply bifid, the apices slender, ventrally with two lateral carinae in basal half and one median carina extending from apical incision to basal third; dorsal plate weakly sclerotized, truncate basally and convex apically, and without separate basal portion; internal sac with an irregular membranous ring-shaped structure, without additional structures.

ㅇ: protarsomeres I-IV dilated, but slightly less so than in male; posterior margin of tergite VIII distinctly angled in the middle (more so than in male); sternite VIII (Fig. 43) approximately 1.1 times as long as broad and with strongly convex posterior margin; tergite IX (Fig. 44) with short antero-median portion with median suture, and with slender postero-lateral processes; tergite X (Fig. 44) flattened and very long, approximately six times as long as antero-median portion of tergite IX.

Comparative notes: Based on the external and sexual characters, particularly on the modifications of the aedeagus, L. tricarinatum belongs to the L. tentaculatum group. It is distinguished from both L. crenatum and L. rostratum by the morphology of the aedeagus and by the smaller posterior excision of the male sternite VIII, from the geographically close L. crenatum additionally by smaller body size, slightly smaller eyes, the different shape and chaetotaxy of the male sternite VII, and by the slightly longer antero-median portion of the female tergite IX.

Distribution and natural history: The type locality is situated near the Sedan Snow Mountain Scenic Resort in the mountains to the West of Dongchuan, northeastern Yunnan. The specimens were sifted from litter, moss, and the roots of herbs in a terraced secondary pine forest at an altitude of $2620 \mathrm{~m}$. One of the paratypes is teneral.

\section{Lathrobium laciniatum spec. nov. (Figs 45-53)}

Type material: Holotype $0^{*}$ : "CHINA [12a] - Yunnan, mt. WNW Wuding, mix. forest, $25^{\circ} 38^{\prime} 45^{\prime \prime} \mathrm{N}, 102^{\circ} 06^{\prime} 55^{\prime \prime} \mathrm{E}$, 2390 m, 1.IX.2014, V. Assing / Holotypus ơ Lathrobium laciniatum spec. nov., det. V. Assing 2014" (cAss).

Paratypes: $11 \sigma^{x} o^{x}, 11$ 우 $\left[50^{x} o^{x}, 4\right.$ ㅇ ㅇ teneral; 1 우 without abdomen]: same data as holotype (cAss, MNHUB); $4 \sigma^{\star} o^{\star}, 3$ 우 우 [1 $\sigma^{\star}, 2$ 우 우 teneral]: same data as holotype, but leg. Schülke (cSch); $30^{\star} o^{\star}, 3$ ㅇ ㅇ $\left[10^{\star}\right.$, 3 우 우 teneral]: "CHINA [12] - Yunnan, mt. WNW Wuding, mix. forest, $25^{\circ} 38^{\prime} 45^{\prime \prime} \mathrm{N}, 102^{\circ} 06^{\prime} 55^{\prime} \mathrm{E}, 2390 \mathrm{~m}$, 18.VIII.2014, V. Assing” (cAss, MNHUB); 3 o $^{\star}$ ๙ $^{\star} 3$ 우 우 [1 $\sigma^{\star}, 1$ ㅇ teneral]: same data, but leg. M. Schülke (cSch).

Etymology: The specific epithet is an adjective derived from the Latin noun lacinia (lobe) and alludes to the shapes of the two apices of the aedeagus.

Description: Species of moderate size, without evident sexual size dimorphism; body length $6.3-7.8 \mathrm{~mm}$; length of forebody 3.3-3.6 mm. Habitus as in Fig. 45. Coloration: body black; legs pale-brown, with the profemora dark-brown and with the tarsi yellowish-brown; antennae reddish.

Head (Fig. 46) usually weakly oblong, 1.00-1.07 times as long as broad, not dilated behind eyes; punctation moderately coarse and moderately sparse, sparser in median dorsal portion; interstices with distinct microreticulation, on average slightly broader than diameter of 
punctures in lateral and posterior dorsal portions. Eyes weakly convex, weakly projecting from lateral contours of head and of moderate size, approximately 0.4 times as long as postocular region in dorsal view and composed of significantly more than 50 ommatidia. Antenna relatively long and slender, approximately 2.0-2.1 mm long. Pronotum (Fig. 46) rather broad and moderately oblong, $1.20-1.23$ times as long as broad and approximately $1.06-$ 1.10 times as broad as head; punctation similar that of head; impunctate midline moderately broad; interstices without microsculpture.

Elytra (Fig. 46) short and broad, approximately 1.75 times as broad (combined width) as long and approximately 0.53 times as long as pronotum, not distinctly dilated posteriad; humeral angles moderately marked; punctation moderately dense, shallower than that of pronotum; interstices without microsculpture. Hind wings completely reduced. Protarsomeres I-IV with weakly pronounced sexual dimorphism.

Abdomen approximately 1.1 times as broad as elytra; punctation fine, rather dense on tergites III-VI, sparser on tergite VII; interstices with shallow transverse microsculpture; posterior margin of tergite VII without palisade fringe; tergite VIII without evident sexual dimorphism, posterior margin very indistinctly angled in the middle. $\mathrm{o}^{*}$ : protarsomeres I-IV moderately dilated; sternite VII (Fig. 47) distinctly transverse, approximately 1.45 times as broad as long, posteriorly without distinct median impression and with very weakly concave posterior margin, pubescence not distinctly modified; sternite VIII (Fig. 48) very weakly oblong, posteriorly with very small and shallow excision and with weakly modified black setae; aedeagus (Figs 49-51) approximately $1.1 \mathrm{~mm}$ long, nearly symmetric, dorso-ventrally depressed, weakly sclerotized apically, and with small basal portion; ventral process nearly symmetric, apically deeply bifid, the apices slender, ventrally with one median and two lateral carinae extending from apical incision to basal fourth; dorsal plate weakly sclerotized, very short, truncate basally and convex apically, and without separate basal portion; internal sac with a membranous ring-shaped structure, without additional structures.

ㅇ: protarsomeres I-IV nearly as dilated as in male; sternite VIII (Fig. 52) approximately 1.15 times as long as broad and with strongly convex posterior margin; tergite IX (Fig. 53) with short antero-median portion with median suture and with slender postero-lateral processes; tergite X (Fig. 53) flattened and very long, nearly ten times as long as antero-median portion of tergite IX.

Comparative notes: Based on the external and sexual characters, particularly on the modifications of the aedeagus, L. laciniatum clearly belongs to the L. tentaculatum group. It is distinguished from other species of this group by the smaller, more symmetric, and differently shaped aedeagus, by the shallower posterior excision of the male sternite VIII, and by the more slender body (head oblong; pronotum more oblong; antennae relatively longer). Based on the similar modifications of the aedeagus (presence of three ventral carinae; apices of ventral process of similar shape), L. laciniatum is most closely allied to L.tricarinatum from the environs of Dongchuan.

Distribution and natural history: The type locality is situated to the west-northwest of Wuding in eastern Yunnan. The specimens were sifted from litter at the margin of a mixed forest with alder, pine, and bushes at an altitude of $2390 \mathrm{~m}$. Numerous paratypes are teneral.

\section{Lathrobium daweianum spec. nov.}

(Figs 54-62)

Type material: Holotype $0^{\star}$ : "CHINA [22] - Yunnan, SE Pingbian, primary forest, $22^{\circ} 54^{\prime} 31^{\prime \prime} \mathrm{N}, 103^{\circ} 41^{\prime} 44^{\prime \prime} \mathrm{E}$, 2100 m, 27.VIII.2014, V. Assing / Holotypus o Lathrobium daweianum spec. nov., det. V. Assing 2014" (cAss). Paratypes: $2 \sigma^{\star} o^{\star}, 2$ 우 우: same data as holotype, but leg. Schülke (cAss, cSch); 1 ๙ 2 우 우 “CHINA [22a] - Yunnan, SE Pingbian, primary forest, $22^{\circ} 54^{\prime} 31^{\prime \prime} \mathrm{N}, 103^{\circ} 41^{\prime} 44^{\prime \prime} \mathrm{E}$, $2100 \mathrm{~m}, 28$. VIII.2014, V. Assing" (cAss); $1 \mathrm{o}^{\star}$ : same data, but leg. M. Schülke (cSch).

Etymology: The specific epithet is an adjective derived from the name of the mountain where the type locality is situated.

Description: Small species of slender habitus, without evident sexual size dimorphism; body length $5.5-7.0 \mathrm{~mm}$; length of forebody $2.6-2.8 \mathrm{~mm}$. Habitus as in Fig. 54. Coloration: head dark-brown; pronotum and elytra reddish-brown to brown, with the suture and the posterior margins of the elytra reddish; abdomen blackish-brown to blackish, with segments VIII-X reddish; legs reddish-yellow; antennae reddish.

Head (Fig. 55) oblong, approximately 1.1 times as long as broad, weakly dilated behind eyes; punctation rather dense and coarse in lateral, anterior, and posterior dorsal portions, sparse and finer in median dorsal portion; interstices with distinct microreticulation, on average approximately as broad as diameter of punctures in lateral and posterior dorsal portions. Eyes weakly convex, weakly projecting from lateral contours of head and small, approximately one-fourth as long as postocular region in dorsal view and composed of approximately 40 ommatidia. Antenna relatively short, 1.4-1.5 mm long. Pronotum (Fig. 55) slender, approximately 1.35 times as long as broad and about 1.1 times as broad as head; punctation similar that of head; impunctate midline moderately broad; interstices without microsculpture. Elytra (Fig. 55) short, 0.51-0.53 times as long as pronotum, not distinctly dilated posteriad; humeral angles moderately marked; punctation moderately dense and shallow; interstices without microsculpture. Hind wings 

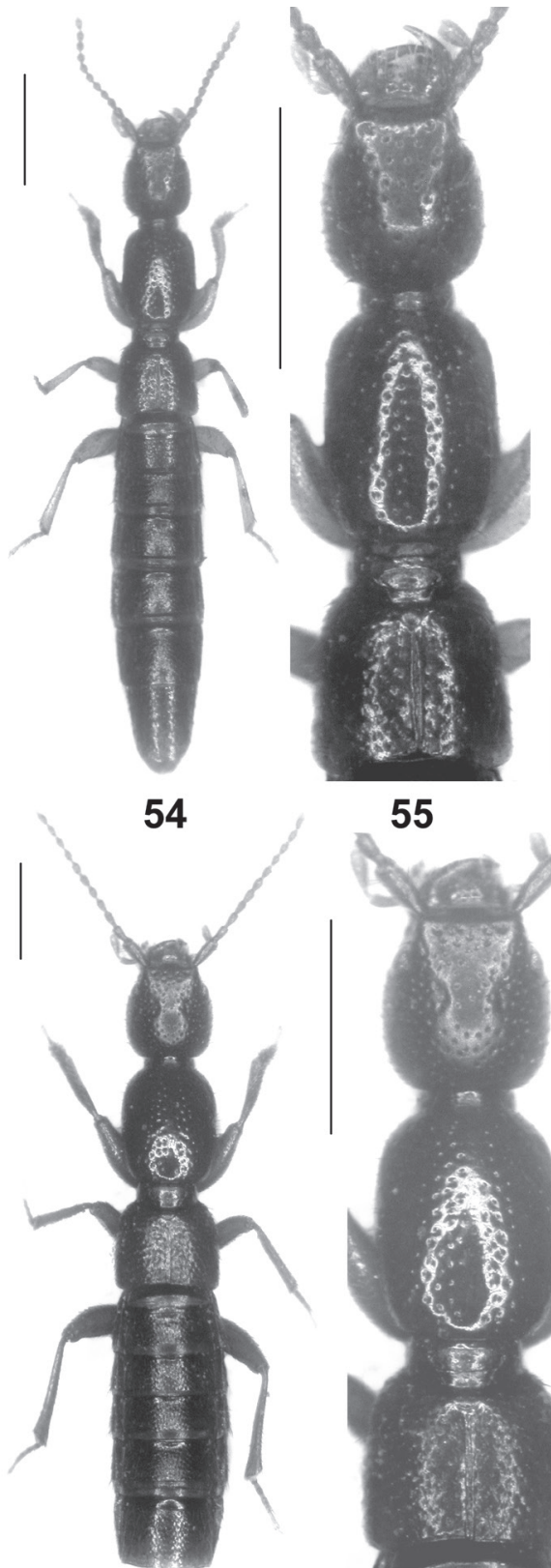

63

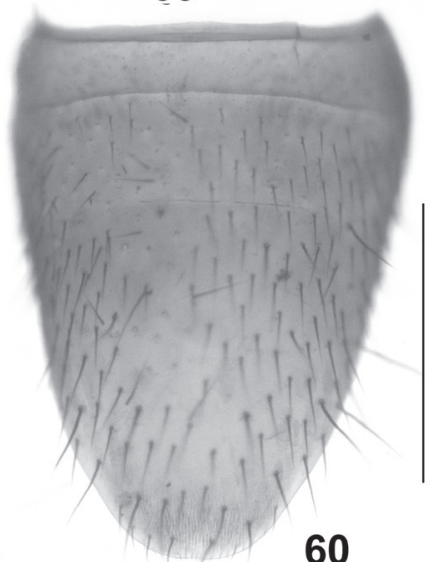

60
55

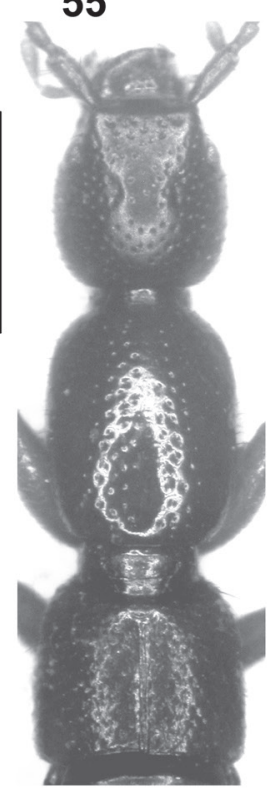

64

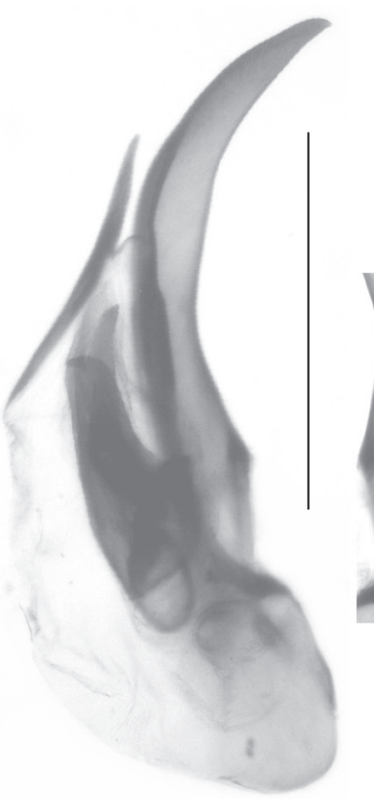

58

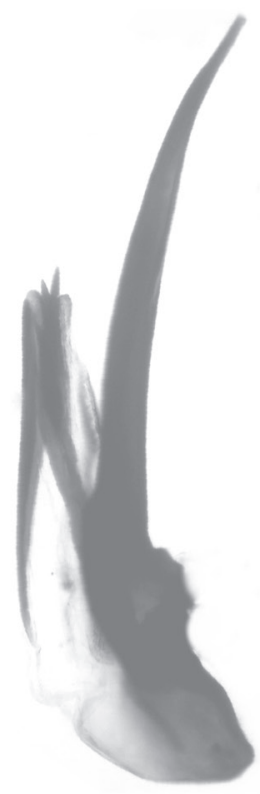

66

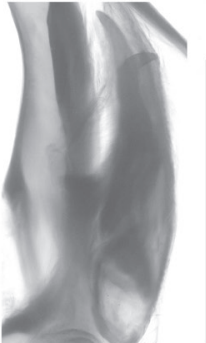

59

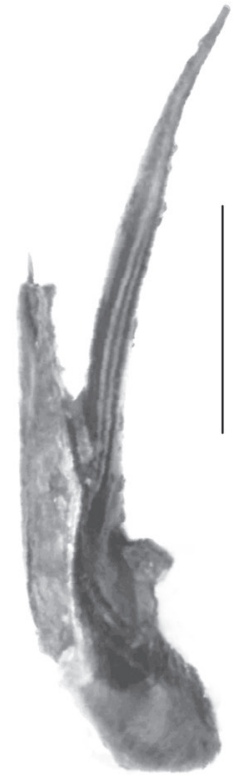

67

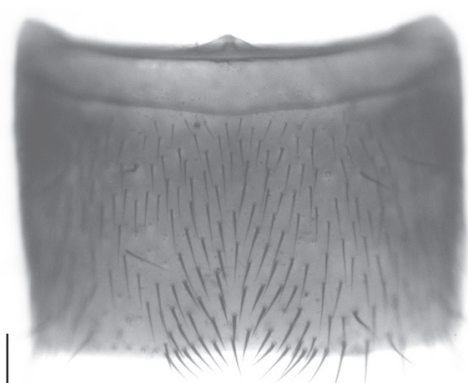

56
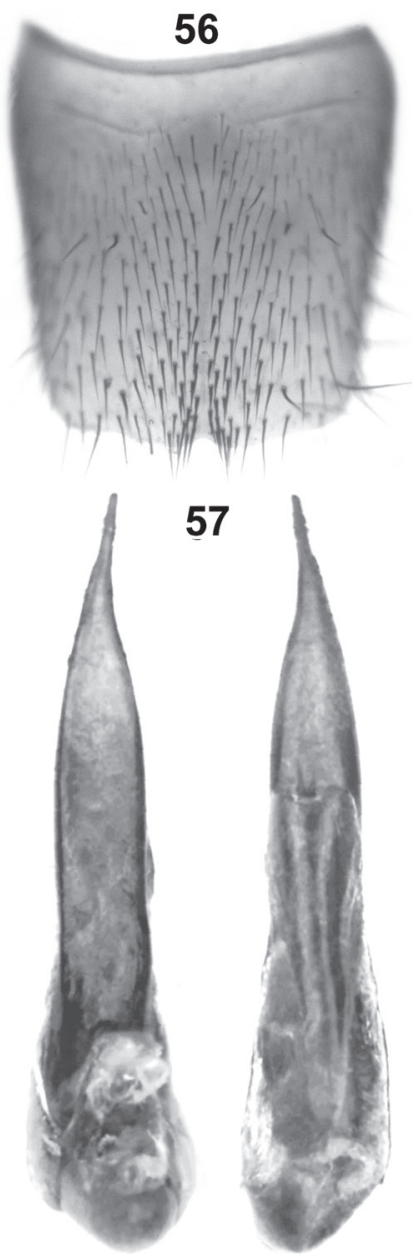

57

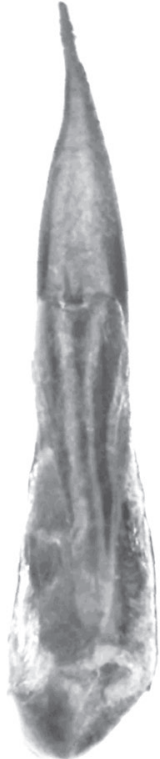

69

Figs 54-69: Lathrobium daweianum spec. nov. (54-62) and L. coadultum spec. nov. (63-69): habitus (54, 63); forebody (55, 64); male sternite VII (56); male sternite VIII (57); aedeagus in lateral view $(58,66)$; internal structures of aedeagus in lateral view (59); female sternite VIII (60); female tergites IX-X (61); female segments IX-X in ventral view (62); median dorsal portion of head (65); aedeagus in dry preparation in lateral, ventral, and dorsal view (67-69). Scale bars: 54-55, 63-64: 1.0 mm; 56-62, 66-69: 0.5 mm; 65: 0.2 mm. 
completely reduced. Protarsomeres I-IV with rather pronounced sexual dimorphism.

Abdomen slender, only slightly broader than elytra; punctation fine, rather dense on tergites III-VII, only slightly less dense on tergite VII than on tergite VI; interstices with shallow transverse microsculpture; posterior margin of tergite VII without palisade fringe; tergite VIII with pronounced sexual dimorphism.

$0^{\text {* }}$ : protarsomeres I-IV strongly dilated; tergite VIII with weakly convex posterior margin; sternite VII (Fig. 56) moderately transverse, approximately 1.4 times as broad as long, posteriorly without shallow median impression, this impression with a cluster of moderately modified long and stout setae; sternite VIII (Fig. 57) approximately as long as broad, with very small and very shallow posterior excision and posteriorly with weakly modified pubescence; aedeagus (Figs 58-59) approximately $1.05 \mathrm{~mm}$ long, nearly symmetric; ventral process long, slender, and strongly curved in lateral view; dorsal plate lamellate, with long and distinctly sclerotized apical portion and with very short unsclerotized basal portion; internal sac with two massive, broad-based, sclerotized spines of different shapes.

오 protarsomeres I-IV moderately dilated, distinctly less so than in male; tergite VIII with strongly convex posterior margin; sternite VIII (Fig. 60) elongated, approximately 1.35 times as long as broad and with strongly convex posterior margin; tergite IX (Fig. 61) with long antero-median portion without median suture and with moderately slender postero-lateral processes; tergite X (Fig. 61) flattened, only slightly longer than antero-median portion of tergite IX; segment IX (Fig. 62) with a conspicuous large black internal structure.

Comparative notes: Lathrobium daweianum is readily distinguished from all other Lathrobium species recorded from eastern Yunnan by much smaller size, paler coloration, the more slender head with smaller eyes, the much more slender pronotum, the denser punctation of the abdominal tergite VII, the pronounced sexual dimorphism of the protarsi and the abdominal tergite VIII, the completely different morphology of the aedeagus, the much more oblong female sternite VIII, and the different morphology of the female tergites IX and X (tergite IX without median suture and with shorter postero-lateral processes; tergite $\mathrm{X}$ shorter).

The species cannot be assigned to any of the species groups previously known from Yunnan and adjacent provinces without difficulty. Based on the morphology of the female tergites IX and X, on the general morphology of the aedeagus, and on the absence of an anterior cluster of gland openings on the male sternite VIII, the only eligible candidates would be the L. curvatissimum, the L. bihamulatum, and the L. desectum groups. The latter two groups can be ruled out, too, as L. daweianum does not share the synapomorphies that constitute these groups. The new species shares the long, slender, and strongly curved ventral process of the aedeagus with species of the L. curvatissimum group, which are distributed in northwestern Yunnan and Sichuan, but it is distinguished from them by much smaller body size, a more slender body (oblong head; much more oblong pronotum, etc.), the presence of massive internal spines in the internal sac of the aedeagus, a flat female tergite X, and the presence of a large black internal structure in the female segment IX. Consequently, L. daweianum is attributed to a species group of its own.

Distribution and natural history: The type locality is situated in the Dawei Shan Virgin Forest Park to the southeast of Pingbian in southeastern Yunnan, close to the border with Vietnam. Thus, L. daweianum and the syntopic L. coadultum represent the southernmost records of the genus in mainland China. The specimens were sifted from leaf litter in a primary subtropical broadleaved forest at an altitude of $2100 \mathrm{~m}$, together with the types of L. coadultum.

\section{Lathrobium coadultum spec. nov. (Figs 63-76)}

Type material: Holotype $\sigma^{*}$ : "CHINA [22] - Yunnan, SE Pingbian, primary forest, $22^{\circ} 54^{\prime} 31^{\prime \prime} \mathrm{N}, 103^{\circ} 41^{\prime} 44^{\prime \prime E}$, 2100 m, 27.VIII.2014, M. Schülke / Holotypus ơ Lathrobium coadultum spec. nov., det. V. Assing 2014" (cAss). Paratypes: 2 우 오 : same data as holotype (cAss, cSch).

Etymology: The specific epithet is the past participle of the Latin verb coadulescere (to grow together) and alludes to the fused female tergites IX and X.

Description: Species of moderate size, without evident sexual size dimorphism; body length 7.0-7.5 mm; length of forebody 3.5-3.6 mm. Habitus as in Fig. 63. Coloration: head and pronotum blackish-brown to blackish; elytra dark-brown to blackish-brown, with the posterior portion slightly paler; abdomen dark-brown to blackishbrown; legs and antennae dark-reddish.

Head (Fig. 64) weakly oblong, approximately 1.05 times as long as broad, lateral contours behind eyes distinctly convex; punctation rather dense and coarse in lateral, anterior, and posterior dorsal portions, sparse and finer in median dorsal portion; interstices with conspicuous microreticulation rendering the head nearly matt, on average approximately as broad as diameter of punctures in lateral and posterior dorsal portions (Fig. 65). Eyes weakly convex, weakly projecting from lateral contours of head and small, approximately one-fourth as long as postocular region in dorsal view and composed of slightly more than 50 ommatidia. Antenna 2.0-2.1 mm long. Pronotum (Fig. 64) moderately slender, 1.27-1.28 times as long as broad and $1.08-1.10$ times as broad as head; punctation slightly coarser than that of head; impunctate midline rather broad; interstices without microsculpture. 
Elytra (Fig. 64) short, $0.51-0.52$ times as long as pronotum, not distinctly dilated posteriad; humeral angles moderately marked; punctation moderately dense and shallow, weakly defined; interstices without microsculpture. Hind wings completely reduced. Protarsomeres I-IV with weak sexual dimorphism.

Abdomen approximately 1.1 times as broad as elytra; punctation fine, rather dense on tergites III-VII, only slightly less dense on tergite VII than on tergite VI; interstices with shallow transverse microsculpture; posterior margin of tergite VII without palisade fringe; tergite VIII with pronounced sexual dimorphism. $\sigma^{*}$ : protarsomeres I-IV moderately strongly dilated; tergite VIII with weakly convex posterior margin; sternite VII (Fig. 70) strongly transverse, approximately 1.6 times as broad as long, with rather pronounced and extensive postero-median impression of triangular shape, this impression with a cluster of strongly modified short and stout black setae, median portion with numerous gland openings (Fig. 71), posterior margin weakly concave; sternite VIII (Fig. 72) distinctly oblong, 1.15 times as long as broad, with pronounced median impression in posterior half, this impression with numerous strongly modified short and stout black

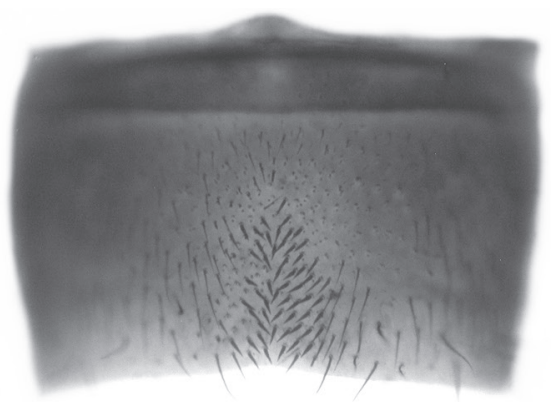

70

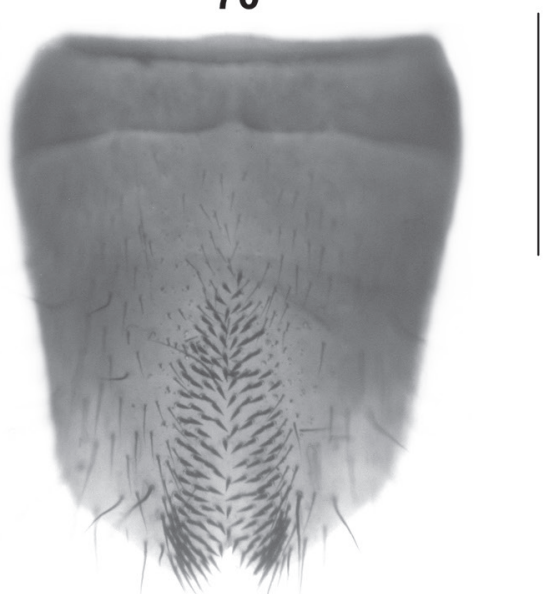

72

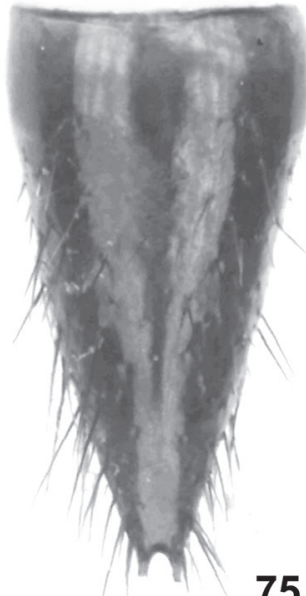

75

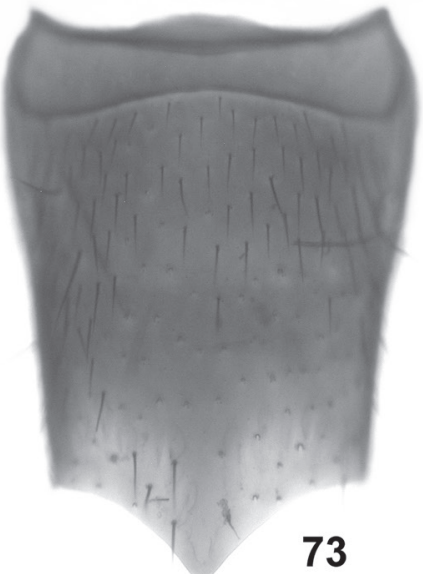

73
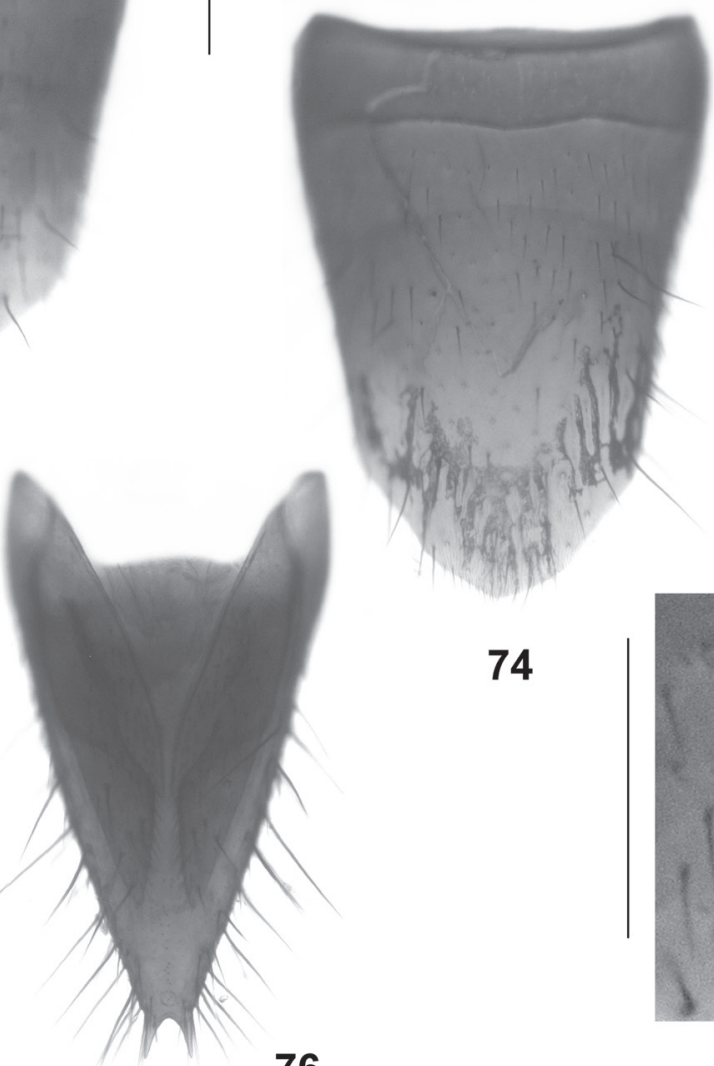

76

74

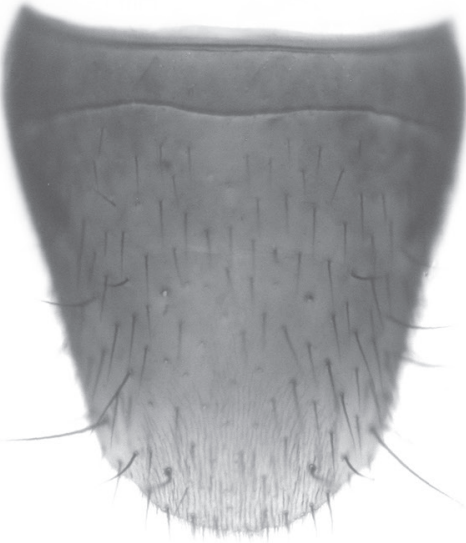

77

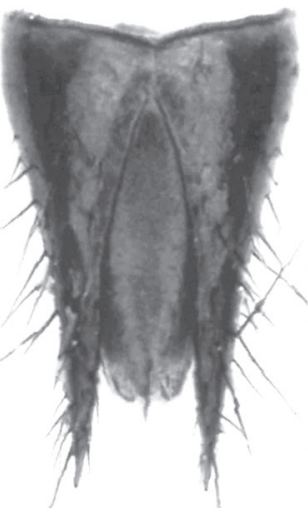

78

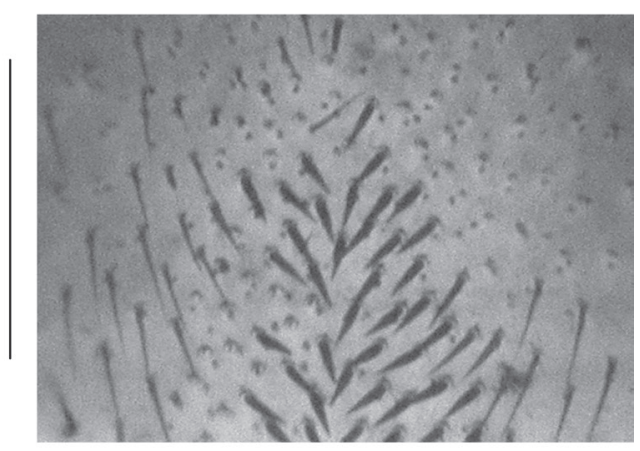

71

Figs 70-78: Lathrobium coadultum spec. nov. (70-76) and L. rostratum spec. nov. (77-78): male sternite VII (70); median portion of male sternite VII (71); male sternite VIII (72); female tergite VIII (73); female sternite VIII $(74,77)$; female tergites IX-X (75, 78); female segments IX-X in ventral view (76). Scale bars: 70, 72-78: $0.5 \mathrm{~mm}$; 71: $0.2 \mathrm{~mm}$. 
setae, posterior margin strongly convex, in the middle with small and broadly V-shaped excision; aedeagus (Figs 66-69) $1.7 \mathrm{~mm}$ long, slender, and nearly symmetric; ventral process conspicuously long, slender, and apically very acute; dorsal plate long, sclerotized, lamellate, and apically concave in dorsal view, without distinctly separated basal portion; internal sac with two very long and slender sclerotized spines.

i : protarsomeres I-IV moderately strongly dilated, only very slightly less so than in male; tergite VIII (Fig. 73) with posterior margin conspicuously acutely produced in the middle; sternite VIII (Fig. 74) elongated, approximately 1.3 times as long as broad and with strongly convex posterior margin; segments IX and X remarkably modified (Figs 75-76): tergites IX (including the posterolateral processes) and X completely fused and forming one long, posteriorly distinctly tapering plate without any sutures whatsoever, apex of this plate reaching far beyond apices of hemi-sternites IX, with two short needle-shaped processes.

Comparative notes: Lathrobium coadultum is distinguished from all other Lathrobium species not only by the distinctive male sexual characters, but also by the shape of the female tergite VIII and above all by the remarkably modified, completely fused female tergites IX and X. Such modifications are unknown from any other species of the genus, suggesting that L. coadultum represents a distinct phylogenetic lineage. This species is additonally separated from other congeners recorded from eastern Yunnan by the more pronounced microreticulation of the head and by the gland openings in the median portion of the male sternite VII.

Distribution and natural history: The type locality and the circumstances of collection are identical to those of L. daweianum.

\subsubsection{Other provinces of China}

\section{Lathrobium brevitergale Assing, 2013}

Material examined: China: Shaanxi: $110^{\top} o^{\star}, 12$ 우 우, Qinling Shan, $34^{\circ} 01^{\prime} \mathrm{N}, 107^{\circ} 52^{\prime} \mathrm{E}, 1700-2200 \mathrm{~m}$, sifted, 17.V.2011, leg. Grebennikov; $20^{\top} 0^{\star}, 3$ 우 우, Qinling Shan, $33^{\circ} 52^{\prime} \mathrm{N}, 108^{\circ} 59^{\prime} \mathrm{E}, 2000-2600 \mathrm{~m}$, sifted, 15.V.2011, leg. Grebennikov (material in CAS, cSme, cAss).

Comment: The distribution of $L$. brevitergale is confined to the Qinling Shan, in the area to the south and southwest of Xi'an (Assing 2013a). In one of the above localities it was collected together with L. grebennikovi, in the other with L. cavisulcatum. Previously recorded syntopic species were L. sociabile Assing, 2013, L. tectiforme Assing, 2013, and L. concameratum Assing, 2013 (Assing 2013a).

\section{Lathrobium grebennikovi spec. nov.}

(Figs 79-87)

Type material: Holotype $\sigma^{*}$ : "P.R. CHINA, Shaanxi, N slope Qin Ling Shan, N3401'07" E107'51'50", 17.v.2011, 1700-2200 m, sift02, V. Grebennikov / Holotypus ơ Lathrobium grebennikovi spec. nov., det. V. Assing 2014" (CAS). Paratypes: $30^{\top} o^{*}, 7$ 우: same data as holotype (CAS, cSme, cAss).

Etymology: The species is dedicated to Vasily Grebennikov (currently Ottawa), who collected the type series, also in appreciation of his merits in discovering numerous other novelties in China.

Description: Species of moderate size and with moderately pronounced sexual size dimorphism; body length $7.5-8.5 \mathrm{~mm}\left(\mathrm{o}^{\star}\right), 6.2-7.5 \mathrm{~mm}$ ( + ); length of forebody 3.6-3.7 mm (o ), 3.1-3.4 mm (o). Coloration: body brown to dark-brown; legs reddish to reddish-brown; antennae dark-reddish.

Head (Fig. 79) 1.00-1.05 times as long as broad, widest behind eyes; punctation moderately coarse and moderately dense, slightly less dense in median dorsal portion; interstices with shallow, but distinct microreticulation. Eyes flat, not projecting from lateral contours of head, and small, approximately one-fourth as long as postocular region in dorsal view, or slightly longer, and composed of fewer than 50 ommatidia. Antenna $1.8-1.9 \mathrm{~mm}\left(\mathrm{o}^{*}\right)$ or $1.5-1.7 \mathrm{~mm}$ ( ㅇ ) long.

Pronotum (Fig. 79) moderately slender, approximately 1.3 times as long as broad and as broad as head; punctation similar to that of head; impunctate midline rather narrow; interstices without microsculpture.

Elytra (Fig. 79) approximately 0.55 times as long as pronotum, weakly dilated posteriad; humeral angles moderately marked; punctation shallow and moderately dense; interstices without microsculpture. Hind wings completely reduced. Protarsomeres I-IV with pronounced sexual dimorphism.

Abdomen approximately 1.1 times as broad as elytra; punctation fine and moderately dense, gradually becoming less dense towards posterior tergites; interstices with shallow transverse microsculpture; posterior margin of tergite VII without palisade fringe; tergite VIII with very weakly pronounced sexual dimorphism.

$\sigma^{*}$ : protarsomeres I-IV strongly dilated; tergite VIII with weakly convex, nearly truncate posterior margin; sternite VII (Fig. 80) strongly transverse, approximately 1.65 times as broad as long, with rather extensive and moderately pronounced postero-median impression of triangular shape, this impression with a cluster of rather weakly modified black setae, posterior margin broadly concave; sternite VIII (Fig. 81) transverse, approximately 1.1 times as broad as long, narrowly impressed along middle, middle of this impression without setae, on either side of middle with dense moderately modified setae, posterior margin with small median excision; aedeagus 


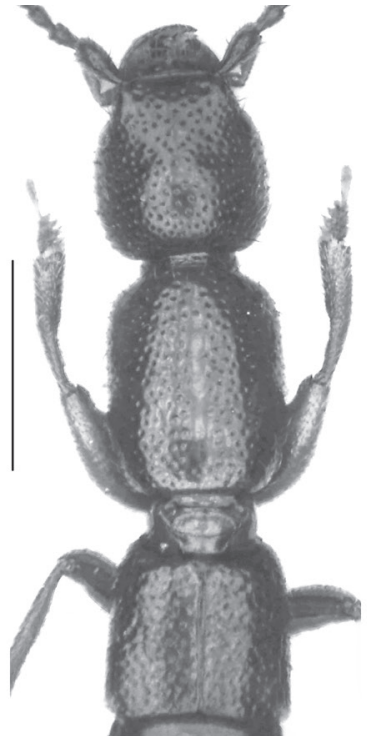

79

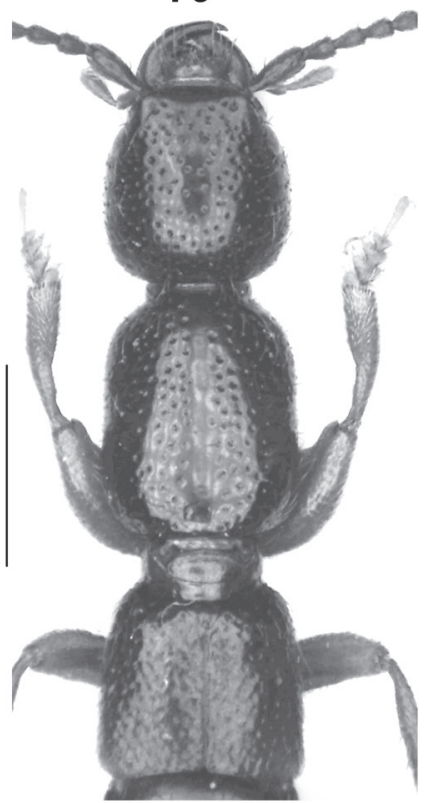

88

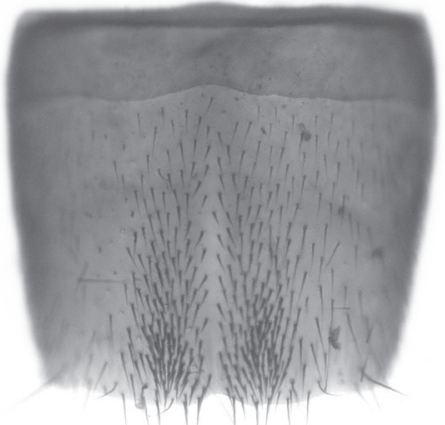

81

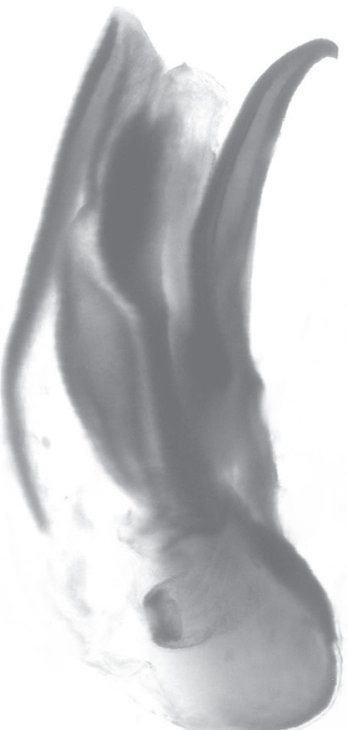

82

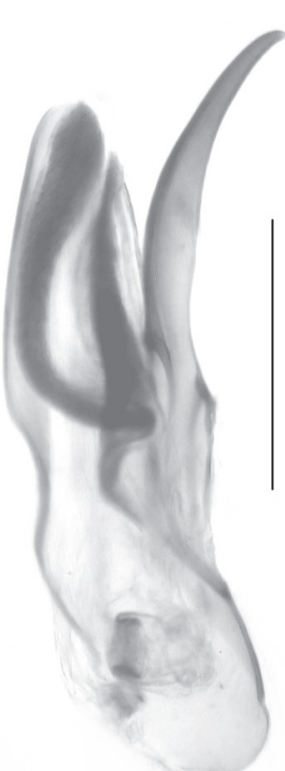

91

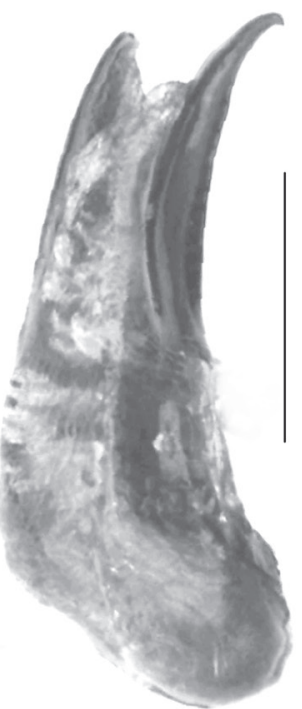

83

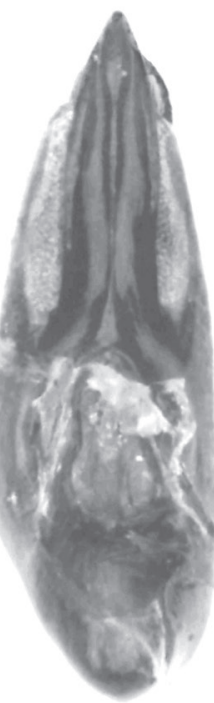

84

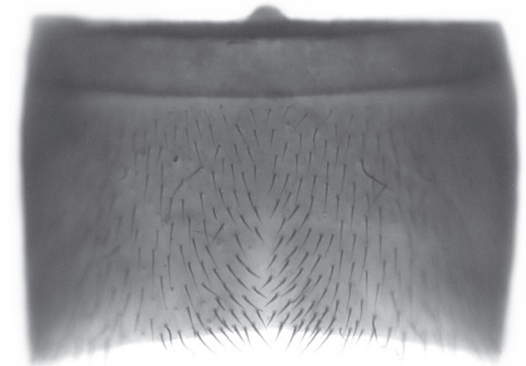

80

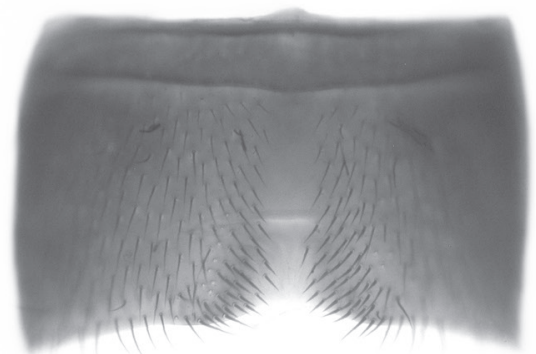

92

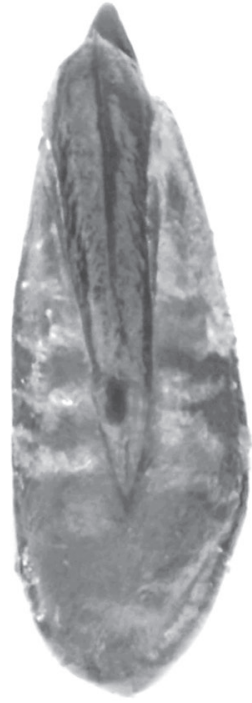

85

89

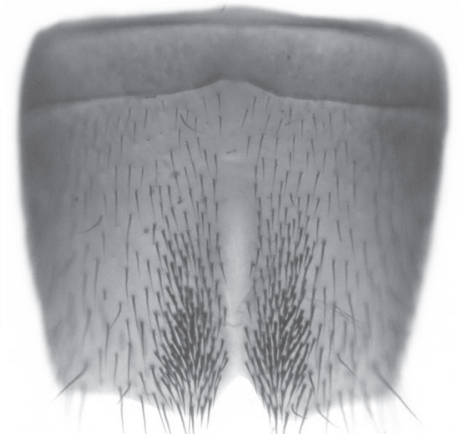

90

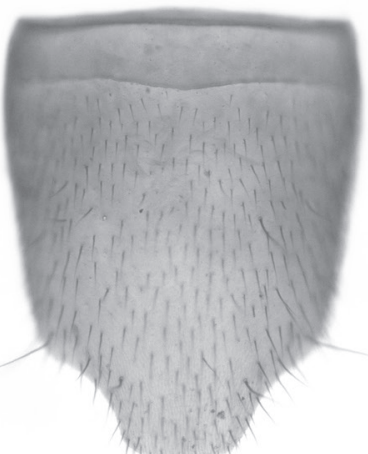

86

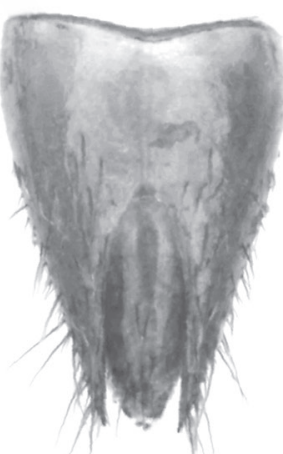

87

Figs 79-92: Lathrobium grebennikovi spec. nov. (79-87) and L. cavisulcatum spec. nov. (88-92): forebody (79, 88); male sternite VII $(80,89)$; male sternite VIII $(81,90)$; aedeagus in lateral view $(82,91)$; aedeagus in dry preparation in lateral, ventral, and dorsal view (83-85); female sternite VIII (86); female tergites IX-X (87); aedeagus in ventral view (92). Scale bars: 79, 88: 1.0 mm; 80-87, 89-92: $0.5 \mathrm{~mm}$. 
(Figs 82-85) 1.30-1.35 mm long, nearly symmetric; ventral process apically bent and acute in lateral view; dorsal plate distinctly sclerotized, with long and broad apical portion with median carina (dorsal view) and with moderately short basal portion; internal sac with moderately sclerotized structures, but without distinct spines.

i: protarsomeres I-IV dilated, but much less so than in male; sternite VIII (Fig. 86) approximately $1.1 \mathrm{~mm}$ long and 1.25 times as long as broad, posterior margin strongly and convexly projecting in the middle; tergite IX (Fig. 87) with long and undivided median portion and with moderately slender postero-lateral processes; tergite X (Fig. 87) moderately convex in cross-section, 1.10-1.15 times as long as antero-median portion.

Comparative notes: As can be inferred from the similar modifications of the male and female sexual characters, L. grebennikovi belongs to the L. varisternale group (see Assing 2013a), which previously included 14 species distributed in the Qinling Shan and adjacent mountain ranges (Assing 2013a; PENG et al. 2013). It is distinguished from all the species of this group primarily by the morphology of the aedeagus. The latter is most similar to that of L. inflexum Assing, 2013 from a mountain range to the southeast of Longnan in southern Gansu. From this species, L. grebennikovi is additionally distinguished by slightly larger body size, the sexual size dimorphism, the more pronounced clusters of modified setae on the male sternites VII and VIII, the absence of a distinct median concavity of the posterior margin of the male sternite VII, the larger aedeagus with a differently shaped ventral process and with a distinctly sclerotized basal portion of the dorsal plate, the differently shaped female sternite VIII, and the longer female tergite $\mathrm{X}$ (L. inflexum: female tergite $\mathrm{X}$ shorter than antero-median portion of tergite IX). For illustrations of $L$. inflexum and other species of the L. varisternale group see Assing (2013a) and PeNg et al. (2013).

Distribution and natural history: The type locality is situated in the northern Qinling Shan in southern Shaanxi. The type specimens were sifted together with L. brevitergale at altitudes between 1700 and $2200 \mathrm{~m}$.

\section{Lathrobium calvisulcatum spec. nov.}

(Figs 88-92)

Type material: Holotype $0^{*}$ [slightly teneral]: "P.R. CHINA, Shaanxi, N slope Qin Ling Shan, N335ㄴ'40" E108 59'27"', 15.v.2011, 2000-2600 m, sift01, V. Grebennikov / Holotypus o Lathrobium calvisulcatum spec. nov., det. V. Assing 2014" (CAS).

Etymology: The specific epithet is an adjective composed of the Latin adjective calvus (bald, bare) and the past participle of the Latin verb sulcare (to furrow). It alludes to the absence of pubescence in the median impressions of the male sternites VII and VIII.
Description: Species of moderate size; body length $7.8 \mathrm{~mm}$; length of forebody $3.7 \mathrm{~mm}$. Coloration: forebody dark-brown; elytra brown; abdomen dark-brown with paler apex; body brown to dark-brown; legs and antennae reddish.

Head (Fig. 88) 1.03 times as long as broad, widest behind eyes; punctation moderately coarse and moderately dense, sparser in median dorsal portion; interstices with shallow, but distinct microreticulation. Eyes flat, not projecting from lateral contours of head, and small, approximately one-fourth as long as postocular region in dorsal view and composed of approximately 50 ommatidia. Antenna $1.8 \mathrm{~mm}$ long.

Pronotum (Fig. 88) moderately slender, approximately 1.3 times as long as broad and 1.02 times as broad as head; punctation similar to that of head; impunctate midline moderately broad; interstices without microsculpture.

Elytra (Fig. 88) 0.55 times as long as pronotum, weakly dilated posteriad; humeral angles moderately marked; punctation shallow and moderately dense; interstices without microsculpture. Hind wings completely reduced. Protarsomeres I-IV with pronounced sexual dimorphism.

Abdomen approximately 1.15 times as broad as elytra; punctation fine and moderately dense, sparser and finer on tergites VII and VIII than on anterior tergites; interstices with distinct transverse microsculpture; posterior margin of tergite VII without palisade fringe.

$\sigma^{*}$ : protarsomeres I-IV strongly dilated; tergite VIII with weakly convex posterior margin; sternite VII (Fig. 89) strongly transverse, approximately 1.7 times as broad as long, with rather extensive and pronounced median impression, this impression broadly without setae along the middle and postero-laterally with a cluster of weakly modified setae, posterior margin distinctly concave in the middle; sternite VIII (Fig. 90) weakly transverse, approximately 1.05 times as broad as long, with narrow and long median impression, this impression without setae, on either side of this impression with an oblong and rather long cluster of weakly modified dark setae, posterior excision distinct and V-shaped; aedeagus (Figs 91-92) nearly $1.5 \mathrm{~mm}$ long and symmetric in ventral view; ventral process smoothly curved, slender, and apically acute in lateral view; dorsal plate with long lamellate apical portion and with distinctly shorter lamellate basal portion; internal sac with membranous structures of characteristic shape in lateral view, the dorsal ones shaped like an inverted comma.

o: unknown.

Comparative notes: Like the preceding species, $L$. calvisulcatum belongs to the L. varisternale group. Among the species of this group, the male sexual characters (chaetotaxy of sternites VII and VIII; morphology of the aedeagus) are most similar to those of L. brevilobatum Assing, 2013, from which L. calvisulcatum differs by the more transverse male sternite VII with sparser 
clusters of less modified setae and without setae in the antero-median portion, by a male sternite VIII with a distinctly deeper posterior excision and with more extensive clusters of modified setae, and by the morphology of the aedeagus (shapes of ventral process, dorsal plate, and internal structures). For illustrations of L. brevilobatum see Assing (2013a).

Distribution and natural history: The type locality is situated in the Qinling Shan to the south of Xi'an in southern Shaanxi. The slightly teneral holotype was sifted together with $L$. brevitergale at an altitude between 2000 and $2600 \mathrm{~m}$.

\section{Lathrobium iunctum Assing \& PeNG, 2013}

Material examined: China: Sichuan: 2 exs., Emei Shan, $29^{\circ} 33^{\prime} \mathrm{N}, 103^{\circ} 21^{\prime} \mathrm{E}, 1730 \mathrm{~m}$, sifted, 25.V.2011, leg. Grebennikov (CAS, cAss).

Comment: This species is endemic to the Emei Shan, where it was previously recorded at altitudes of 1800 2500 m (Assing et al. 2013).

\section{Lathrobium coniunctum Assing \& PENG, 2013}

Material examined: China: Sichuan: 10 exs., Emei Shan, $29^{\circ} 35^{\prime} \mathrm{N}, 103^{\circ} 22^{\prime} \mathrm{E}, 1460 \mathrm{~m}$, sifted, 27.V.2011, leg. Grebennikov (CAS, cSme, cAss).

Comment: Like L. iunctum, L. coniunctum is endemic to the Emei Shan, where it was previously recorded at altitudes of 1700-2310 m (Assing et al. 2013).

\section{Lathrobium conexum Assing \& PENG, 2013}

Material examined: China: Sichuan: 1 , Emei Shan, $29^{\circ} 35^{\prime} \mathrm{N}, 103^{\circ} 22^{\prime} \mathrm{E}, 1460 \mathrm{~m}$, sifted, 27.V.2011, leg. Grebennikov (CAS).

Comment: This endemic of the Emei Shan apparently lives at lower altitudes; it was previously found at $1100 \mathrm{~m}$ (Assing et al. 2013).

\section{Lathrobium ventricosum Assing, 2013}

Material examined: China: Sichuan: 1 ex., Gongga Shan, $29^{\circ} 56^{\prime} \mathrm{N}, 101^{\circ} 59^{\prime} \mathrm{E}, 3550 \mathrm{~m}$, sifted, 17.VI.2011, leg. Grebennikov; 3 exs., Gongga Shan, $29^{\circ} 53^{\prime} \mathrm{N}, 102^{\circ} 02^{\prime} \mathrm{E}$, 3890 m, sifted, 8.VI.2011, leg. Grebennikov; 1 ex., Gongga Shan, $29^{\circ} 51^{\prime} \mathrm{N}, 102^{\circ} 02^{\prime} \mathrm{E}, 3170 \mathrm{~m}$, sifted, 21.VI.2011, leg. Grebennikov (material in CAS, cSme, cAss).
Comment: This species is endemic to the Gongga Shan and was previously found at altitudes of $2750-3350 \mathrm{~m}$ (Assing 2013b).

\section{Lathrobium hailuogouense PENG, Li \& ZHAO, 2012}

Material examined: China: Sichuan: 2 exs., Gongga Shan, $29^{\circ} 34^{\prime} \mathrm{N}, 101^{\circ} 59^{\prime} \mathrm{E}, 3140 \mathrm{~m}$, sifted, 3.VI.2011, leg. Grebennikov (CAS, cAss).

Comment: Like L. ventricosum, L.hailuogouense is endemic to the Gongga Shan (Assing 2013b).

\section{Lathrobium abruptum spec. nov. (Figs 93-101)}

Type material: Holotype ${ }^{\top}$ : "P.R. CHINA, Sichuan, NE slope Gongga Shan, N2947'49" E10203'46", 14.vi.2011, $2684 \mathrm{~m}$, sift18, V. Grebennikov / Holotypus o Lathrobium abruptum spec. nov., det. V. Assing 2014" (CAS). Paratypes: $3 \sigma^{\star} \sigma^{\star}, 1 \%$ : same data as holotype; $3 \sigma^{\star} \sigma^{*}$, 3 우 ㅇ: "P.R. CHINA, Sichuan, NE slope Gongga Shan, N294'15" E10203'44", 20.vi.2011, $2765 \mathrm{~m}$, sift22, V. Grebennikov"; 1 o , 1 옹 same data, but "6.VI.2011, ..., sift11" (paratypes in CAS, cSme, cAss).

Etymology: The specific epithet (Latin, adjective) alludes to the abruptly angled ventral process of the aedeagus (lateral view).

Description: Species of moderately large size and with weakly pronounced sexual size dimorphism; body length 9.7-10.8 mm ( $\left.\sigma^{+}\right), 9.0-10.2 \mathrm{~mm}$ ( + ); length of forebody $4.1-4.6 \mathrm{~mm}\left(\sigma^{\star}\right), 3.8-4.2 \mathrm{~mm}$ ( + ). Coloration: body blackish-brown to black, with the elytra sometimes slightly paler; legs dark-reddish to reddish-brown, with the profemora mostly darker (blackish-brown); antennae dark-reddish.

Head (Fig. 93) 1.00-1.04 times as broad as long, widest behind eyes; punctation not very coarse, moderately dense in lateral and posterior dorsal portions, sparser in median dorsal portion; interstices with distinct microreticulation. Eyes flat, not projecting from lateral contours of head, and small, approximately one-fourth as long as postocular region in dorsal view, composed of somewhat more than 50 ommatidia. Antenna 2.2-2.4 mm long.

Pronotum (Fig. 93) moderately slender, 1.25-1.30 times as long as broad and 1.01-1.04 times as broad as head; punctation similar to that of head; impunctate midline moderately broad; interstices without microsculpture.

Elytra (Fig. 93) 0.55-0.59 times as long as pronotum, not distinctly dilated posteriad; humeral angles moderately marked; punctation conspicuously fine and sparse; interstices without microsculpture. Hind wings completely reduced. 
Abdomen approximately $1.05-1.10$ times as broad as elytra; punctation fine and dense on tergites III-VII, only slightly less dense on tergite VIII; interstices with fine microsculpture; posterior margin of tergite VII without palisade fringe; tergite VIII without sexual dimorphism, posterior margin weakly convex.

$0^{\text {* }}$ : protarsomeres I-IV strongly dilated; sternite VII (Fig. 94) strongly transverse, approximately 1.6 times as broad as long, with moderately pronounced posteromedian impression of triangular shape, this impression with a cluster of modified stout black setae, posterior margin broadly concave, in the middle somewhat more distinctly concave; sternite VIII (Fig. 95) distinctly transverse, approximately 1.2 times as broad as long, shallowly impressed and with dense weakly modified setae in postero-median portion, posterior excision not very deep and broadly V-shaped; aedeagus (Figs 96-99) approximately $2.0 \mathrm{~mm}$ long and slender, not distinctly asymmetric in ventral view; ventral process very long, slender, and apically acute, abruptly angled at apical third in lateral view; dorsal plate with strongly scle- rotized, long, strongly curved (lateral view) and apically acute apical portion and with short, weakly sclerotized, lamellate basal portion; internal sac with pair of long and weakly sclerotized structures.

i: protarsomeres I-IV dilated, but distinctly less so than in male; sternite VIII (Fig. 100) approximately $1.4 \mathrm{~mm}$ long and 1.15 times as long as broad, posterior margin convexly projecting in the middle; tergite IX (Fig. 101) with long and undivided median portion and with slender postero-lateral processes; tergite X (Fig. 101) long and slender, approximately 1.3 times as long as anteromedian portion.

Comparative notes: Based on the similar modifications of the male and female sexual characters, this species is undoubtedly most closely related to L. hailuogouense, which too is endemic to the Gongga Shan. It differs from this species only by the more extensive and more distinct postero-median cluster of modified setae on the male sternite VII and by the morphology of the aedeagus (L. hailuogouense: ventral process less strongly narrowed

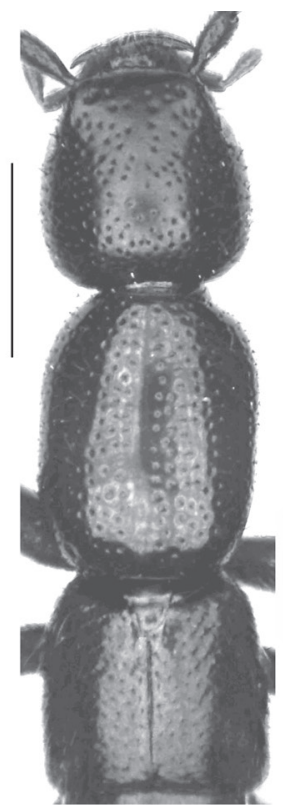

93

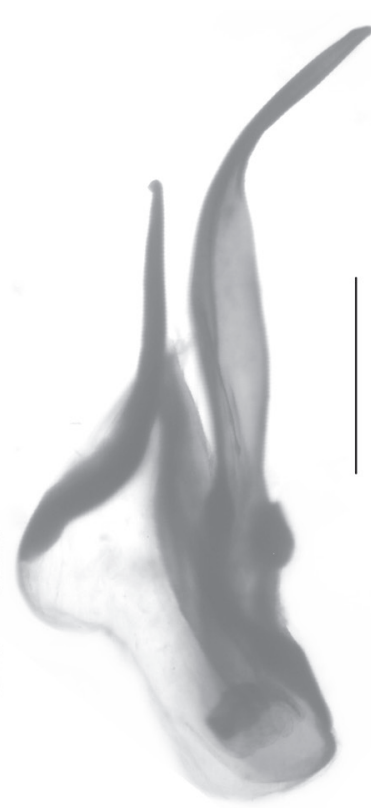

96

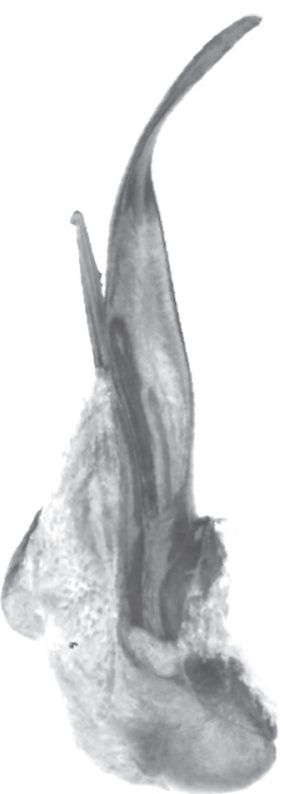

97

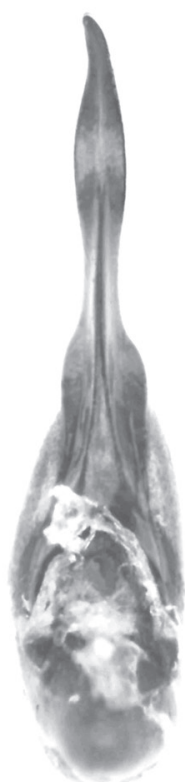

98

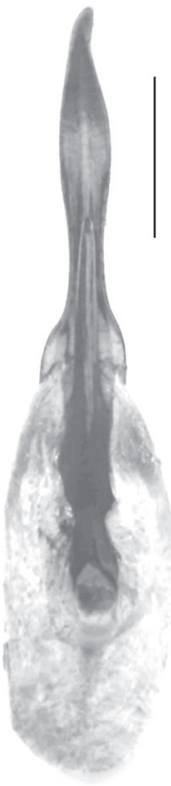

99

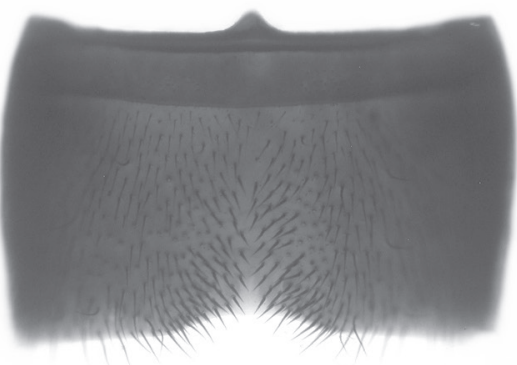

94

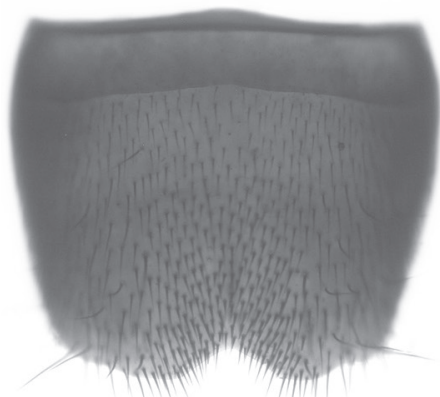

95

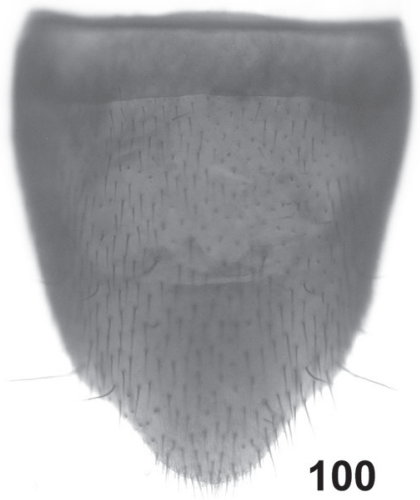

Figs 93-101: Lathrobium abruptum spec. nov.: forebody (93); male sternite VII (94); male sternite VIII (95); aedeagus in lateral view (96); aedeagus in dry preparation in lateral, ventral, and dorsal view (97-99); female sternite VIII (100); female tergites IX-X (101). Scale bars: 93: $1.0 \mathrm{~mm}$; 94-101: $0.5 \mathrm{~mm}$. 
and less strongly angled at apical third, apex of ventral process shorter and less slender; apical portion of dorsal plate curved in apical half, in L. abruptum in basal half, in lateral view). For illustrations of L. hailuogouense see Peng et al. (2012).

Distribution and natural history: The type material was collected by sifting forest litter in the northeastern Gongga Shan at altitudes of approximately 2680 and $2760 \mathrm{~m}$.

\section{Lathrobium guizhouense CHEN, LI \& ZHAO, 2005}

Material examined: China: Guizhou: $1 \sigma^{\star}$, Fanjing Shan, $27^{\circ} 54^{\prime} \mathrm{N}, 108^{\circ} 42^{\prime} \mathrm{E}, 1800-2000 \mathrm{~m}$, pitfall trap, 5.-11. VI.2014, leg. Reuter (cAss).

Comment: The original description of L. guizhouense is based on twelve type specimens from the Fanjing Shan (CHEN et al. 2005), where this micropterous species is probably endemic.

\section{Lathrobium erectum spec. nov. (Figs 102-110)}

Type material: Holotype $\sigma^{*}$ : "CHINA, Guizhou, Fanjing Shan, $27^{\circ} 54^{\prime} \mathrm{N}, 108^{\circ} 42^{\prime} \mathrm{E}, 1800-2000 \mathrm{~m}, 5 .-11 . V I .2014$, pitfall, leg. C. Reuter / Holotypus ơ Lathrobium erectum spec. nov., det. V. Assing 2014" (cAss).

Etymology: The specific epithet (Latin, adjective) alludes to the shape of the conspicuous process (lateral view) at the base of the ventral process of the aedeagus.

Description: Species of rather large size; body length $11.0 \mathrm{~mm}$; length of forebody $5.1 \mathrm{~mm}$. Habitus as in Fig. 102. Coloration: body dark-brown; legs and antennae dark-reddish.

Head (Fig. 103) approximately as long as broad, weakly dilated behind eyes; punctation not very coarse, rather dense in lateral, anterior, and posterior dorsal portions, sparser in median dorsal portion; interstices with very shallow, barely noticeable microreticulation, on average approximately as broad as diameter of punctures in lateral and posterior dorsal portions. Eyes weakly convex, not projecting from lateral contours of head, and small, approximately one-fifth as long as postocular region in dorsal view and composed of slightly more than 50 ommatidia. Antenna $2.9 \mathrm{~mm}$ long.

Pronotum (Fig. 103) moderately slender, 1.29 times as long as broad and 1.02 times as broad as head; punctation similar to that of head; impunctate midline moderately broad; interstices without microsculpture.

Elytra (Fig. 103) short, 0.49 times as long as pronotum, not distinctly dilated posteriad; humeral angles moderately marked; punctation rather dense and defined; interstices without microsculpture. Hind wings completely reduced.

Abdomen approximately 1.05 times as broad as elytra; punctation fine, rather dense on tergites III-VI, sparser on tergite VII; interstices with shallow transverse microsculpture; posterior margin of tergite VII without palisade fringe.

$0^{*}$ : protarsomeres I-IV strongly dilated; tergite VIII with weakly convex posterior margin; sternite VII (Fig. 104) moderately strongly transverse, approximately 1.4 times as broad as long, with rather pronounced postero-median impression of triangular shape, this impression with a cluster of modified stout black setae, posterior margin broadly concave, in the middle somewhat more distinctly concave; sternite VIII (Fig. 105) as long as broad, with pronounced median impression in posterior half, this impression with conspicuously dense modified stout black setae, posterior excision broadly V-shaped, its depth approximately one-seventh the length of sternite; aedeagus (Figs 106-109) $1.9 \mathrm{~mm}$ long, strongly asymmetric, with small basal portion, and of remarkably modified morphology; ventral process strongly asymmetric, of very distinctive shape, partly fused with the asymmetric dorsal plate, and at base with conspicuous erect process; internal sac with a very long, slender, and basally bifid sclerotized spine (Fig. 110) and with a membranous ringshaped structure.

o: unknown.

Comparative notes: Based on the morphology of the aedeagus (strongly asymmetric; small basal portion; internal sac with a long sclerotized spine) and on the male secondary sexual characters, L. erectum is attributed to the L. fissispinosum group (see Assing 2013a). The only other species of this group recorded from Guizhou is L. pium Assing, 2013 (Leigong Shan), from which $L$. erectum differs by larger size ( $L$. pium: length of forebody $4.5-4.7 \mathrm{~mm}$ ), weakly pronounced microsculpture on the head, smaller eyes, the more oblong pronotum (L. pium: approximately 1.2 times as long as broad), the completely different modifications of the male sternites VII and VIII, and by the distinctive shape of the aedeagus. For illustrations of L. pium see Assing (2013b).

Distribution and natural history: The Fanjing Shan is situated in the northeast of Guizhou, not far from the borders with Hunan and Chongqing. The holotype was collected with a pitfall trap at an altitude between 1800 and $2000 \mathrm{~m}$. 


\subsection{Taiwan}

\section{Lathrobium shaolaiense WATANABE, 1998}

Material examined: Taiwan: $1 \sigma^{\star}$, Taichung, Anma Shan, 2000 m, 8.IV.2002, leg. Sugaya (MNHUB).

Comment: The original description of this species is based on a single male from "Mt. Shao-lai Shan, Ta-hsüeh Shan Mts., Taichung Hsien” (Watanabe 1998).

\subsection{Japan}

\section{Lathrobium dignum SHARP, 1874}

Material examined: Japan: Hokkaido: 1 ㅇ, Oshamanbe, Toyotsu seashore, 27.VII.1991, leg. Smetana [J10] (CNC). Honshu: $1 o^{\star}$, Kanagawa Pref., Kamakura, leg. Sauter (CNC); 1 \%, Iwate Pref., Kawai, Yoshibezawa, 1050 m, 15.VIII.1991, leg. Smetana [J55] (CNC); 1 오,

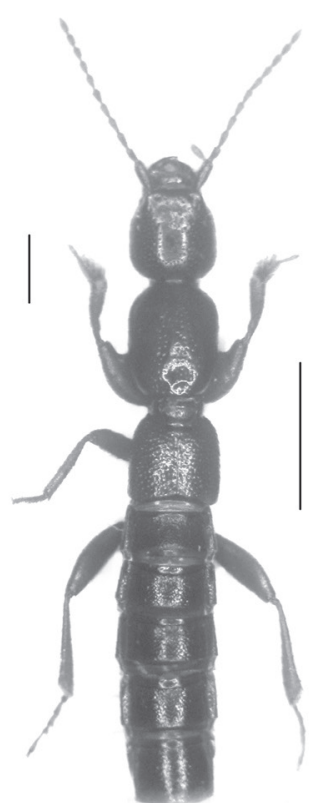

102

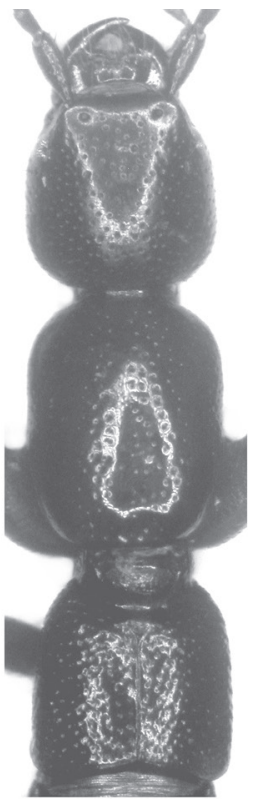

103

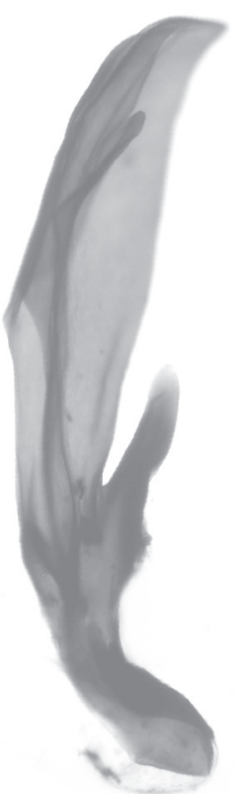

106

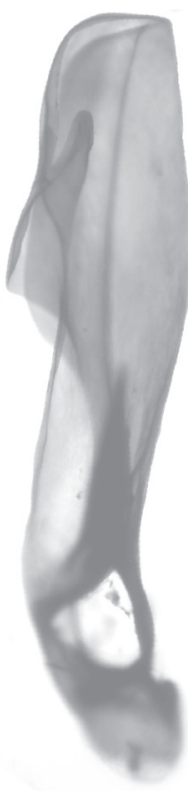

107

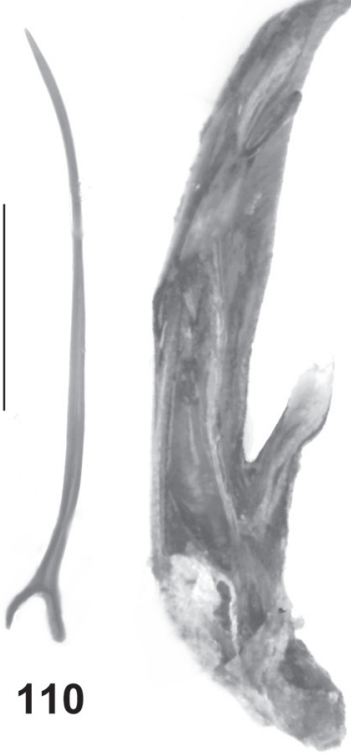

108

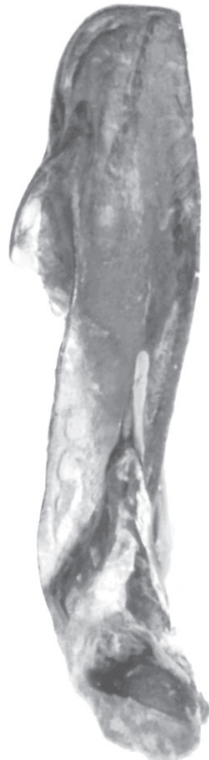

109

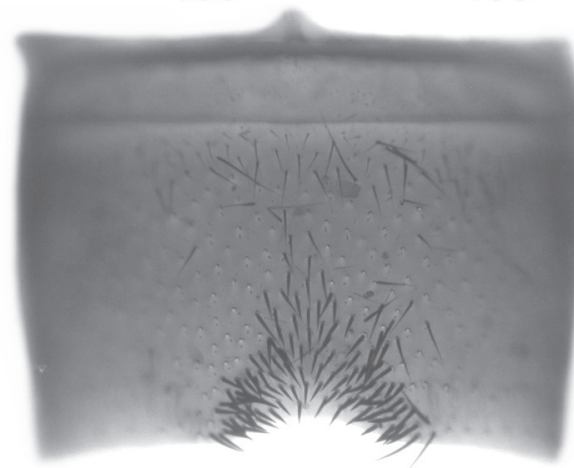

104

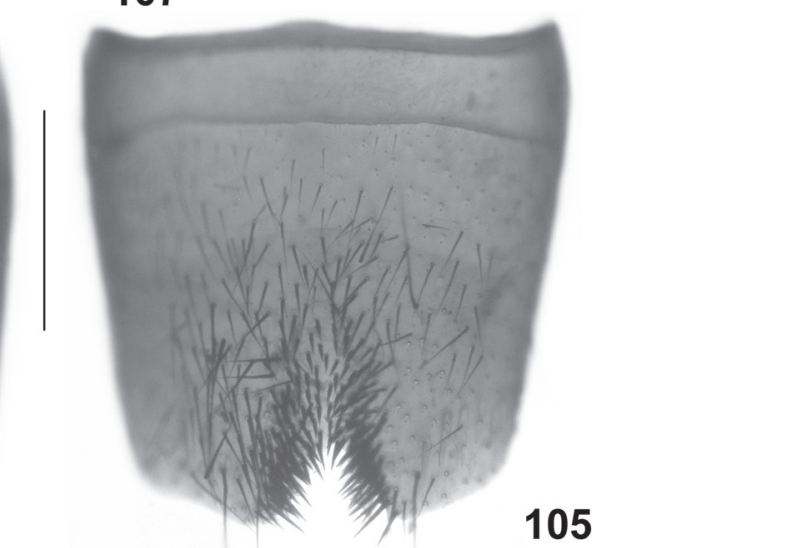

Iwate Pref., Iwaizumi, Hitsutori, 790 m, 11.VIII.199, leg. Smetana [J45] (CNC); 1 ㅇ, Ibaraki Pref., Yatabeho, 12.VII.1980, leg. A. \& Z. Smetana (CNC); 1 웅 Nagano Pref., Shibu Onsen, 800 m, 23.VII.1980, leg. A.

Comment: In Japan, this widespread East Palaearctic species has been recorded from various localities in Hokkaido and Honshu (Assing 2013f).

Material examined: Japan: Hokkaido: 2 exs., Shiretoko Peninsula, Shari, Idashubetsu creek, 310 m, 1.VIII.1991, leg. Smetana [J22] (CNC).

Comment: This species had been recorded only from the Russian Far East and was previously unknown from Japan (Assing 2013f; Smetana 2004).

Figs 102-110: Lathrobium erectum spec. nov.: habitus (102); forebody (103); male sternite VII (104); male sternite VIII (105); aedeagus in lateral and in ventral view (106-107); aedeagus in dry preparation in lateral and in ventral view (108-109); internal structure of aedeagus (110). Scale bars: 102-103: $1.0 \mathrm{~mm}$; 104-110: $0.5 \mathrm{~mm}$. 


\section{Lathrobium viduum EPPELSHEIM, 1893}

Material examined: Japan: Hokkaido: 2 exs., Hokkaido, Kushiro marsh between Horo and Oshima rivers, $5 \mathrm{~m}$, 31.VII.1991, leg. Smetana [J21] (CNC, cAss); 2 exs., Hokkaido, Rubeshibe, Itonmuka river, marsh, $770 \mathrm{~m}$, 29.VII.1991, leg. Smetana [J16] (CNC).

Comment: Lathrobium viduum was previously recorded from East Siberia and the Russian Far East (Ryvkin 2011, SmEtana 2004). The above specimens represent the first records from Japan.

\section{Lathrobium shingon WATANABE, 1992}

Material examined: Japan: Honshu: 14 exs., Nara Pref., Nara, 11.VIII.1980, leg. A. \& Z. Smetana (CNC, cAss); 1 ex., same data, but 10.VIII.1980 (CNC).

Comment: This species has been recorded from several localities in Nara and Wakayama Prefectures (Assing 2013f; WATANABE 2005).

\section{Lathrobium kasaharai WATANABE, 2002}

Material examined: Japan: Honshu: $3 \sigma^{\top} \sigma^{\top}$ [1 teneral], 1 ㅇ, Chiba Pref., Fudago, Kimitsu, Mt. Kiusumi, 180 m, 19.VII.1991, leg. Smetana [J1] (CNC, cAss).

Comment: Lathrobium kasaharai was previously known only from the type locality, "Kameyama-ko, Kimitsu City, Chiba Pref." (Watanabe 2002).

\section{Lathrobium kurosawai WATANABE, 2001}

Material examined: Japan: Honshu: 3 exs., Gumma Pref., $5 \mathrm{~km}$ E Usui pass, 900 m, 25.VII.1980, leg. A. \& Z. Smetana (CNC, cAss); 7 exs., Gumma Pref., 6 km E Usui pass, 750 m, 20.VII.1980, leg. A. \& Z. Smetana (CNC, cAss); 4 exs. [1 teneral], Gumma Pref., 7 km EUsui pass, 850 m, 24.VII.1980, leg. A. \& Z. Smetana (CNC); 3 exs., Gumma Pref., Usui Bypass, 700 m, 20.VII.1980, leg. A. \& Z. Smetana (CNC); 4 exs., Gumma Pref., 4 km SW Tsumagoi, 1050 m, 18.VII.1980, leg. A. \& Z. Smetana (CNC, cAss); 1 ex., Tochigi Pref., Nikko National Park, Lake Chuzenjiko, Chisan-Shukuhakusho, 1300 m, 15.VII.1980, leg. A. \& Z. Smetana (CNC); 4 exs., Tochigi Pref., Nikko National Park, Lake Chuzenjiko, 1280 m, 14.VII.1980, leg. A. \& Z. Smetana (CNC, cAss); 2 exs. [1 teneral], Tochigi Pref., Shioya-Gun, Kuriyama-Mura, Meotobuchi, 1180 m, 19.VIII.1991, leg. Smetana [J60] (CNC); 1 ex., Gifu Pref., 9 km S Gero, Highway 41, 475 m, 31.VII.1980, leg. A. \& Z. Smetana (CNC).
Comment: This species is widespread and apparently rather common in Fukushima, Gumma, Gifu, Toyama, and Tochigi Prefectures, North Honshu (Assing 2013f).

\section{Lathrobium masumotoi WATANABE, 2011}

Material examined: Japan: Honshu: 4 exs., Toyama Pref., Bijodaira [ $\left.36^{\circ} 35^{\prime} \mathrm{N}, 137^{\circ} 28^{\prime} \mathrm{N}\right], 1000 \mathrm{~m}, 28 . \mathrm{VII} .1980$, leg. A. \& Z. Smetana (CNC, cAss).

Comment: The previously known distribution of L. masumotoi was confined to the Japanese Alps in Nagano Prefecture (Assing 2013f).

\section{Lathrobium sinense HERMAN, 2003}

Material examined: Japan: $1 \sigma^{\star}, 1$ [both brachypterous], Hokkaido, Kaihatsu-cho-minami, 15 m, 25.VII.1991, leg. Smetana [J7] (CNC, cAss); 1 ㅇ, Honshu, Toshigi Pref., Nikko National Park, Senjogahara, 1400 m, 15.VII.1980, leg. A. \& Z. Smetana (CNC).

Comment: This widespread wing-dimorphic species was previously known from numerous localities in China and one (Senjogahara) in Honshu (Assing 2013f). The above specimens from Hokkaido represent a new island record.

\section{Lathrobium nikkoense WATANABE, 2001}

Material examined: Japan: Honshu: 1 , Gumma Pref., Nikko National Park, below Konsei pass, W-side, 15001600 m, 15.VII.1980, leg. A. \& Z. Smetana (CNC).

Comment: This species was previously known from four localities in Gumma Prefecture and doubtfully recorded also from two localities in Fukushima Prefecture (Assing 2013f).

\section{Lathrobium nidoagense WATANABE, 2001}

Material examined: Japan: Honshu: $20^{\star} o^{\star}, 2$ 우 온 Gumma Pref., near Mt. Shirane, 1750 m, 22.VII.1980, leg. A. \& Z. Smetana (CNC); 3 우, same data, but $2000 \mathrm{~m}$ (CNC, cAss); 1 ơ, 1 ㅇ, Gumma Pref., Mt. Kurofu, 2100 m, 19.VII.1980, leg. A. \& Z. Smetana (CNC); 1 o $^{\star}$, Gumma Pref., 4 km SW Tsumagoi, 1050 m, 18.VII.1980, leg. A. \& Z. Smetana (cAss); 1 o , 1 ㅇ, Nagano Pref., Shiga, 1500 m, 23.VII.1980, leg. A. \& Z. Smetana (CNC).

Comment: The previously known distribution of L. nidoagense was confined to the type locality "near Nidoage, Gunma Pref." (Watanabe 2001). Based on external and 
the male sexual characters, the species is closely allied to L. sinense.

\section{Lathrobium inflatum Assing, 2013}

Material examined: Japan: Honshu: $1 \sigma^{\star}$ [heavily damaged], 1 ㅇ, Gumma Pref., near Mt. Shirane, 1750 m, 22.VII.1980, leg. A. \& Z. Smetana (CNC, cAss).

Comment: The original description is based on a unique male from Mt. Hotaka in Gumma Prefecture (Assing 2013f).

\section{Lathrobium japonicum BERNHAUER, 1907}

Material examined: Japan: Hokkaido: 1 , Kushiro Marsh, Iwahogi, 5 m, 31.VII.1991, leg. Smetana [J20] (CNC). Russia: Sakhalin: 1 ex., Aniva district, Kamiyshoviye mountains, Bryanka river, $30 \mathrm{~km} \mathrm{~W} \mathrm{Aniva,}$ 200 m, 14.VII.1993, leg. Pütz \& Wrase (cSch); 1 ex., Aniva district, Zuneyiskiy mountains, $10 \mathrm{~km}$ N Novo Aleksandrovsk, Mt. Tshekhov, 1000 m, 13.VII.1993, leg. Pütz \& Wrase (cSch); 1 ex., Aniva district, $5 \mathrm{~km} \mathrm{~W} \mathrm{Petropav-}$ lovskoye, tributary of Lyutoga river, 20.-21.VII.1993, leg. Pütz \& Wrase (cSch); 1 ex., Korsakov district, Ismenshiroye Lake, 21.-22.VII.1993, leg. Pütz \& Wrase (cSch). (The material from Sakhalin was identified and communicated by M. Schülke.).

Comment: In Japan, L. japonicum was previously known only from Rishiri-tô, an island to the west of Hokkaido. In the recent checklist of the Lathrobium species of Japan in (Assing 2013f), L. japonicum is categorized as macropterous. However, according to Ryvkin (e-mail, 2 December, 2014), all the specimens from Kunashir, Iturup, and Sakhalin examined by him have reduced hind wings.

\section{Lathrobium oharai WATANABE, 2004 \\ (Figs 111-118)}

Material examined: Japan: Hokkaido: $40^{\top} o^{\star}, 3$ 우 우, Kushiro marsh, between Horo and Oshima rivers, $5 \mathrm{~m}$, 31.VII.1991, leg. Smetana [J21] (CNC, cAss); 2 우 우, Sapporo, Nakayama Pass, 800 m, 26.VII.1991, leg. Smetana [J8] (CNC); 1 đ, 1 옹, Shiretoko Peninsula, Rausu, Rausu Lake Trail, 720 m, 1.VIII.1991, leg. Smetana [J24] (CNC, cAss); $2 o^{\star} o^{\star}, 1$ ㅇ, Horokanai, Butokamabetsu river, 430 m, 3.VIII.1991, leg. Smetana [J29] (CNC, cAss);

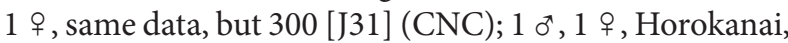
Dorogawa, 280-300 m, 5.VIII.1991, leg. Smetana [J34] (CNC). Russia: Sakhalin: 1 ex., Aniva district, Zuneyiskiy mountains, $10 \mathrm{~km}$ N Novo Aleksandrovsk, Mt. Tshekhov, 1000 m, 13.VII.1993, leg. Pütz \& Wrase (cSch); 1 ex., Aniva district, Kamiyshoviye mountains, Levedskiy pass, 30 km NW Aniva, 700-800 m, 14.VII.1993, leg. Pütz \&
Wrase (cSch); 1 ex., Aniva district, $5 \mathrm{~km} \mathrm{~W} \mathrm{Petropav-}$ lovskoye, tributary of Lyutoga river, 20.-21.VII.1993, leg. Pütz \& Wrase (cSch); 1 ex., Aniva district, Ogonoki near Yuzhno-Sakhalinsk, 29.VI.1992, leg. Basarukin (cSch). (The material from Sakhalin was identified and communicated by $\mathrm{M}$. Schülke.).

Comment: The original description is based on three type specimens from "Urup, Kuril Arch. Russia, ..., $45^{\circ} 39.04^{\prime} \mathrm{N}, 149^{\circ} 28.78^{\prime} \mathrm{E}^{\prime}$ (WATANABE 2004). The phylogenetic affiliations of this species are somewhat unclear. It is characterized particularly by the conspicuously oblong and posteriorly tapering head, the nearly unmodified male sternite VII, and by the absence of micropubescence on the female sternite VIII. Watanabe (2004) suggests that $L$. oharai is closely allied to L. japonicum, whose head is oblong, too (though much less so than in L.oharai). However, in L.japonicum the shapes and chaetotaxy of the male sternites VII and VIII are distinctly modified, and the female sternite VIII has micropubescence. According to a recent study (Assing 2013e), the presence of micropubescence in the posterior portion of the female sternite VIII is one of the characters separating Lathrobium from other closely related genera within the Lathrobiina.

Redescription: Body length 7.0-9.0 mm; length of forebody $4.0-4.5 \mathrm{~mm}$. Habitus as in Fig. 111. Coloration: body blackish; legs and antennae dark-reddish to darkbrown.

Head (Fig. 112) conspicuously oblong, 1.15-1.20 times as long as broad, tapering posteriorly; posterior angles almost obsolete; punctation rather coarse and dense, somewhat sparser in median dorsal portion; interstices with pronounced microreticulation and subdued shine. Eyes slightly less than one-third as long as distance from posterior margin of eye to posterior constriction of head in dorsal view and composed of numerous small ommatidia. Antenna 2.2-2.4 mm long.

Pronotum (Fig. 112) approximately 1.2 times as long as broad and about 1.05 times as broad as head; punctation similar to that of head; impunctate midline moderately broad; interstices without microsculpture.

Elytra (Fig. 112) moderately short, approximately 0.8 times as long as pronotum, weakly dilated posteriad; humeral angles weakly marked; punctation shallow and moderately dense; interstices without microsculpture. Hind wings reduced. Protarsomeres I-IV distinctly dilated, without evident sexual dimorphism.

Abdomen as broad as, or slightly broader than elytra; punctation moderately fine and rather dense, nearly as dense on tergite VII as on anterior tergites; interstices with very shallow microsculpture; posterior margin of tergite VII with palisade fringe; tergite VIII with weakly convex posterior margin.

$o^{*}$ : sternite VII (Fig. 113) moderately strongly transverse, with weakly concave posterior margin, but without other modifications; sternite VIII (Fig. 114) 
transverse, with very small posterior excision; aedeagus (Figs 115-116) approximately $1.3 \mathrm{~mm}$ long and symmetric; ventral process apically strongly narrowed apically in ventral view and bisinuate in lateral view; dorsal plate with moderately long, moderately sclerotized, plate-shaped, and apically acute apical portion, and with short and very thin basal portion; internal sac without sclerotized structures.

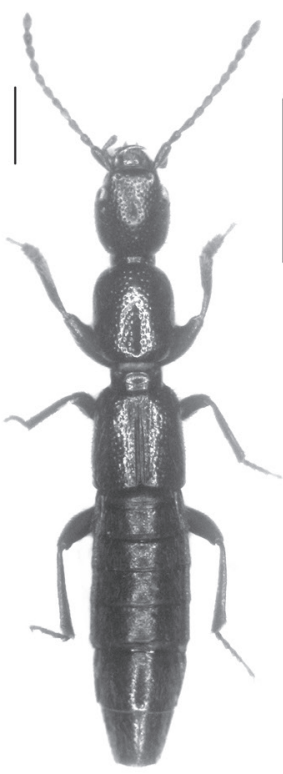

111

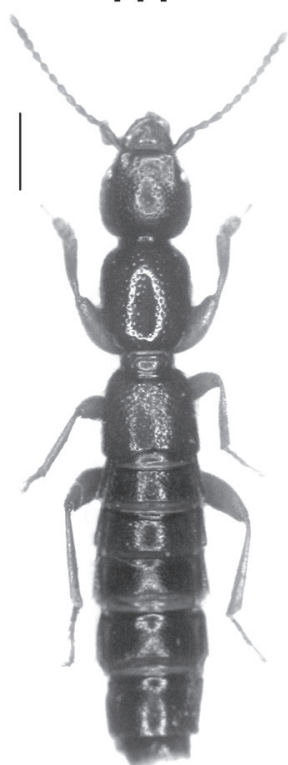

119

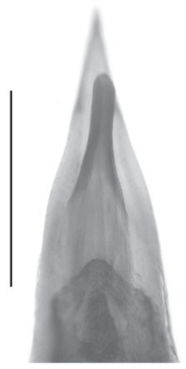

125

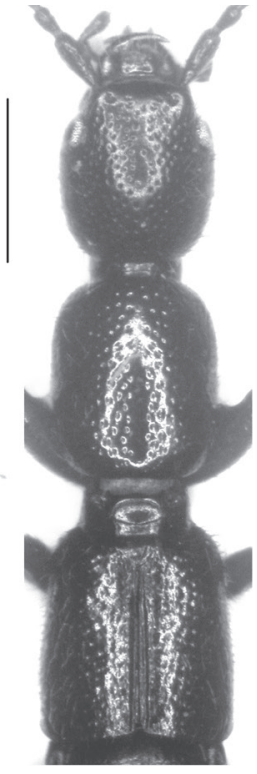

112

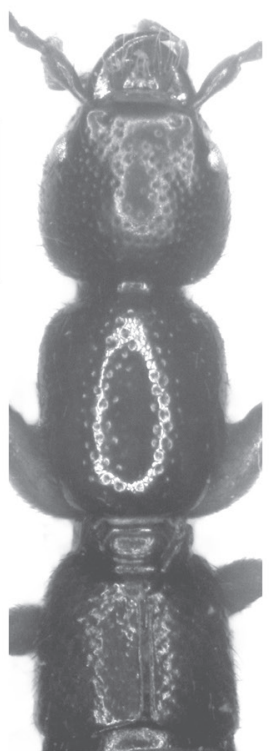

120

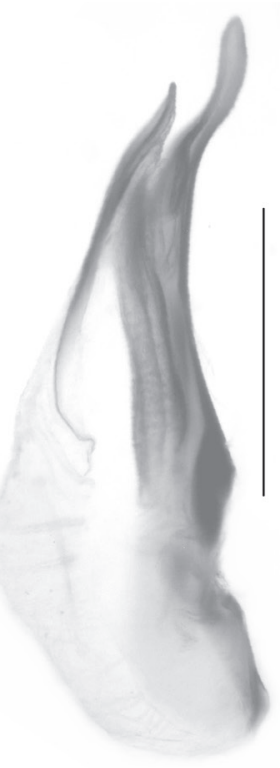

115

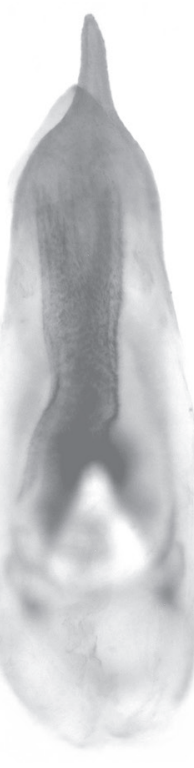

116

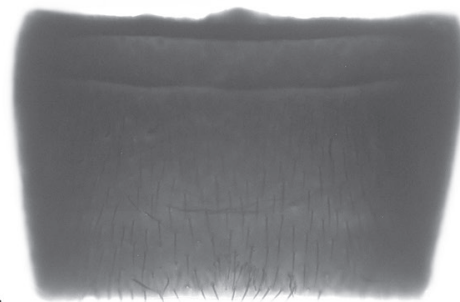

113

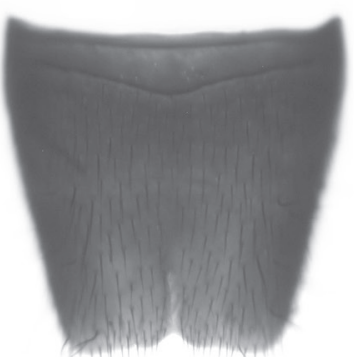

114

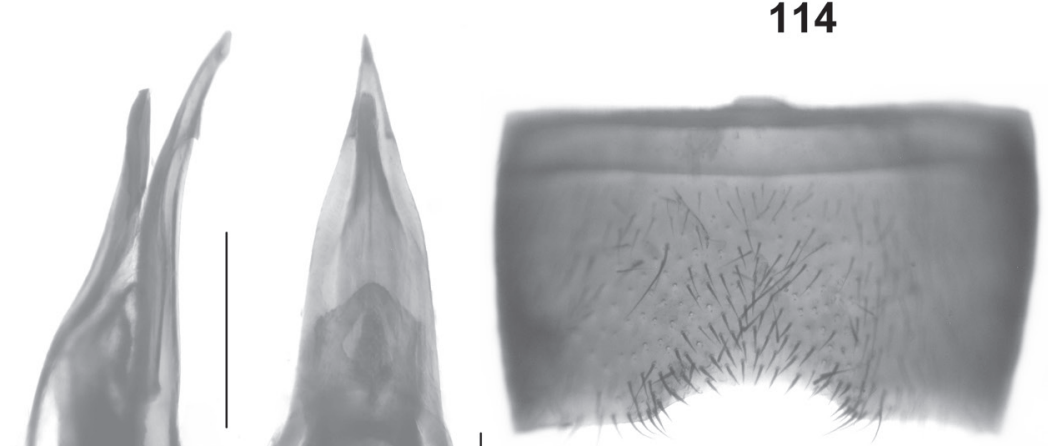

121

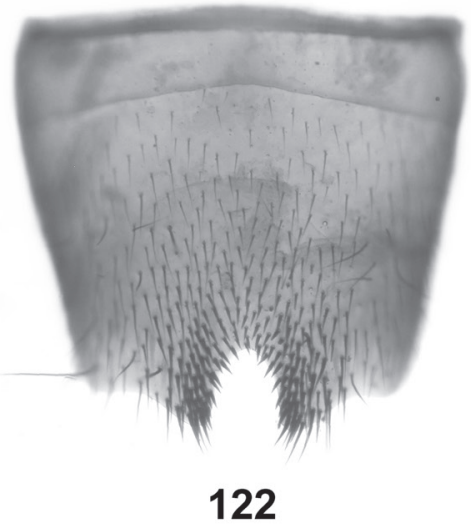

117

124

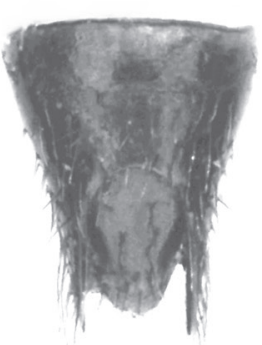

118

Figs 111-125: Lathrobium oharai WatANABE and L. scaphiforme spec. nov. (119-125) habitus (111-119); forebody (112, 120); male sternite VII $(113,121)$; male sternite VIII $(114,122)$; aedeagus in lateral and in ventral view $(115-116,123-124)$; female sternite VIII (117); female tergites IX-X (118); apical portion of aedeagus in dorsal view (125). Scale bars: 111-112, 119-120: $1.0 \mathrm{~mm} ; 113-118,121-125: 0.5 \mathrm{~mm}$. 
o : sternite VIII (Fig. 117) approximately as broad as long and with broadly convex posterior margin, without micropubescence in posterior portion; tergite IX (Fig. 118) with undivided antero-median portion; tergite X (Fig. 119) flattened and of broadly oval shape, approximately as long as antero-median portion of tergite IX.

Distribution and natural history: The known distribution of L. oharai is confined to the Kuril Islands and Hokkaido, but it does not seem unlikely that it is present also in Sakhalin and/or mainland Russia. The palisade fringe at the posterior margin of the abdominal tergite VII is still present, suggesting that the species may be wing-dimorphic. The above specimens from Hokkaido represent the first records from Japan. They were collected at altitudes of 5-800 m.

\section{Lathrobium scaphiforme spec. nov.}

(Figs 119-125)

Type material: Holotype $\sigma^{\star}$ : "JAPAN, Honshu, Iwate, Kawai, Yoshibezawa [39³7'N, 141 $\left.{ }^{\circ} 31^{\prime} \mathrm{E}\right], 600-700$ m, 16.VIII.91, A. Smetana [J57] / Holotypus o Lathrobium scaphiforme spec. nov., det. V. Assing 2014" (CNC).

Paratype + [teneral]: "JAPAN, Honshu, Iwate, Kawai, Zaimokuzawa, 720 m, 15.VI.91, A. Smetana [J54]” (cAss).

Etymology: The specific epithet is an adjective composed of the Latin noun scapha (boat) and the suffix -forme. It alludes to the boat-shaped dorsal plate of the aedeagus.

Description: Body length $8.3-9.0 \mathrm{~mm}$; length of forebody $4.4 \mathrm{~mm}$. Habitus as in Fig. 119. Coloration: body blackish; legs pale-brown; antennae dark-brown.

Head (Fig. 120) transverse, 1.04-1.07 times as broad as long; punctation moderately coarse and rather dense, sparser in median dorsal portion; interstices with distinct microreticulation. Eyes weakly projecting from lateral contours of head, approximately one-third as long as postocular region in dorsal view and composed of approximately 50 ommatidia. Antenna $2.3 \mathrm{~mm}$ long.

Pronotum (Fig. 120) approximately 1.2 times as long as broad and about as broad as head; punctation similar to that of head, but somewhat sparser; impunctate midline moderately broad; interstices without microsculpture. Elytra (Fig. 120) short, approximately half as long as pronotum, weakly dilated posteriad; humeral angles weakly marked; punctation shallow and moderately dense; interstices without microsculpture. Hind wings completely reduced. Protarsomeres I-IV with pronounced sexual dimorphism.

Abdomen distinctly broader than elytra; punctation fine and moderately dense, density decreasing towards posterior tergites; posterior margin of tergite VII without palisade fringe.

$\sigma^{\star}$ : protarsomeres I-IV strongly dilated; sternite VII (Fig. 121) strongly transverse, with impression of subtriangular shape in postero-median portion, this impression with moderately dense short black setae, posterior margin distinctly concave in the middle; sternite VIII (Fig. 122) weakly transverse and longitudinally impressed in postero-median portion, posterior excision U-shaped, on either side of posterior excision acutely produced and with a dense cluster of stout black setae; aedeagus (Figs 123-125) $1.9 \mathrm{~mm}$ long and symmetric; ventral process long, weakly curved in lateral view, with a long median carina ventrally, subapically with a pair of tooth-like processes; dorsal plate with a long, distinctly sclerotized and dorsally excavate apical portion and with an even longer lamellate basal portion; internal sac with a broad, curved (cross-section), and moderately sclerotized structure.

ㅇ: protarsomeres I-IV moderately dilated, distinctly less so than in male; sternite VIII longer than tergite VIII, convexly produced posteriorly; tergite IX with long and undivided antero-median portion and short posterolateral processes; tergite $\mathrm{X}$ short, approximately half as long as antero-median portion of tergite IX.

Comparative notes: The similarly modified male sternites VII and VIII, as well as the similar general morphology of the aedeagus suggest that L. scaphiforme is allied to L. pollens SHARP, 1889 and related species. It differs from L. pollens by the differently shaped pronotum (more slender and less strongly tapering posteriad), the more strongly transverse male sternite VII with a more distinctly modified chaetotaxy, the shape and chaetotaxy of the male sternite VIII (more pronounced clusters of modified setae on either side of the posterior excision; posterior excision narrower), and by the structure of the aedeagus (ventral process differently shaped, subapically dentate; dorsal plate much more massive and of different shape; presence of a large internal structure). For characters separating it from the syntopic L. volutum, the only other micropterous Lathrobium species recorded from Iwate Prefecture, see the comparative notes in the following section.

Distribution and natural history: The type material was collected in two localities near Kawai (northern Honshu: Iwate Prefecture) at altitudes between 600 and $720 \mathrm{~m}$. The paratype is distinctly teneral. 


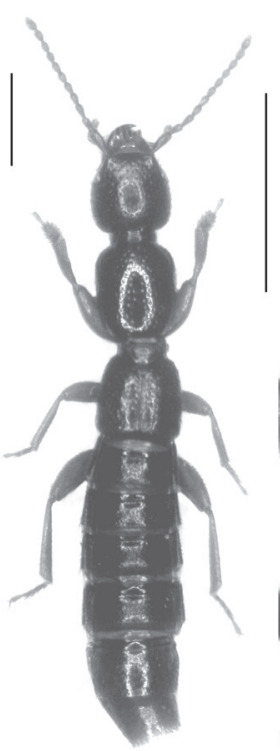

126

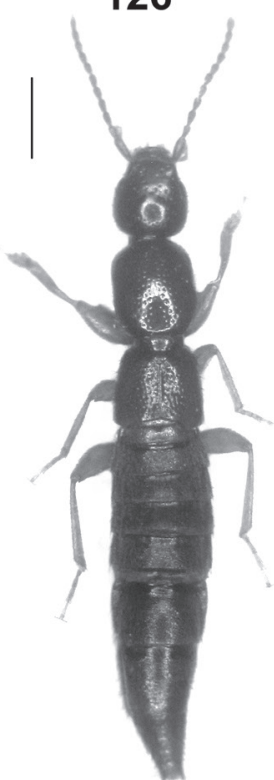

135

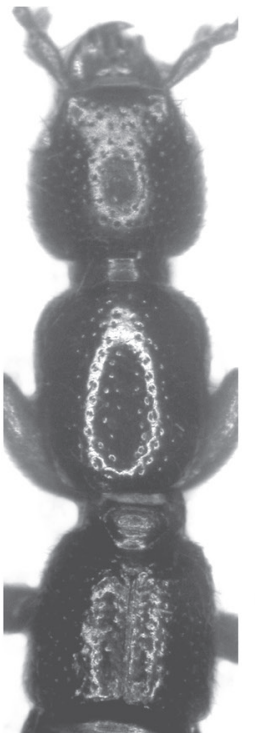

127

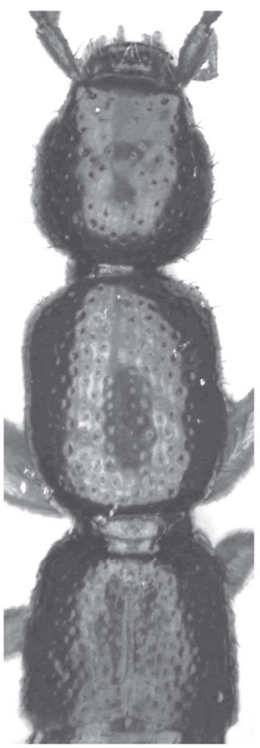

136

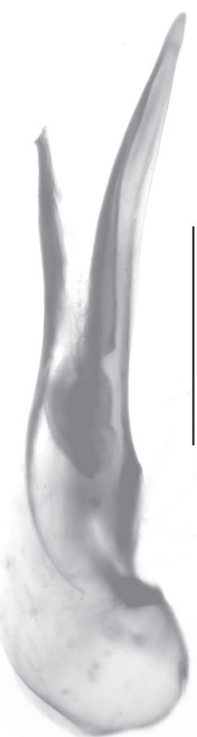

130

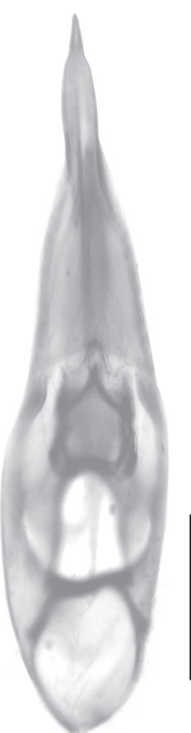

131

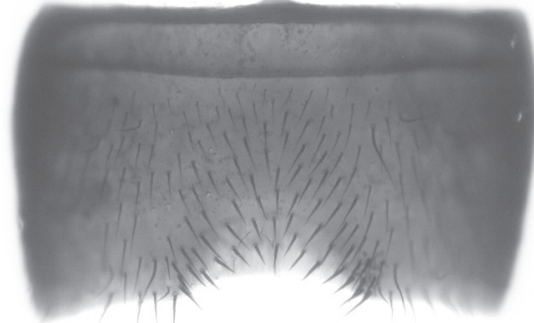

128

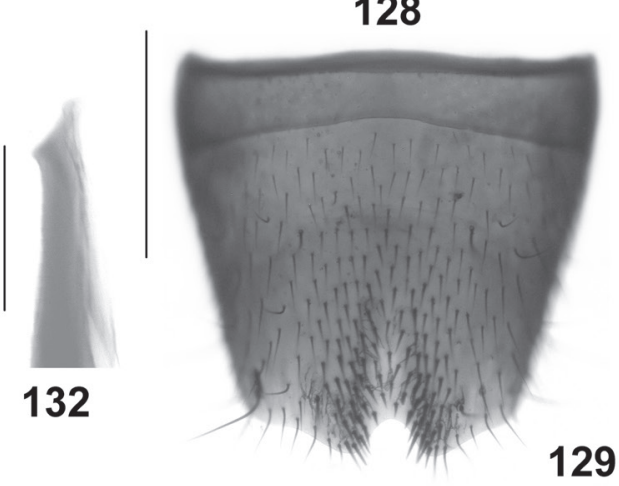

129

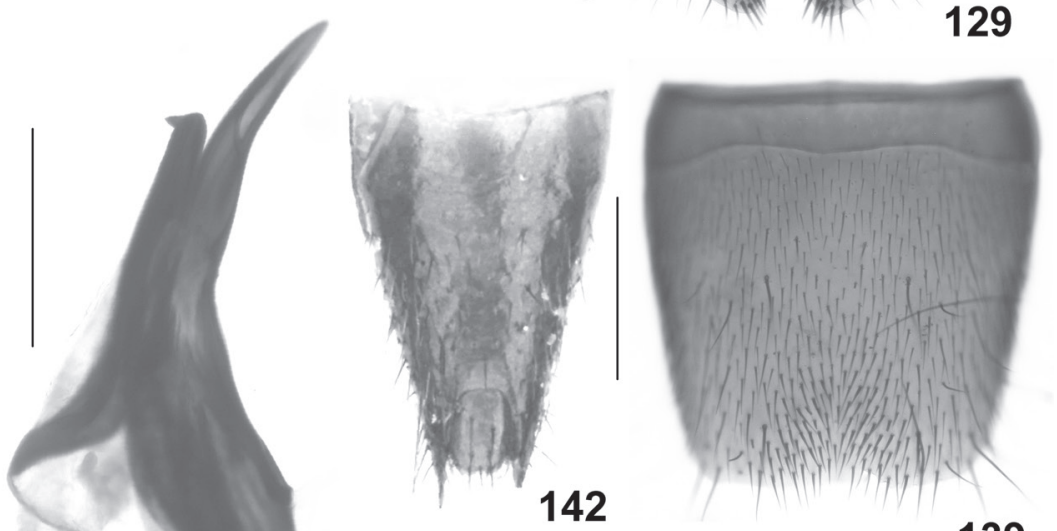

139

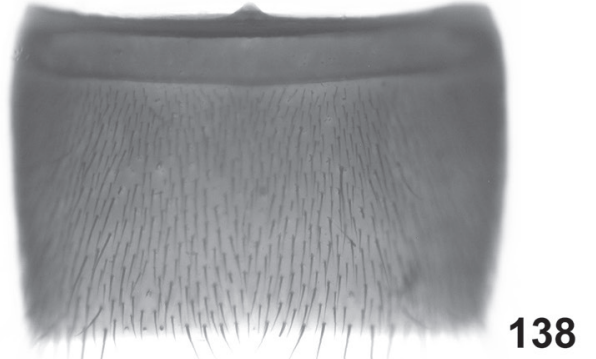

138
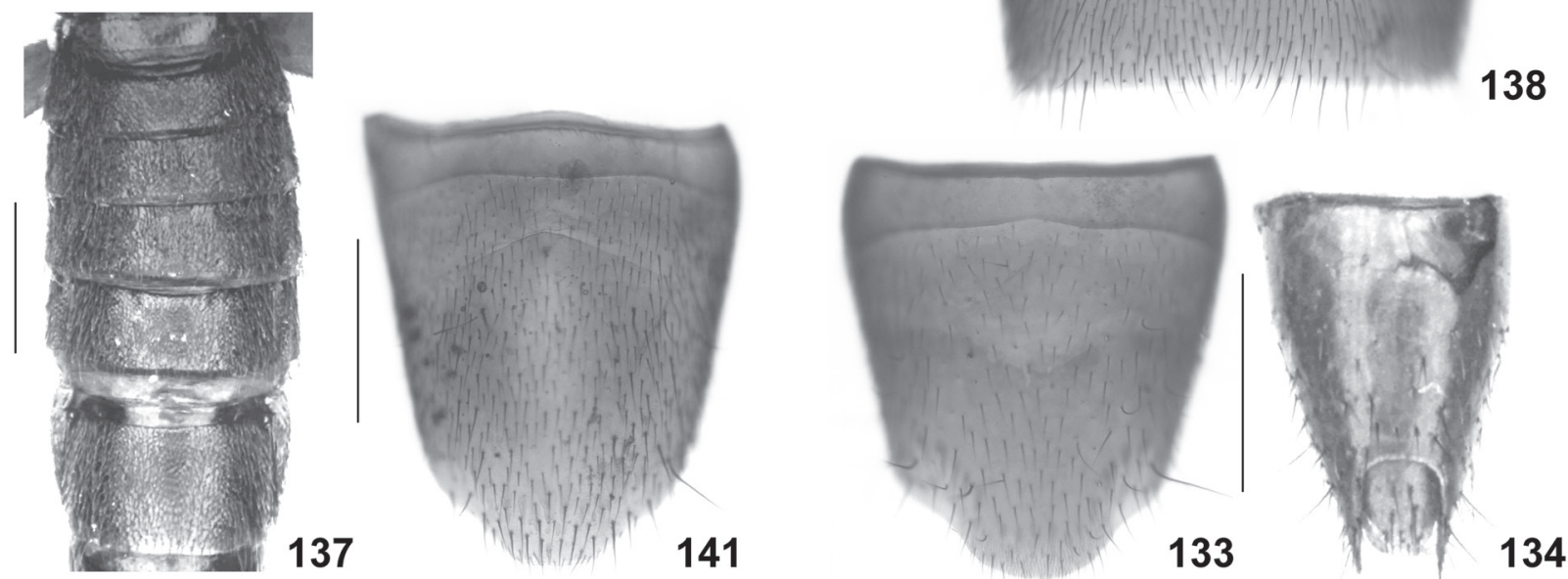

Figs 126-142: Lathrobium volutum spec. nov. (126-134) and L. trabale spec. nov. (135-142): habitus (126, 135); forebody (127, 136); male sternite VII $(128,138)$; male sternite VIII $(129,139)$; aedeagus in lateral view $(130,140)$; aedeagus in ventral view (131); apical portion of dorsal plate of aedeagus in lateral view (132); female sternite VIII (133, 141); female tergites IX-X (134, 142); abdominal segments III-VII (137). Scale bars: 126-127, 135-137: $1.0 \mathrm{~mm}$; 128-131, 133-134, 138-142: $0.5 \mathrm{~mm}$; $132: 0.1 \mathrm{~mm}$. 


\section{Lathrobium volutum spec. nov.}

(Figs 126-134)

Type material: Holotype $0^{\star}:$ "JAPAN, Honshu, Iwate,

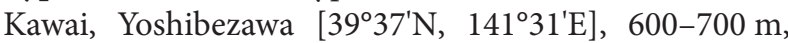
16.VIII.91, A. Smetana [J57] / Holotypus o Lathrobium volutum spec. nov., det. V. Assing 2014" (CNC).

Paratypes: $1 \sigma^{\wedge}, 2$ ㅇ ㅇ: same data as holotype (CNC, cAss).

Etymology: The specific epithet is the past participle of the Latin verb volvere (to roll) and alludes to the shape of the internal structure of the aedeagus.

Description: Body length $6.5-7.5 \mathrm{~mm}$; length of forebody $3.4-3.6 \mathrm{~mm}$. Habitus as in Fig. 126. Coloration: body blackish-brown to blackish; legs yellowish-brown; antennae dark-reddish.

Head (Fig. 127) weakly transverse, 1.02-1.04 times as broad as long; punctation moderately coarse and moderately dense, sparser in median dorsal portion; interstices with distinct microreticulation. Eyes weakly projecting from lateral contours of head, approximately one-third as long as postocular region in dorsal view, or even shorter, and composed of approximately 50 ommatidia. Antenna approximately $1.8 \mathrm{~mm}$ long.

Pronotum (Fig. 127) approximately 1.2 times as long as broad and about as broad as head; punctation similar to that of head, but somewhat sparser; impunctate midline moderately broad; interstices without microsculpture.

Elytra (Fig. 127) approximately 0.55 times as long as pronotum, weakly dilated posteriad; humeral angles weakly marked; punctation shallow and moderately dense; interstices without microsculpture. Hind wings completely reduced. Protarsomeres I-IV with pronounced sexual dimorphism.

Abdomen distinctly broader than elytra; punctation fine and moderately dense, density decreasing towards posterior tergites; posterior margin of tergite VII without palisade fringe; tergite VIII with sexual dimorphism.

$\mathrm{o}^{*}$ : protarsomeres I-IV strongly dilated; posterior margin of tergite VIII truncate; sternite VII (Fig. 128) strongly transverse, with impression of subtriangular shape in postero-median portion, this impression with moderately dense and moderately modified black setae, posterior margin distinctly concave in the middle; sternite VIII (Fig. 129) weakly transverse and longitudinally impressed in postero-median portion, posterior excision small and U-shaped, on either side of posterior excision weakly produced, posterior portion with dense stout black setae; aedeagus (Figs 130-131) $1.7 \mathrm{~mm}$ long and symmetric; ventral process long, weakly curved in lateral view, apically acute, with a pronounced median carina ventrally; dorsal plate with a long, distinctly sclerotized, dorsally weakly excavate, and apically dentate apical portion (Fig. 132) and with a shorter lamellate basal portion; internal sac with a broad, curved (cross-section), and moderately sclerotized structure.
$:$ protarsomeres I-IV moderately dilated, distinctly less so than in male; posterior margin of tergite VIII convex; sternite VIII (Fig. 133) longer than tergite VIII, convexly produced posteriorly; tergite IX (Fig. 134) with very long and undivided antero-median portion and short postero-lateral processes; tergite X (Fig. 134) short, little more than one-third as long as antero-median portion of tergite IX.

Comparative notes: Based on the similarly modified male sternites VII and VIII, as well as the similar general morphology of the aedeagus, particularly the presence of an internal structure of similar general shape, L. volutum is very closely allied to the syntopic L. scaphiforme, from which it differs by distinctly smaller size, the more slender habitus, the less pronounced median concavity of the male sternite VII, the different shape and chaetotaxy of the male sternite VIII, the different shapes of the ventral process and the dorsal plate of the aedeagus, the relatively longer antero-median portion of the female tergite IX, and the shorter female tergite $\mathrm{X}$.

Distribution and natural history: The type locality is situated near Kawai (northern Honshu: Iwate Prefecture) at an altitude of $600-700 \mathrm{~m}$. The specimens were collected together with the holotype of L. scaphiforme.

\section{Lathrobium trabale spec. nov. (Figs 135-142)}

Type material: Holotype $\sigma^{*}$ : "JAPAN, Kyoto Pref., Honshu, 6.VIII.1980, S. Naomi / P.M. Hammond, BMNH(E) 2003-84 / Holotypus o Lathrobium trabale spec. nov., det. V. Assing 2014" (BMNH).

Paratypes: $10^{\star}$ [teneral], 7 우: same data as holotype (BMNH, cAss).

Etymology: The specific epithet is an adjective derived from the Latin noun trabs (beam) and alludes to the massive dorsal plate of the aedeagus.

Description: Size subject to distinct sexual dimorphism; body length $8.2-8.8 \mathrm{~mm}\left(\mathrm{o}^{\star}\right), 6.8-8.0 \mathrm{~mm}$ ( 9 ); length of forebody $4.1 \mathrm{~mm}\left(o^{\star}\right), 3.4-3.7 \mathrm{~mm}$ ( क ). Habitus as in Fig. 135. Coloration: body blackish-brown; legs yellowish-red; antennae reddish.

Head (Fig. 136) approximately as broad as long; punctation moderately coarse and sparse, very sparse in median dorsal portion; interstices with distinct microreticulation. Eyes weakly projecting from lateral contours of head, approximately half as long as postocular region in dorsal view, or nearly so, and composed of $>50$ ommatidia. Antenna $2.4\left(\sigma^{\star}\right)$ or 2.0-2.1 ( ( ) $\mathrm{mm}$ long.

Pronotum (Fig. 136) approximately 1.2 times as long as broad and 1.10-1.14 times as broad as head; punctation similar to that of head; impunctate midline moderately broad; interstices without microsculpture. 
Elytra (Fig. 136) 0.54-0.60 times as long as pronotum, dilated posteriad; humeral angles weakly marked; punctation shallow and moderately dense; interstices without microsculpture. Hind wings completely reduced. Protarsomeres I-IV with pronounced sexual dimorphism.

Abdomen slightly broader than elytra; punctation very fine and extremely dense on all tergites (Fig. 137); posterior margin of tergite VII without palisade fringe; tergite VIII with weakly convex posterior margin, without distinct sexual dimorphism.

$\sigma^{*}$ : protarsomeres I-IV strongly dilated; sternite VII (Fig. 138) strongly transverse, otherwise without appreciable modifications; sternite VIII (Fig. 139) nearly as broad as long, with weakly defined and extensive cluster of stouter and darker setae in postero-median portion, posterior margin indistinctly concave in the middle, nearly truncate; aedeagus (Fig. 140) $1.7 \mathrm{~mm}$ long; ventral process long, slender, and apically acute both in lateral and in ventral view; dorsal plate with strongly sclerotized, robust, and long apical portion and with very short lamellate basal portion; apex of apical portion of dorsal plate with pronounced dorsal tooth.

ㅇ: protarsomeres I-IV moderately dilated, distinctly less so than in male; sternite VIII (Fig. 141) oblong, approximately 1.2 times as long as broad, posteriorly distinctly produced, posterior margin truncate in the middle; tergite IX (Fig. 142) with very long and undivided antero-median portion; tergite X (Fig. 142) very small, only approximately one-third as long as antero-median portion of tergite IX.

Comparative notes: Only two species (L. kuramaicum Assing, 2013; L. uenoi Watanabe, 1980) have been recorded from Kyoto Prefecture; not a single Lathrobium species is known from the adjacent Shiga Prefecture (Assing 2013f). Lathrobium trabale is distinguished from the above two species, as well as from other species from neighbouring prefectures by the completely different male sexual characters. It additionally differs from L. kuramaicum, the geographically closest congener, by larger body size, the smaller head (in relation to the pronotum), the sparser punctation of the pronotum, and by the much denser punctation of the abdomen.

Distribution and natural history: The type material was collected at the southern foot of Mount Kibune, near the railway station Kibune, at approximately $35^{\circ} 06^{\prime} \mathrm{N}$, $135^{\circ} 46^{\prime} \mathrm{E}$ (NAOMI pers. comm.). One of the paratypes is teneral.

\section{Additional records and a new species of Elytrobium \\ Elytrobium monilicorne (SHARP, 1889)}

Additional material examined: Japan: 1 ex., Honshu, Gumma Pref., Kirizumi Spa, 30.V.1955, leg. Watanabe (MNHUB).

Comment: Confirmed records were previously known only from Fujisan in Honshu, Japan (Assing 2013e).

\section{Elytrobium gongganum Assing, 2013}

Additional material examined: China: 1 ex., Sichuan, Gongga Shan, $29^{\circ} 34^{\prime} \mathrm{N}, 101^{\circ} 59^{\prime} \mathrm{E}, 3140 \mathrm{~m}$, sifted, 3.VI.2011, leg. Grebennikov (CAS).

Comment: Previously, only the holotype from the Gongga Shan was known (Assing 2013e).

\section{Elytrobium edentulum spec. nov. (Figs 143-149)}

Type material: Holotype $\sigma^{\star}$ [antennomeres X-XI of left antenna and antennomere XI of right antenna missing]: "P. R. CHINA, Shaanxi, N slope Qin Ling Shan, N34 01'07", E10751'50", 17.v.2011, 1700-2200 m, sift02, V. Grebennikov / Holotypus o Elytrobium edentulum spec. nov., det. V. Assing 2014" (CAS).

Etymology: The specific epithet (Latin, adjective: without tooth) alludes to the apically smoothly convex ventral process of the aedeagus, one of the characters distinguishing this species from the sympatric E. qinlinganum Assing, 2013.

Description: Body length $7.3 \mathrm{~mm}$; length of forebody $3.7 \mathrm{~mm}$. Coloration: body black; legs with dark-brown femora, brown tibiae, and yellowish to pale-brown tarsi; antennae reddish with slightly darker antennomere I.

Head (Fig. 144) 1.13 times as long as broad, broadest across eyes, and distinctly tapering behind eyes; posterior angles broadly rounded, indistinct; postero-median dorsal portion somewhat elevated; punctation coarse and dense, slightly sparser in median dorsal portion; interstices narrower than diameter of punctures (except in median dorsal portion), with distinct microreticulation, and subdued shine (Fig. 145). Eyes moderately large, nearly half as long as postocular region from posterior margin of eye to neck in dorsal view. Antennomeres IV-X weakly oblong. Maxillary palpi with palpomere III slender, approximately 3.5 times as long as broad.

Pronotum (Fig. 144) 1.2 times as long as broad and 1.13 times as broad as head, broadest in posterior half, distinctly tapering anteriad; lateral margins nearly 
straight in dorsal view; punctation similar to that of head; interstices without microreticulation along midline, with very shallow microreticulation laterally; impunctate median band narrow, not reaching posterior margin.

Elytra (Fig. 143) long and large, 1.05 times as long and more than 1.5 times as broad as pronotum; punctation dense, distinct, coarser than that of pronotum, and not distinctly seriate; interstices without microreticulation, glossy. Protarsomeres I-IV strongly dilated. Metatarsomere I shorter than II.

Abdomen distinctly narrower than elytra, segments III-VI of subequal width; punctation dense and rather coarse on anterior tergites, gradually becoming finer and sparser towards abdominal apex; interstices with shallow microreticulation; posterior margin of tergite VII with palisade fringe.

$o^{\top}$ : sternite VII unmodified; sternite VIII (Fig. 146) distinctly oblong, 1.1 times as long as broad, posterior excision shallow and with noticeable angle in the middle, pubescence unmodified; aedeagus (Figs 147-148) small in relation to body size, $0.7 \mathrm{~mm}$ long; dorsal plate short and apically acute (Fig. 149); internal sac with plateshaped internal structure (Fig. 149).

Comparative notes: Using the key in Assing (2013e), E. edentulum would key out at couplet 3, together with E. qinlinganum Assing, 2013, from which it differs by the elevated postero-median dorsal portion of the head, the slightly more oblong antennomeres IV-X, the different shape of the pronotum (E. qinlinganum: lateral margin nearly parallel in dorsal view), the presence of shallow microsculpture on the pronotum, the less strongly dilated protarsomeres I-IV, and the distinctly smaller and differently shaped aedeagus. For illustrations of E. qinlinganum and other species of the genus see Assing (2013e).

Distribution and natural history: The type locality is situated in the Qinling Shan in southern Shaanxi. The holotype was sifted at an altitude between 1700 and $2200 \mathrm{~m}$.

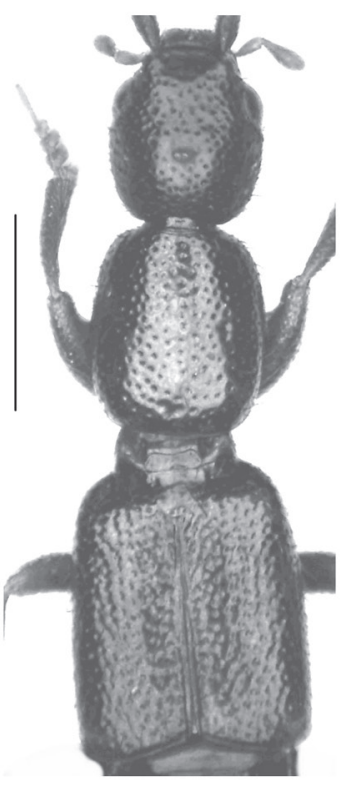

143

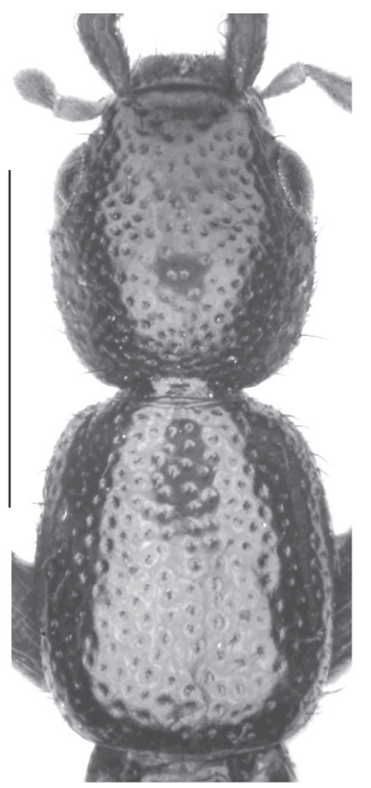

144

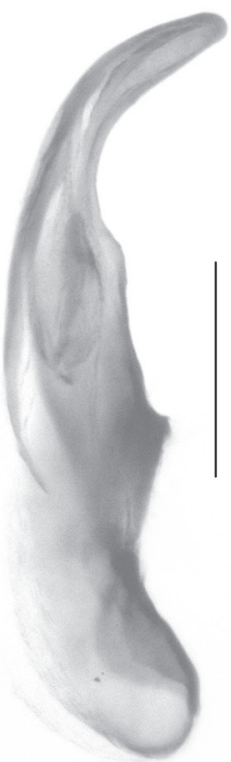

147

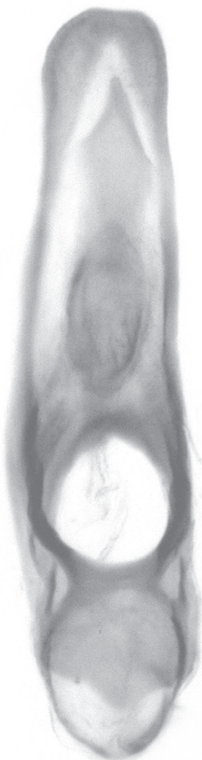

148

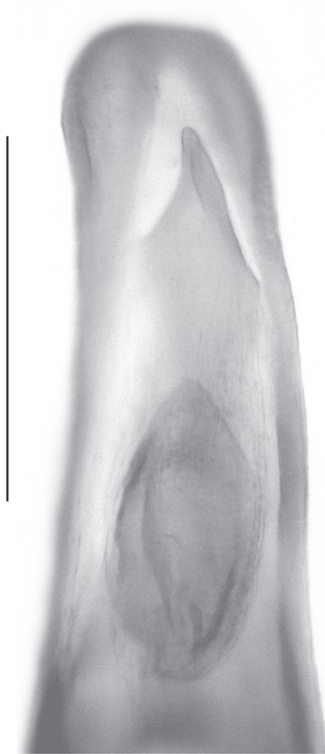

149
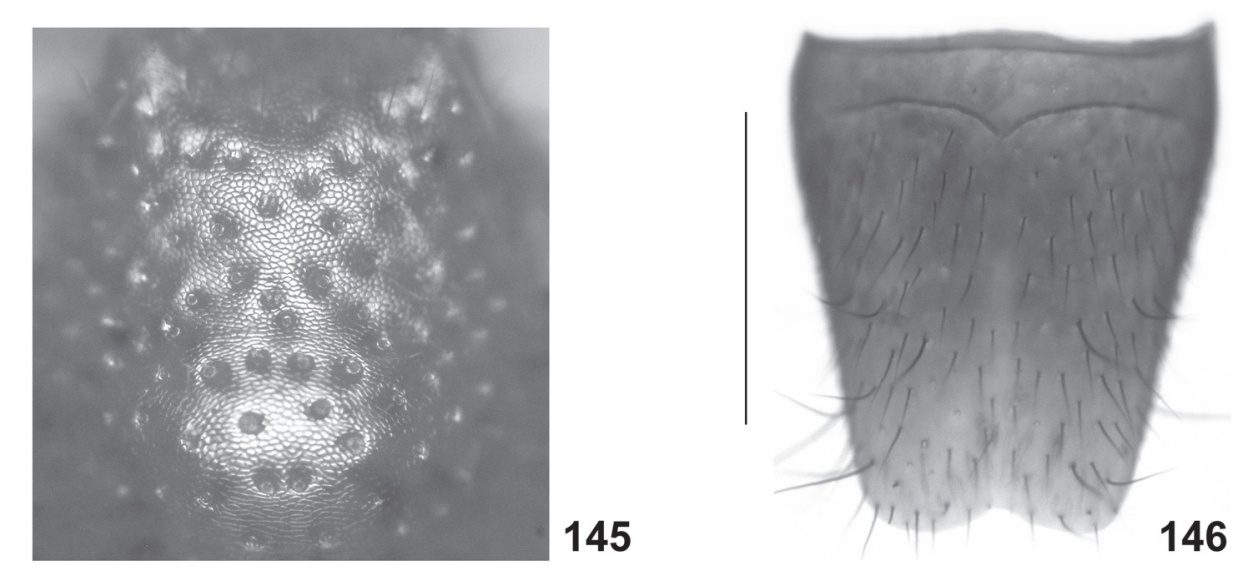

Figs 143-149: Elytrobium edentulum spec. nov.: forebody (143); head and pronotum (144); median dorsal portion of head (145); male sternite VIII (146); aedeagus in lateral and in ventral view (147-148); apical portion of aedeagus in dorsal view (149). Scale bars: 143-144: $1.0 \mathrm{~mm}$; 146: $0.5 \mathrm{~mm}$; 145, 147-149: $0.2 \mathrm{~mm}$. 


\section{Acknowledgements}

I am indebted to the colleagues indicated in the material section for the loan of relevant material. In particular, I am grateful to Benedikt Feldmann (Münster) and Michael Schülke (Berlin) for the generous gift of the holotypes of L. erectum and L. coadultum, respectively. Alexandr Ryvkin (Moscow) assisted in the identification of L. krilioni, L. viduum, and L. oharai, and provided information on L. japonicum.

\section{References}

Assing, V. 2010: On the Lathrobiina of Taiwan (Coleoptera: Staphylinidae: Paederinae). - Beiträge zur Entomologie, Keltern 60 (2): 301-361.

Assing, V. 2012: A revision of the Lathrobium species of the Himalaya (Coleoptera: Staphylinidae: Paederinae). - Bonn Zoological Bulletin 61 (2): 142-209.

Assing, V. 2013a: On the Lathrobium fauna of China I. The species of the Qinling Shan, the Daba Shan, and adjacent mountain ranges (Coleoptera: Staphylinidae: Paederinae). - Bonn Zoological Bulletin 62 (1): 1-29.

Assing, V. 2013b: On the Lathrobium fauna of China III. New species and additional records from various provinces (Coleoptera: Staphylinidae: Paederinae). Contributions to Entomology 63 (1): 25-52.

Assing, V. 2013c: On the Lathrobium fauna of China V. New species and additional records from Yunnan (Coleoptera: Staphylinidae: Paederinae). Contributions to Entomology 63 (1): 53-128.

Assing, V. 2013d: Six new species and additional records of Lathrobium from the Palaearctic region (Coleoptera: Staphylinidae: Paederinae). - Linzer Biologische Beiträge 45 (1): 247-266.

Assing, V. 2013e: Two new genera of Lathrobiina from the East Palaearctic region (Coleoptera: Staphylinidae: Paederinae). - Contributions to Entomology 63 (2): 219-239.

Assing, V. 2013f: On the Lathrobium fauna of Japan (Coleoptera: Staphylinidae: Paederinae). - Linzer Biologische Beiträge 45 (2): 1615-1641.

Assing, V. 2013g: On the Nazeris fauna of China II. New species and records from Zhejiang, Sichuan, and Yunnan (Coleoptera: Staphylinidae: Paederinae). Bonn Zoological Bulletin 62 (2): 125-170.

Assing, V. 2014a: New species and records of Lathrobium from the Palaearctic region, primarily from Nepal (Coleoptera: Staphylinidae: Paederinae). Contributions to Entomology 64 (1): 1-28.

Assing, V. 2014b: A revision of Nazeris. VI. On the fauna of East Yunnan, China (Coleoptera: Staphylinidae: Paederinae). - Contributions to Entomology 64 (2): 355-373.

Assing, V.; Peng, Z. \& ZhaO, M.-J. 2013: On the Lathrobium fauna of the Emei Shan, Sichuan, China
(Coleoptera, Staphylinidae, Paederinae). - ZooKeys 277: 47-67.

Bordoni, A. \& MAgRINI, P. 2014: Lathrobium bastianinii n. sp. of the limestone caves of Piteccio (Tuscany, Italy) (Coleoptera, Staphylinidae). - Bollettino dell' Associazione Romana di Entomologia 66 (1-4) (2011): 1-4.

Chen, J.; LI, L.-Z. \& ZhaO, M.-J. 2005: A new species of the genus Lathrobium (Coleoptera, Staphylinidae) from Guizhou province, Southwest China. - Acta Zootaxonimica Sinica 30 (3): 598-600.

Peng, Z.; LI, L.-Z. \& Zhao, M.-J. 2012: Three new species of Lathrobium Gravenhorst (Coleoptera, Staphylinidae, Paederinae) from Sichuan, Southwest China. - ZooKeys 205: 33-44.

Peng, Z.; LI, L.-Z. \& ZhaO, M.-J. 2013: A new species of Lathrobium Gravenhorst (Coleoptera, Staphylinidae) from Shaanxi, Central China. - Zootaxa 3608: 158-160.

Peng, Z.; LI, L.-Z. \& Zhao, M.-J. 2014: Seventeen new species and additional records of Lathrobium (Coleoptera, Staphylinidae) from mainland China. Zootaxa 3780: 1-35.

Peng, Z.; LI, L.-Z.; Shen, L. \& Gu, F.-K. 2015: On the Lathrobium fauna of the Donggong Mountains, eastern China. - Zootaxa 3902 (2): 245-263.

Ryvkin, A. B. 2011: On new and poorly known Lathrobium (s. str.) species from Siberia and the Russian Far East (Insecta: Coleoptera: Staphylinidae: Paederinae). - Baltic Journal of Coleopterology 11 (2): 135-170.

Smetana, A. 2004: Subfamily Paederinae Fleming, 1821. - In: LöBl, I. \& SmetanA, A. (eds): Catalogue of Palaearctic Coleoptera. Volume 2. Hydrophiloidea - Histeroidea - Staphylinoidea. - Apollo Books, Stenstrup: 579-624.

Watanabe, Y. 1998: Two new apterous Lathrobium (Coleoptera, Staphylinidae) from the Ta-hsüeh Shan Mountains in Taiwan. - Elytra, Tokyo 26 (2): 303-311.

Watanabe, Y. 2001: Four new species of apterous Lathrobium (Coleoptera, Staphylinidae) from Central Honshu, Japan. - Elytra, Tokyo 29 (2): 465-475.

Watanabe, Y. 2002: A new species of the group of Lathrobium brachypterum (Coleoptera, Staphylinidae) from the Bôsô Peninsula in Central Honshu, Japan. - Elytra, Tokyo 30 (2): 314-319.

Watanabe, Y. 2004: Lathrobium japonicum and its new relatives (Coleoptera, Staphylinidae) from the Kuril Islands. - Biodiversity and Biogeography of the Kuril Islands and Sakhalin 1: 37-44.

Watanabe, Y. 2005: Apterous Lathrobium (Coleoptera, Staphylinidae) from the Kii Peninsula in Japan. 1. Group of Lathrobium shingon. - Elytra, Tokyo 33 (1): 313-325.

WATANABE, Y. 2014: New brachypterous Lathrobium (Coleoptera, Staphylinidae) from the island of Awajishima in Hyôgo Prefecture, Japan. - Elytra, Tokyo, New Series 4 (1): 133-140. 